$$
\begin{aligned}
\text { ANL-7066 } & 39 \\
6^{-2}-61^{-6} & \text { ANL-7066 }
\end{aligned}
$$

Argonne Mational Laboratom REMOVAL OF PLUTONIUM HEXAFLUORIDE FROM CELL EXHAUST AIR BY HYDROLYSIS AND FILTRATION by

R. W. Kessie and D. Ramaswami

REUEASDD FOS ANNCUNCENENTI

IN TUCLEAR SCIERCE ABSTRACIS 


\section{DISCLAIMER}

This report was prepared as an account of work sponsored by an agency of the United States Government. Neither the United States Government nor any agency Thereof, nor any of their employees, makes any warranty, express or implied, or assumes any legal liability or responsibility for the accuracy, completeness, or usefulness of any information, apparatus, product, or process disclosed, or represents that its use would not infringe privately owned rights. Reference herein to any specific commercial product, process, or service by trade name, trademark, manufacturer, or otherwise does not necessarily constitute or imply its endorsement, recommendation, or favoring by the United States Government or any agency thereof. The views and opinions of authors expressed herein do not necessarily state or reflect those of the United States Government or any agency thereof. 


\section{DISCLAIMER}

Portions of this document may be illegible in electronic image products. Images are produced from the best available original document. 


\section{LEGAL NOTICE}

This report was prepared as an account of Government sponsored work. Neither the United States, nor the Commission, nor any person acting on behalf of the Commission:

A. Makes any warranty or representation, expressed or implied, with respect to the accuracy, completeness, or usefulness of the information contained in this report, or that the use of any information, apparatus, method, or process disclosed in this report may not infringe privately owned rights; or

B. Assumes any liabilities with respect to the use of, or for damages resulting from the use of any information, apparatus, method, or process disclosed in this report.

As used in the above, "person acting on behalf of the Commission" includes any employee or contractor of the Commission, or employee of such contractor, to the extent that such employee or contractor of the Commission, or employee of such contractor prepares, disseminates, or provides access to, any information pursuant to his employment or contract with the Commission, or his employment with such contractor.

Printed in USA. Price $\$ 3.00$. Available from the Clearinghouse for Federal Scientific and Technical Information, National Bureau of Standards,

U. S. Department of Commerce, Springfield, Virginia 22151 
RELEASED FOR ANNCUNCEMENT

IN NUCLEAR SCIENCE ABSTRACTS
ANL-7066

Chemical Separations

Processes for Plutonium

and Uranium (TID-4500)

AEC Research and

Development Report
ARGONNE NATIONAL LABORATORY 9700 South Cass Avenue Argonne, Illinois 60439
CFSTI PRICES

H. C. $\$$ S. O

MN

\section{REMOVAL OF PLUTONIUM HEXAFLUORIDE FROM CELI EXHAUST AIR BY HYDROLYSIS AND FILTRATION}

by

R. W. Kessie and D. Ramaswami

Chemical Engineering Division

\section{LEGAL NOTICE}

The report was prepared as an account of Goveroment sponsol This report was prepred acting on behalf of the Commission:

tates, nor the Comsistion, with respect to the accu-

A. Mukes any warranty ar raprese information contalned in this repuit, or that tho use racy, completeness, or usefol this report may not infringe of any informatlon, appara

privately owned rights; or

B. Assumes any llabllities with respect to the.use of, or for damages resuld

use of any informatlon, apparatus, method, or process of the commisston" includes any em-

As used in the above. "person acting on behalf of th

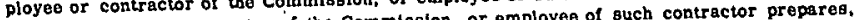

such employee or contractor of the Commiselon, or employeo to bls employment or contract

disserinates, or provides access to, any information pursector.

December 1965

Operated by The University of Chicago under

Contract W-31-109-eng-38

with the

U. S. Atomic Energy Commission 
THIS PAGE

WAS INTENTIONALLY

LEFT BLANK 
TABLE OF CONTENTS

Page

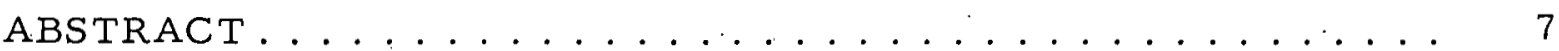

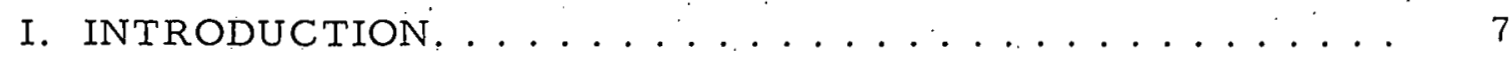

II. HYDROLYSIS REACTION OF PLUTONIUMM HEXAFLUORIDE . 9

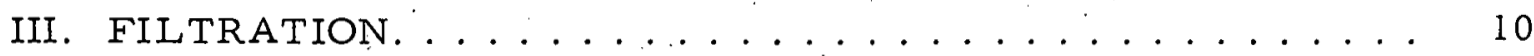

A. Characteristics of High-efficiency AEC Filters . . . . . 11

B. Filtration Mechanisms ................ 12

C. Filter Performance ................ 17

IV. HUMIDITY MEASUREMENT AND CONTROL. . . . . . . . 19

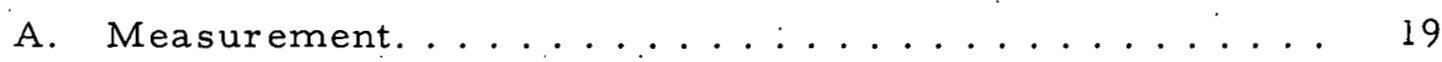

B. Supply-air Humidification ............... 20

C. Exhaust-air Humidification .............. 20

V. THE BURST-T YPE RELEASE OF PURE HEXAFLUORIDES : . 23

A. Experimental Equipment and Procedure......... 23

B. Results and Discussion ............... 26

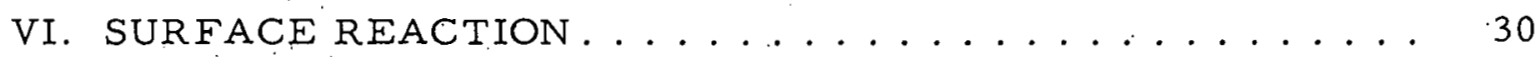

A. Laminar-flow Experiments with Uranium Hexafluoride. . 30

B. Hydrolysis of Uranium Hexafluoride in Packed Beds. . . 33

C. Hydrolysis of Plutonium Hexafluoride in Packed Beds. . . 37

D. Hydrolysis of the Mixed Plutonium and. Uranium Hexafluorides in Packed Beds. ... . . . . . . . . 40

VII. DESIGN CRITERIA . . . . . . . . . . . . . . 48

A. Types of Açcidental Releases............. 48

B. Effect of Mixing Patterns in the Enclosures on the Plutonium Concentration in the Exhaust Air . . . . . . 48

C. Stack Monitors.................... 50

D. Discharge Air Dilution ................... 51 
TABLE OF CONTENTS

$\underline{\text { Page }}$

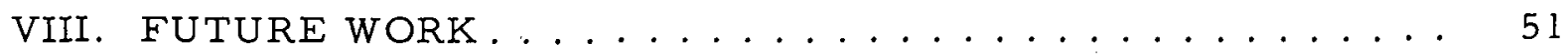

A. Effect of Air Velocity on AEC Filter Penetration . . . . . 51

B. Effect of Nonuniformity of the Filter Media on

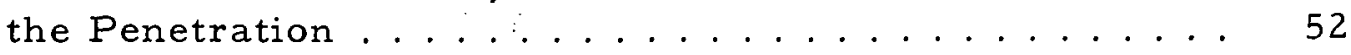

C. Effects of Chemical Reaction, Impurities, and Nuclei on Generated-fume Particle Size. . . . . . . . . . 52

D. Size Distribution of Particles Discharged from AEC Filters ..................... 53

E. Determination of Mixing Safety Factors . . . . . . . 53

F. Capacities of Air Scrubbers ............... 54

G. Computational Program. .............. 54

H. Full-scale Controlled Releases of Plutonium Hexafluoride................... 54

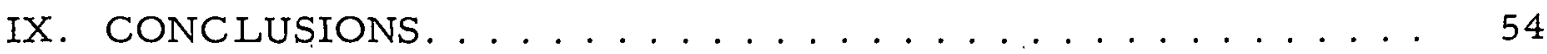

APPENDIXES

A. Accidental Release of Plutonium Hexafluoride....... 56

B. Model of the Agglomeration Process Affecting Filtration. 60

C. Model of the Effect of Filter Loading on Filtration

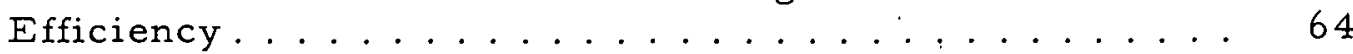

D. Electron-microscope Techniques ...........66 66

ACKNOWLEDGMENTS . . . . . . . . . . . . . . . . 68

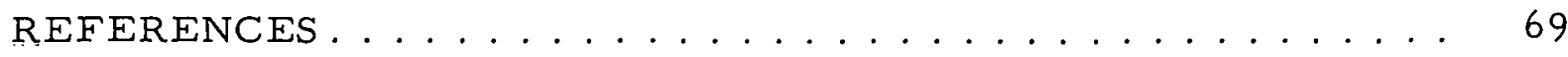




\section{LIST OF FIGURES}

No.

Title

Page

1. X-ray Powder Patterns for $\mathrm{UO}_{2} \mathrm{~F}_{2}$, Hydrolyzed $\mathrm{PuF}_{6}$ and $\mathrm{PuF}_{4}$.

2. Electron Micrograph of a Thin Section of AEC-type Filter

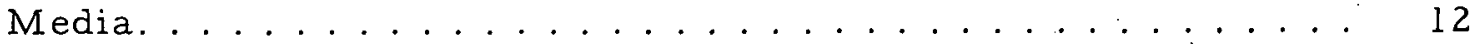

3. Size Distribution of Hydrolyzed $\mathrm{PuF}_{6}$ and AEC Filter Fibers . . 12

4. Viscous Flow about a Circular Cylinder . . . . . ....... 13

5. Equipment for Studying Plutonium Particulate Filtration of AEC Filter-media Discs ..................... 23

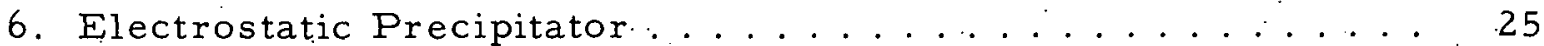

7. Fraction of Released Plutonium Hexafluoride ( $F$ ) Passing through Two AEC Filter Discs ............... 27

8. Electron Micrograph of $\mathrm{PuF}_{6}$ Hydrolysis Product. ... . . . . 28

9. Correlation of Data of Filter Penetration in $\mathrm{PuF}_{6}$ Release

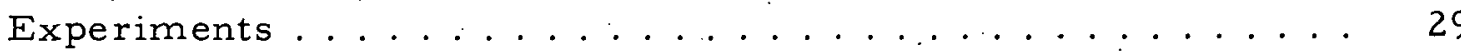

10. Laminar-flow Apparatus for Hydrolysis of $\mathrm{UF}_{6} \ldots \ldots \ldots$

11. Uranium Hexafluoride Hydrolysis Product Deposited on Filter Fibers in Run $1 \ldots \ldots \ldots$

12. Uranium Hexafluoride Hydrolysis Product Deposited on Filter

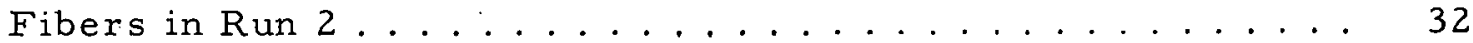

13. Uranium Hexafluoride Hydrolysis Product Deposited on Filter Fibers in Run $3 \ldots \ldots \ldots$

14. Uranium Hexafluoride Hydrolysis Product Deposited on Filter

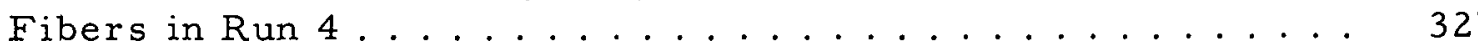

15. Packed-bed Apparatus for Hydrolysis of $\mathrm{PuF}_{6}$ or $\mathrm{UF}_{6} \ldots \ldots 33$

16. Schematic Diägram of Packed-bed Equipment for the Hydrolys is of $\mathrm{PuF}_{6}$ or $\mathrm{UF}_{6} \ldots \ldots \ldots \ldots \ldots$

17. Pseudo-first-order Rate Constant for $\mathrm{PuF}_{6}$ or $\mathrm{UF}_{6}\left(\mathrm{MF}_{6}\right)$

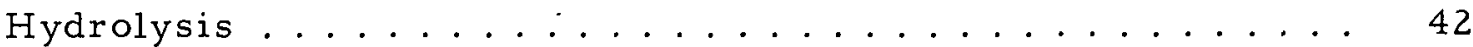

18. Pseudo-first-order Rate Constant from Rate Equations. . . . . 42

19. Graph Obtained from Stack Monitor . . . . . . . . . . . 56

20. Schematic Diagram of Ventilation System of Glovebox. . . . . 58

21. Agglomeration and Loading Functions ............. 63

22. Tctrahedral Sectioning of AEC Filter Media ........... 66 


\section{LIST OF TABLES}

No.

Title

Page

I. Some Properties of $\mathrm{PuO}_{2} \mathrm{~F}_{2}$ and $\mathrm{UO}_{2} \mathrm{~F}_{2} \ldots \ldots \ldots 10$

II. High-efficiency Filters, AEC Type (ANL Basic

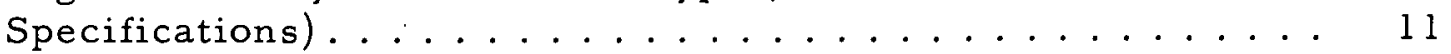

III. Effect of Flow Rate on Pressure Drop and DOP Smoke Penetration for Various Air-sampling Media. . . . . . . 18

IV. Frequency Distribution of Atmospheric Moisture at Argonne . 20

V. Filtration Results from Uranium Hexafluoride Release . . . . 26

VI. Filtration Results from Plutonium Hexafluoride Release. . . . 27

VII. Hydrolysis and Filtration of $\mathrm{UF}_{6}$ in Laminar-flow Equipment. 31

VIII. Surface-reaction Data for Hydrolysis Kinetics of Uranium

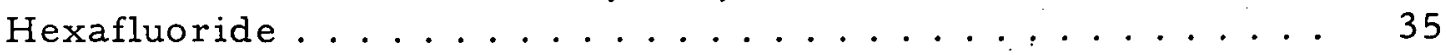

IX. Surface-reaction Data for Hydrolysis Kinetics of PlutoniumUranium Hexafluorides . . . . . . . . . . . . 39

X. Comparison of Packed Beds and Filters. . . . . . . . . 46

XI. Penetration of AEC Filters from Surface Reaction Data . . . 46

XII. Maximum Release Burst of $\mathrm{PuF}_{6}-\mathrm{UF}_{6}$ Mixtures . . . . . . . 49

XIII. Maximum Release Rate of $\mathrm{PuF}_{6}-\mathrm{UF}_{6}$ Mixtures. . . . . . . 50

XIV. Plutonium Content and Test Results of Filters after 5.7-g $\mathrm{PuF}_{6}$ Release........................ 58

XV. Comparison of $\mathrm{PuF}_{6}$ Release Accident with Small-scale

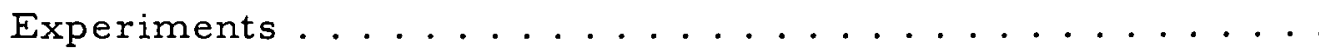




\title{
REMOVAL OF PLUTONIUM HEXAFLUORIDE FROM CELL EXHAUST AIR BY HYDROLYSIS AND FILTRATION
}

by

R. W. Kessie and D. Ramaswami

\begin{abstract}
The fluoride volatility process for recovering fissionable plutonium from spent reactor fuel as the volatile plutonium hexafluoride $\left(\mathrm{PuF}_{6}\right)$ requires a demonstrated ability to contain the highly toxic plutonium.

The experimental studies indicate that at low concentrations of $\mathrm{PuF}_{6}$ and moisture, the hydrolysis reaction rate is directly proportional to both the partial pressure of the $\mathrm{PuF}_{6}$ and moisture and to the area of the solid surfaces available for reaction. Adsorbed $\mathrm{PuF}_{6}$ and $\mathrm{HF}$ reduce the reaction rate at partial pressures greater than $0.001 \mathrm{~mm} \mathrm{Hg}$.

At high concentrations of $\mathrm{PuF}_{6}$ and moisture, the reaction proceeds rapidly in the gas phase to produce a finely dispersed product $\mathrm{PuO}_{2} \mathrm{~F}_{2}$. Most of the particles are smaller than 0.1 micron. With air containing excess moisture, the fraction of released plutonium penetrating two high-efficiency filters in series amounted to between $10^{-9}$ and $10^{-6}$ at a filtermedia velocity of $1.0 \mathrm{~cm} / \mathrm{sec}$.

Filter efficiency is increased by the agglomeration of particles before filtration and by loading effects of the collected particles on the filters. When an excess of moisture is available, agglomeration effects tend to limit the maximum discharge rate of plutonium, and loading effects tend to limit the maximum total quantity of plutonium that can be discharged from a single filter. Design criteria of practical air clean-up systems are presented.
\end{abstract}

\section{INTRODUCTION}

$\mathrm{PuF}_{6}$ is the only known compound of plutonium having a significant vapor pressure at room temperature. Because of the extreme toxicity of plutonium-containing materials, highly effective means of containing of these 
materials are essential. The containment requirements for $\mathrm{PuF}_{6}$ are magnified by its high volatility. At present, $50-\mathrm{g}$ batches of $\mathrm{PuF}_{6}$ are being handled in process-development studies, and this quantity is expected to increase to kilogram amounts within a few years. Therefore this study was initiated to determine the efficiency of removal of $P_{4 F}$ from cell exhaustair.

The maximum permissible concentration of plutonium in air is $3 \times 10^{-8} \mathrm{mg}$ of $\mathrm{Pu}^{239}$ per cubic meter. ${ }^{31}$ This is the concentration of occupational exposure of $40 \mathrm{hr} /$ week, 50 week/year, for 50 years that will result in a maximum permissible body burden of $0.6 \mu \mathrm{g}$.

Engineèring-scale facilities are in construction ${ }^{21}$ for demonstrating the fluid-bed fluoride volatility process for reprocessing nuclear reactor fuels at Argonne National Laboratory, Oak Ridge National Laboratory, and the nuclear center at Mol, Belgium. In this reprocessing, the uranium and plutonium in the spent fuel are separated from the cladding materials and the fission products, and are recovered as their hexafluorides.

In view of the increasing use of $\mathrm{PuF}_{6}$ and the potential hazards upon its release into ambient air, studies were initiated on its removal from exhaust air by hydrolysis and filtration. The objective of these studies was to obtain information needed for the design of equipment for cleanup of ventilation air exhausted from areas that might become contaminated with $\mathrm{PuF}_{6}$.

The ventilation air from gloveboxes, shielded cells, or other enclosures containing experimental or process equipment in which $\mathrm{PuF}_{6}$ is handled, will be discharged to the atmosphere after cleanup and not returned for a second pass through the cell. The main reason for the use of this once-through type ventilation system is the difficulty of removing trace quantities of fluorine and other fluorides, which, in a recirculating type system, would build up and corrode equipment, principally glass surfaces needed for viewing inside the enclosure. This effect would be significant even at concentrations of the fluorides that are safe for discharging to lhe alinusphiere.

Frequently, the air flow rate in such systems is determined by the amount of process heat to be removed and the enclosure temperature limits. Experimental enclosures presently used have ventilation flow rates between 10 and $1000 \mathrm{cfm}$, volumes between 25 and $1600 \mathrm{cu} \mathrm{ft}$, and air residence times between 0.5 and $5 \mathrm{~min}$.

More highly efficient removal of plutonium from the enclosure air is necessary for systems containing $\mathrm{PuF}_{6}$ compared to those containing other plutonium compounds. Plutonium hexafluoride is the only known compound of plutonium that has appreciable vapor pressure at room temperature, and when it is released to the atmosphere, as much as $60 \%$ of 
the plutonium will remain airborne as particles less than $0.1 \mu$ in diameter. With other plutonium compounds, this extent of dispersion can only be produced under special conditions.

The combination of high dispersibility and low permissible concentration usually requires a reduction in plutonium concentration by filtration or other processes by a factor of less than $10^{-6}$. This high performance is beyond that normally reported in the literature for air-cleaning equipment, not because the equipment cannot be made to perform, but because their performance in this range cannot be readily measured. For example, the dioctyl phthalate (DOP) smoke test to evaluate the performance of AEC filters does not measure filter penetrations less than $10^{-5}$. Because of the lack of experience in determining the effectiveness of filters in removing particlate material from gas streams in situations requiring very low penetrations, an intensive study was conducted to evaluate the performance of filters with $\mathrm{PuF}_{6}$-air mixtures.

\section{HYDROLYSIS REACTION OF PLUTONIUM HEXAFLUORIDE}

When $\mathrm{PuF}_{6}$ reacts slowly with moisture at room temperature, a solid product is formed, which was identified as $\mathrm{PuO}_{2} \mathrm{~F}_{2}$ by $\mathrm{X}$-ray diffraction isomorphism with $\mathrm{UO}_{2} \mathrm{~F}_{2}{ }^{14,28}$ and by weight change on conversion to dioxide. ${ }^{28}$ Contact of $\mathrm{PuF}_{6}$ with liquid water or moist air produced a violent reaction, accompanied by flashes of light, forming $\mathrm{PuF}_{4}$ and $\mathrm{PuO}_{2} \cdot{ }^{28}$ These products are likely to be formed because of the high temperatures generated. Above $300^{\circ} \mathrm{C}, \mathrm{PuF}_{6}$ is rapidly decomposed to $\mathrm{PuF}_{4}$ and $\mathrm{F}_{2} \cdot{ }^{11}$ No information is available on the thermal decomposition of $\mathrm{PuO}_{2} \mathrm{~F}_{2}$, but $\mathrm{UO}_{2} \mathrm{~F}_{2}$ decomposes to $\mathrm{U}_{3} \mathrm{O}_{8}$ above $300^{\circ} \mathrm{C}$ (Ref. 22, p. 570).

In the current work, up to $20 \mathrm{mg}$ of pure $\mathrm{PuF}_{6}$ has been rapidly $(K 2 \mathrm{sec})$ injected into air containing up to $10 \mathrm{~mm} \mathrm{Hg}$ of moisture without any evidence of the flashes of light from the reaction. The solid product from several of these releases was collected for obtaining the X-ray powder pattern, and the resulting pattern is compared with those from $\mathrm{UO}_{2} \mathrm{~F}_{2}$ and $\mathrm{PuF}_{4}$ in Fig. 1. At least seven lines correspond between the hydrolysis product and $\mathrm{UO}_{2} \mathrm{~F}_{2}$. Therefore, it is concluded that the reaction between $\mathrm{PuF}_{6}$ and air of normal atmospheric moisture content yields $\mathrm{PuO}_{2} \mathrm{~F}_{2} \mathrm{ac}_{-}$ cording to the equation

$$
\mathrm{PuF}_{6}(\mathrm{~g})+2 \mathrm{H}_{2} \mathrm{O} \rightarrow \mathrm{PuO}_{2} \mathrm{~F}_{2}(\mathrm{~s})+4 \mathrm{HF}(\mathrm{g}) \text {. }
$$

Some useful properties of $\mathrm{PuO}_{2} \mathrm{~F}_{2}$, (Ref. 2) and $\mathrm{UO}_{2} \mathrm{~F}_{2}$ (Ref. 22, p. 567) are presented in Table I. The structure of $\mathrm{PuO}_{2} \mathrm{~F}_{2}$ changes in water solution ${ }^{2}$ and may account for its low solubility compared with $\mathrm{UO}_{2} \mathrm{~F}_{2}$. 


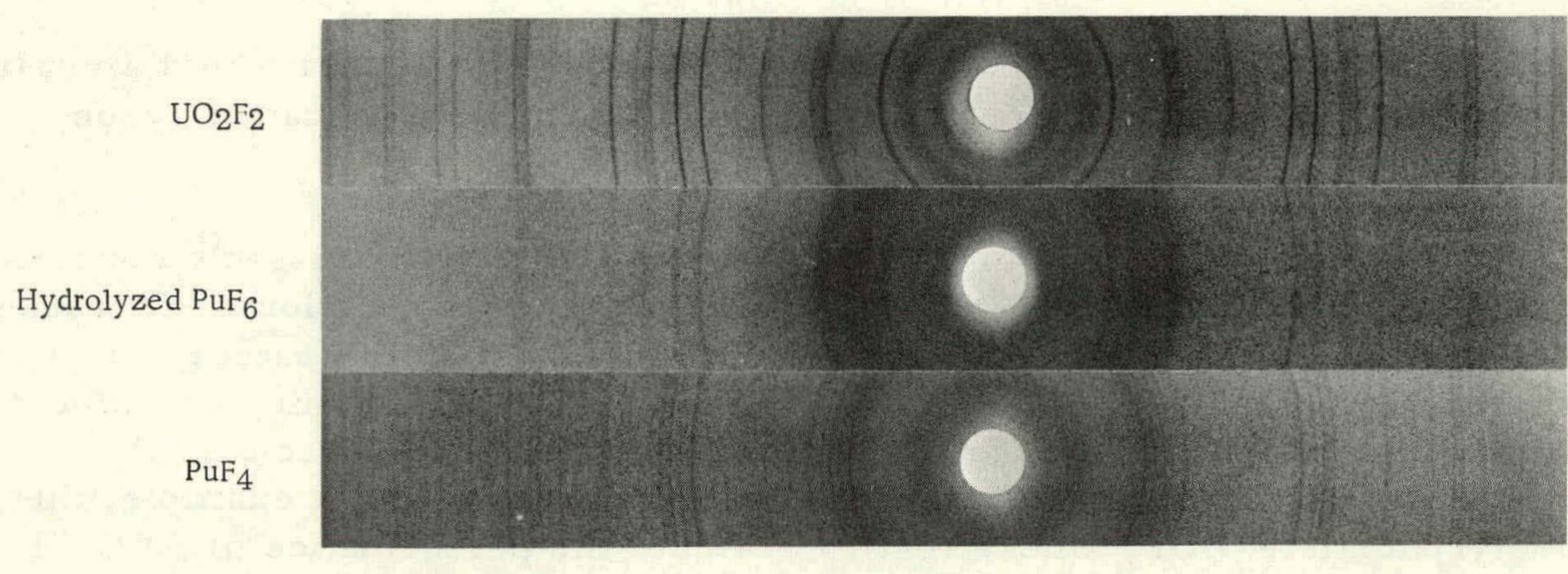

$108-6414 \mathrm{~B}$

Fig. 1. X-ray Powder Patterns for $\mathrm{UO}_{2} \mathrm{~F}_{2}$. Hydrolyzed $\mathrm{PuF}_{\mathrm{C}}$ and $\mathrm{PuF}_{4}$

TABLE I. Some Properties of $\mathrm{PuO}_{2} \mathrm{~F}_{2}$ and $\mathrm{UO}_{2} \mathrm{~F}_{2}$

\begin{tabular}{crr}
\hline & $\mathrm{PuO}_{2} \mathrm{~F}_{2}$ & $\mathrm{UO}_{2} \mathrm{~F}_{2}$ \\
\hline $\begin{array}{c}\text { Rhombohedral Unit } \\
\text { Cell Dimensions } \\
\text { a }\end{array}$ & $5.797 \pm 0.005 \AA$ & \\
$\alpha$ & $42^{\circ} \pm 3^{\prime}$ & $5.755 \pm 0.003 \AA$ \\
Density (X Idy) & $6.50 \mathrm{~g} / \mathrm{cm}^{3}$ & $42^{\circ} 47^{\prime} \pm 3^{\prime}$ \\
Solubility in Water \\
at Temperature $\left({ }^{\circ} \mathrm{C}\right)$
\end{tabular}

\section{FILTRATION}

Removal of plutonium trom air depends primarily on the removal of solid particles from the air after any volatile plutonium has been converted to a solid. For removing solids, <0.1 micron in diameter, from a gas, only filtration, electrostatic precipitation, and thermal precipitation are efficient. Of these three methods, only filtration can provide a barrier. against the penetration of solids during a failure of energy sources; consequently, filtration is the only method given further consideration for the final cleanup of air. Information on the auxiliary system design and engineering is given in Ref. 41 . 


\section{A. Characteristics of High-efficiency AEC Filters}

High-efficiency filters of the AEC type,* sometimes called absolute filters, are the best when high flow rate and low pressure drop are desired. The basic specifications of the filters are listed in Table II. The filters use a glass fiber media with a maximum of $5 \%$ organic binder, capable of withstanding $75 \%$ relative humidity, 10 in. $\mathrm{H}_{2} \mathrm{O}$ pressure differential, having an initial capacity of $5 \mathrm{cfm}$ per sq ft of superficial media area at a maximum pressure drop of 0.90 in. $\mathrm{H}_{2} \mathrm{O}$. The thickness of the media is about $0.025 \mathrm{in}$.

TABLE II. High-efficiency Filters, AEC Type (ANL Basic Specifications)

\begin{tabular}{|c|c|c|c|c|c|c|c|c|}
\hline \multirow{2}{*}{$\begin{array}{l}\text { ANL Model } \\
\text { No. }\end{array}$} & \multirow{2}{*}{$\begin{array}{l}\text { Rated } \\
\text { Flow, } \\
\mathrm{cfm} \text { at } \\
1.0 \text { in. } \mathrm{H}_{2} \mathrm{O}\end{array}$} & \multicolumn{3}{|c|}{$\begin{array}{c}\text { Nominal } \\
\text { Dimension, in. } \\
\text { (without gaskets) }\end{array}$} & \multirow[b]{2}{*}{ Gaskets } & \multirow[b]{2}{*}{ Bearing Plate ${ }^{a}$} & \multirow[b]{2}{*}{ Handle } & \multirow[b]{2}{*}{ Cleats ${ }^{b}$} \\
\hline & & Length & Width & Depth & & & & \\
\hline 25 & 25 & 8 & 8 & $3 \frac{1}{16}$ & One side & None & None & None \\
\hline 50 & 50 & 8 & 8 & $5 \frac{7}{8}$ & One side & None & None & None \\
\hline 135 & 135 & 12 & 12 & 6 & One side & None & None & None \\
\hline 250 & 250 & 24 & 24 & $3 \frac{9}{16}$ & None & None & None & None \\
\hline 500 & 500 & 24 & 24 & $6 \frac{3}{8}$ & None & None & None & None \\
\hline $1000 \mathrm{~A}$ & 1000 & 24 & 24 & 12 & None & None & None & Required \\
\hline $1000 \mathrm{~B}$ & 1000 & 24 & 24 & 12 & One side & Required & Required & None \\
\hline $1000 \mathrm{C}$ & 1000 & 24 & 24 & 12 & One side & None & None & Required \\
\hline
\end{tabular}

awo $1 / 8$-in.-thick brass plates secured on ungasketed edge of frame.

bTwo supporting strips on opposite sides of frame.

An electron micrograph of a very thin section cut from the surface of the filter media (see Appendix D) is shown in Fig. 2. It indicates the wide range of fiber diameters and the regularity of the individual fiber diameters. The frequency distribution of fibers measured from several of these electron micrographs is given in Fig. 3. The internal surface area of the filter media is 77 times the superticial area, as compuled from the frequency distribution of fibers, and is in agreement within $10 \%$ of that measured by the BET nitrogen adsorption method on the same filter media used for the electron micrographs.

The filter-media superficial area per filter, expressed in square feet, is to a first approximation one-fifth of the rated volume flow rate in cubic feet per minute. The superficial area for Model 135 Filters (with rated volume of $135 \mathrm{cfm}$ ) ranged from 20 to $25 \mathrm{sq} f t$ per filter and averaged $23.6 \mathrm{sq} \mathrm{ft}$ per filter in a sample lot of 11 filters. The superficial surface area of Model 1000 Filters (with rated volume of $1000 \mathrm{cfm}$ ) averaged $217 \mathrm{sq} \mathrm{ft.}$

\footnotetext{
* Manufactured by Flanders Filter Corporation, Riverhead, N. Y., Cambridge Filter Manufacturing Corporation, Syracuse, N. Y., and American Air Filter Corporation, Louisville, Kentucky.
} 


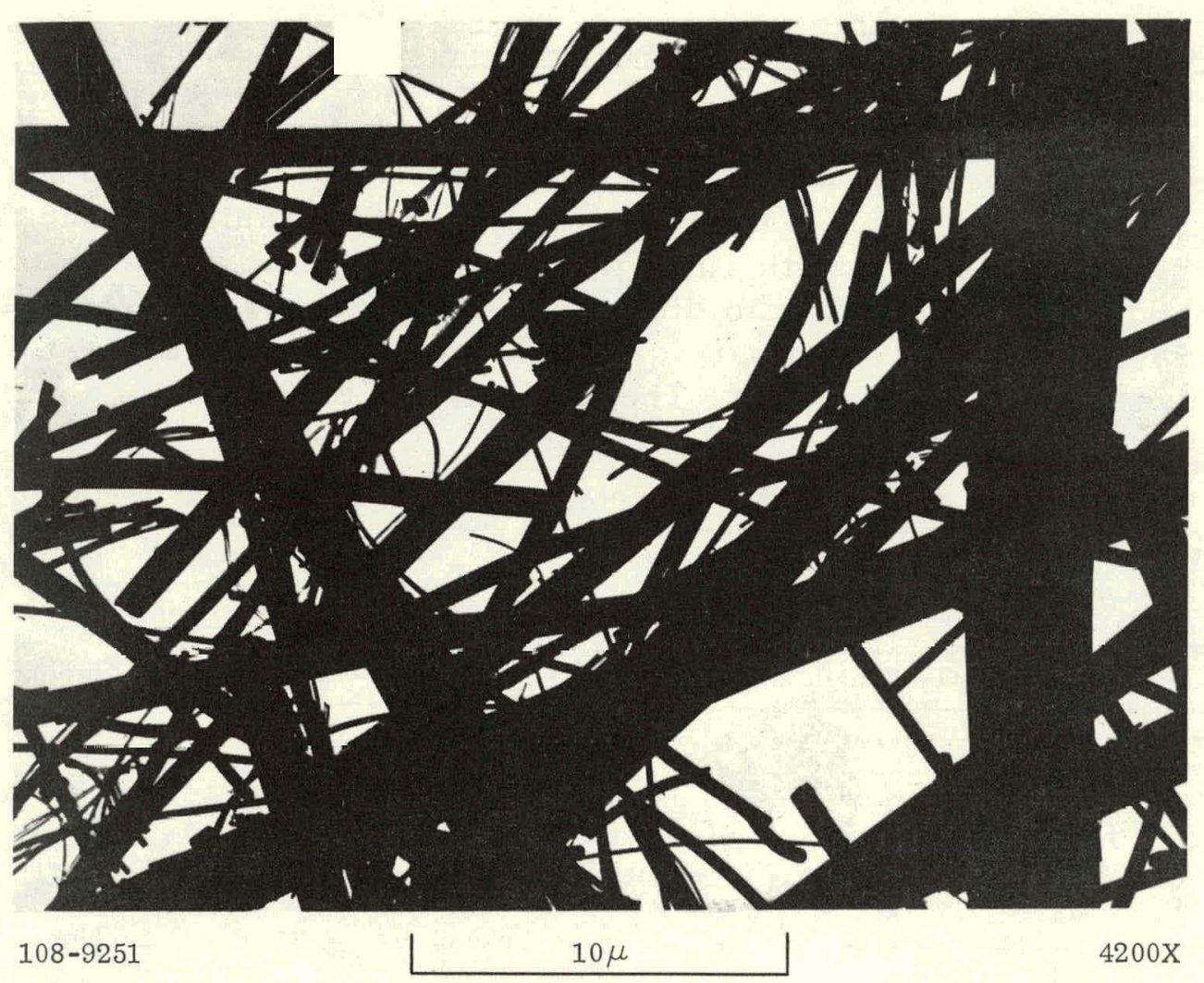

Fig. 2. Electron Micrograph of a Thin Section of AEC-type Filter Media

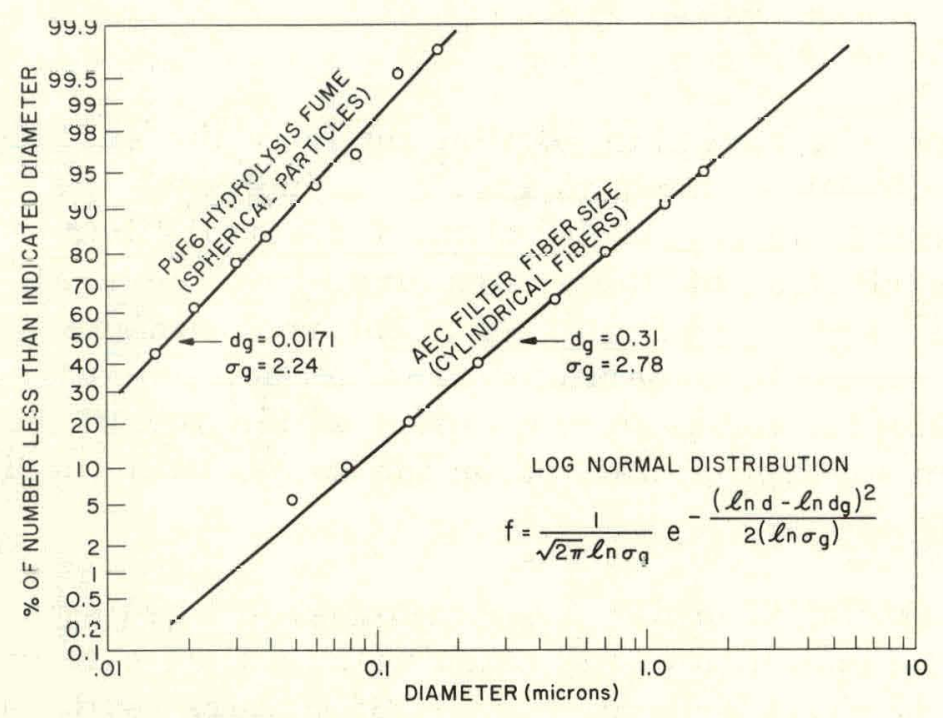

108-6890 Rev. 1

Fig. 3. Size Distribution of Hydrolyzed $\mathrm{PuF}_{6}$ and AEC Filter Fibers
B. Filtration Mechanisms

Filtration mechanisms are discussed extensively in the open literature, and only a few of the recent and comprehensive references are listed here. ${ }^{6,15,16,37,41}$ A brief summary of the mechanisms follows.

The flow in highefficiency filters is always laminar when used within ratings. At rated flow rate, $5 \mathrm{ft} / \mathrm{min}$, for one of the largest fibers (3-micron diam) present, the Reynolds number $\left(\mathrm{N}_{\mathrm{Re}}\right)$ is 0.005 . A Reynolds number greater than one is necessary before turbulence is generated in the wake of the fiber. 
Since the flow lines are not straight, inertial forces affect the flow pattern even in the laminar region. Further, even for laminar flow normal to a single infinite cylinder, an exact solution of the flow equations has not been obtained, although good approximations of flow equations applicable for flow close to the cylinder have been reported. ${ }^{6,7,24}$ The nomenclature and profiles of flow close to the cylinder are shown in Fig. 4 for the following equations:

$$
\begin{aligned}
& u_{r}=C_{L}\left[\left(1-\frac{r_{f}^{2}}{r^{2}}\right)-2 \ell n \frac{r}{r_{f}}\right] \sin \theta ; \\
& u_{\theta}=C_{L}\left[\left(1-\frac{r_{f}^{2}}{r^{2}}\right)+2 \ln \frac{r}{r_{f}}\right] \cos \theta ; \\
& C_{L}=\frac{u_{0}}{2\left(2-\ell n N_{R e}\right)} ; \\
& u_{x}=C_{L}\left[2 \ln \frac{r}{r_{f}}+\left(1-\frac{r_{f}^{2}}{r^{2}}\right) \cos 2 \theta\right] \\
& u_{y}=-C_{L}\left(1-\frac{r_{f}^{2}}{r^{2}}\right) \sin 2 \theta .
\end{aligned}
$$

The drag force, $F$, per unit length of cylinder is given by

$$
F=8 \pi \mu C_{L}
$$

where $\mu$ is the viscosity of the gas. Of particular significance to later discussions is the fact, shown in Fig. 4, that in the region of the fiber the distance between streamlines increases

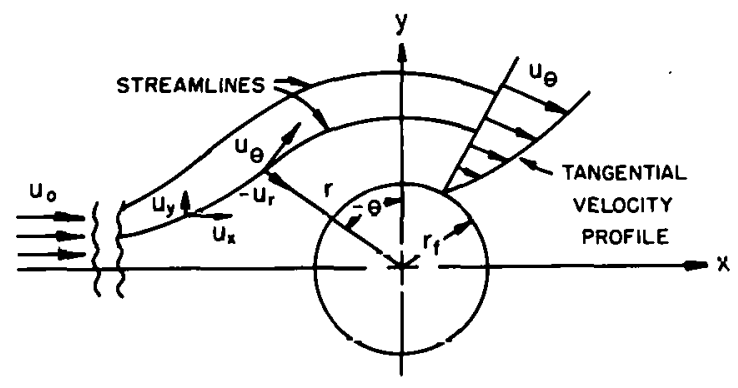

$108-9332$

Fig. 4. Viscous Flow about a Circular Cylinder and the velocity decreases. The opposite effects occur in potential flow (nonviscous approximation of turbulent flow), which sometimes is the flow type considered in the literature on filtration mechanisms.

It is generally assumed that once a particle contacts a collecting surface, it remains adhered to that surface. With small particles, the attractive van der Waals' forces between the particle and surface are much larger than forces tending to remove the particle. 
There is some evidence for particle rebound from a surface due to a gas-cushion effect as the particle approaches the surface. This effect is more significant with liquid particles than with solid particles; however, this effect is neglected for both cases.

\section{Interception}

The center of a particle of low mass will tend to follow a fluid streamline. A streamline that passes within a distance of one-half the particle diameter from the fiber surface will cause the particle in it to contact the surface. This mechanism is called interception.

The interception efficiency, $\eta_{0}$, is primarily a function of the particle diameter $d_{p}$ divided by the fiber diameter $d_{f}\left(R=d_{p} / d_{f}\right)$ and was derived by Langmuir: ${ }^{6}$

$$
\eta_{0}=\frac{1}{2\left(2-\ell \mathrm{nN}_{\mathrm{Re}}\right)}\left[2(1+\mathrm{R}) \ln (1+\mathrm{R})+\frac{1}{1+\mathrm{R}}\right] \text {. }
$$

The interception efficiency is dependent on gas velocity only to a small extent, and this dependence is due only to changes in the flow pattern. The effi-: ciency, $\eta_{0}$, is the particle-removal cross-sectional area, referred to gas flow in a region undisturbed by the fiber, divided by the cross-sectional area of the fiber, normal to the flow direction.

\section{Impaction}

The impaction mechanism is the collection resulting from the inertia of the particle. The inertia causes the particle to move ar.ross streamlines that curve. The inertial force (centrifugal) on the particle is equal to the frictional force given by Stokes' law:

$$
f=3 \pi \mu d \mathrm{p}^{\mu l}
$$

For small particles with diameters less than the mean free path of the gas molecules, Cunningham's correction factor to Stokes' law is needed. Thus,

$$
f=\frac{3 \pi \mu \mathrm{d}_{\mathrm{p}} \mathrm{u}}{\mathrm{C}}
$$

where

$$
C=1+\frac{\lambda}{d_{p}}\left[1.24+0.44 \exp \left(\frac{1.1 d_{p}}{\lambda}\right)\right]
$$


For air at $760 \mathrm{~mm} \mathrm{Hg}$ and $20^{\circ} \mathrm{C}$, "the mean free path, $\lambda$, is $0.131 \mathrm{micron}$. A maximum value for the inertial displacement results from a flowdirection change of $90^{\circ}$ and is the same as the stopping distance for the particle when the gas stops moving. Substituting

$$
\mathrm{f}=\mathrm{ma}
$$

in Equation (10) and integrating twice, gives for the stopping distance

$$
\mathbf{x}=\frac{\operatorname{D\rho ud}_{\mathrm{p}}^{\overline{2}}}{18 \mu}
$$

For a particle of $\mathrm{PuO}_{2} \mathrm{~F}_{2}, 0.1$ micron in diameter, $\rho=6.5 \mathrm{~g} / \mathrm{cm}^{3}$, and $\mathrm{v}_{0}=$ $5 \mathrm{ft} / \mathrm{min}$ (maximum in AEC-type filters), the stopping distance is $0.005 \mathrm{mi}-$ cron or $5 \%$ of the particle diameter. Impaction effects are of minor importance for small particles, at the gas velocities normally used in highefficiency filters.

\section{Diffusion}

Particulate diffusion is the result of Brownian motion and results in the only filtration mechanism that increases in effectiveness as the particle size decreases.

in time $t$ is $^{8}$

The mean-square displacement of a particle in the $\mathrm{x}$-direction

$$
\overline{x^{2}}=2 \mathrm{Dt}
$$

where the particle diffusivity is

$$
D=\frac{C k T}{3 \pi \mu d_{p}}
$$

in which $k$ is Boltzmann's constant and $\mathrm{T}$ is the absolute temperature.

No work has been done on obtaining the exact solution of diffusion to a cylinder in a laminar gas flow, but Langmuir ${ }^{6}$ has obtained an approximate solution that is estimated to be within $\pm 20 \%$ of the effect of $D$ on the solution. The procedure involves trial-and-error approach to the solution ${ }^{37}$ and is too involved for inclusion here.

\section{Electrostatic Collection}

Elertrostatic effects are probably very significant in the collection of radioactive aerosols on high-efficiency filters. Aerosols generated 
by chemical reaction in the gas phase are generally charged to a very small extent initially, but in a radiation field the ions generated in the gas will rapidly charge the aerosol. $\mathrm{A} \mathrm{Pu}^{239}$ concentration of $4 \mathrm{mg} / \mathrm{liter}$ of air will produce $1.4 \times 10^{9}$ ion pairs $/ \mathrm{ml} / \mathrm{sec}$ (35 eV per ion pair). Ion recombination rates, given by ${ }^{4}$

$$
\frac{d N}{d t}=-\alpha N^{2}
$$

at 1 atm $\alpha=2.2 \times 10^{-6} \mathrm{~cm}^{3} \mathrm{sec}^{-1}$, give $\mathrm{N}=2.5 \times 10^{7}$ ion pairs $/ \mathrm{ml}$ for the ion concentration. A particle of $0.1-$ micron radius in this ion concentration will be charged, by ion diffusion, in 10 sec to an average 15 electronic charges (Ref. 16, p. 211). This charge distribution will be bipolar. ${ }^{15}$ Even if the collection surfaces are uncharged, there will be an attractive force on the particle due to the higher dielectric constant of the glass fibers compared to that of the gas. A preliminary estimate of the effect is obtained by combining Coulomb's law,

$$
f=\frac{q q^{\prime}}{r^{2}}
$$

with Stokes law. For a particle of 0.1 -micron radius that is 0.1 micron from the collection surface and has a single electronic charge, the velocity of the particle toward the surface will be $0.12 \mathrm{~cm} / \mathrm{sec}$. Since this is about $5 \%$ of the maximum gas velocity, the se effects should be appreciable.

The ion content of the gas being filtered would result in charge collection by the filter by the same mechanism by which the aerosol became charged. Even if the filter collected equal amounts of both positive and negative charge, there would be a small-scale random distribution of net charge that should be very effective in promoting the collection of charged aerosol. A charged filter may even promote the collection of neutral aerosol due to the higher dielectric constant or higher electrical conductivity of the particle as compared to that of the gas.

Very little quantitative work on the determination of electrostatic effects on filtration have been reported (Ref. 16, p. 222). Most of the work reported has been concerner with the significance of electroctatic effects on aerosol filtration. ${ }^{29}$ Electrostatic effects in filtration of particulate from $\mathrm{PuF}_{6}$ hydrolysis may be unique in the high levels of radioactivity combined with high concentration of particles of less than 0.1-micron diameter.

\section{Gravitational Settling}

Gravitational forces are normally negligible in filtration of particles of interest to the current study. A 0.1-micron particle with a 
density of $6.5 \mathrm{~g} / \mathrm{ml}$ will have a settling velocity of $6 \times 10^{-4} \mathrm{~cm} / \mathrm{sec}$ in air at atmospheric pressure. During a period of $1 \mathrm{sec}$, the same particle would, on the average, move six times as far by diffusion as by gravitational settling.

\section{Agglomeration}

At high particulate concentration in the gas, particles will collide with each other due to diffusion and will collect into larger particles. Thus, the size of the particles being filtered can be very different from that initially generated. Generally any significant release of concentrated $\mathrm{PuF}_{6}$ (or $\mathrm{UF}_{6}$ ) over a short period of time, such as produced by opening (or rupture) of a vessel under pressure, will produce particulate concentrations where agglomeration is significant.

\section{Loading}

Filter loading describes the change in filter characteristics due to the material collected by the filter. As the filter becomes loaded with solids, the pressure drop and filtration efficiency increase. However, these effects normally occur slowly over a period of months in a normal system.

During a large release of $\mathrm{PuF}_{6}$ ( $\circ \mathrm{r} \mathrm{UF}_{6}$ ), loading effects could change the characteristics of the filters by many orders of magnitude in a few seconds. The consequent decrease in particulate penetration would be beneficial because it would tend to place an upper limit on theramount of particulate that could pass a filter, and the penetration would be independent of the amount released to the filter (see Appendix C). However, the increased pressure drop could be detrimental to some systems.

The collection of liquid on a filter can drastically reduce the efficiency. ${ }^{19,23}$ The efficiency will normally remain at the decreased value even after the liquid is removed by evaporation. The surface tension of the liquid tends to collect fine fibers into bundles and thus reduces the collection by fine fibers. Van der Waals' forces hold the fibers together after they have dried.

\section{Filter Performance}

Fitzgerald ${ }^{12,13}$ reported measurements on millipore, AEC-1 paper, and other media for filtering particles down to 0.005 micron in size, but his work is contradicted by Megaw. ${ }^{29}$ No reliable information is available on the penetration characteristics of high-efficiency filters to particulate of less than 0.1-micron diam. However, more information is available for particulate larger than 0.2--micron diam. The most reproducible measurements have been made by means of monodisperse smokes of dioctyl phthalate (DOP). ${ }^{18,23}$ Table III contains data on several filter media as a function uf veluity for 0.3-micron DOP. 
TABLE III. Elfect of Flow Rate on Pressure Dropa and DOP Smoke Penetration' tor Various Air-sampling Media 35

\begin{tabular}{|c|c|c|c|c|c|c|c|c|c|c|c|c|c|c|c|c|c|c|c|c|c|}
\hline \multirow{3}{*}{$\begin{array}{l}\text { Flow Rate, } \\
\text { linear } \\
\text { ft/min }\end{array}$} & & \multirow{3}{*}{$\begin{array}{c}\text { AEC } \\
\text { No. } 1\end{array}$} & \multirow{3}{*}{$\begin{array}{l}\text { CWS } \\
\text { No. } 6\end{array}$} & \multirow{2}{*}{\multicolumn{2}{|c|}{ HV $70^{C}$}} & \multirow{3}{*}{$\begin{array}{l}\text { Hur lbut } \\
\text { Glass } \\
\text { Paper }\end{array}$} & \multirow{2}{*}{\multicolumn{9}{|c|}{ Whatman Chemical Filter Papers }} & \multirow{3}{*}{$\begin{array}{l}S \& 5^{d} \\
\text { No. } 604\end{array}$} & \multirow{2}{*}{\multicolumn{2}{|c|}{$\begin{array}{c}\text { Membrane } \\
\text { Filters }\end{array}$}} & \multicolumn{2}{|c|}{$\begin{array}{c}\text { AFC: } \\
\text { Mineral } \\
\text { Filters } \\
\end{array}$} & \multirow{3}{*}{$\begin{array}{l}\text { MSA } \\
\text { Iype 'S" }\end{array}$} \\
\hline & & & & & & & & & & & & & & & & & & & & & \\
\hline & & & & 9 mil & $18 \mathrm{mill}$ & & No. 1 & No. 4 & No. 32 & No. 40 & No. 41 & No. $41 \mathrm{H}$ & No. 42 & No. 44 & No. 50 & & $" H A A^{\circ}$ & $" A A^{\prime}$ & Asbestos & All-glass & \\
\hline \multirow[t]{2}{*}{5} & \multirow{2}{*}{$\begin{array}{l}\text { Penetration } \\
\text { Pressure } \\
\text { drop }\end{array}$} & 0.022 & 0.015 & 5.0 & 0.47 & 0.001 & 73.0 & 84.0 & 3.7 & 32.0 & 89.0 & 93.0 & 5.0 & 6.5 & 30.0 & 93.00 & 0.002 & 0.002 & 0.029 & 0.008 & 45.0 \\
\hline & & 0.7 & 0.67 & 1.1 & 1.2 & 1.05 & 1.9 & 0.5 & 7.2 & 2.5 & 0.35 & 0.45 & 8.7 & 7.7 & 9.5 & 0.35 & 5.4 & 2.2 & 0.7 & 0.75 & 0.3 \\
\hline \multirow[t]{2}{*}{10} & \multirow{2}{*}{$\begin{array}{l}\text { Penetration } \\
\text { Pressure } \\
\text { drop }\end{array}$} & 0.036 & 0.023 & 5.0 & 0.53 & 0.001 & 68.0 & 81.0 & 3.0 & 26.0 & 84.0 & 89.0 & 2.0 & $4.5^{\circ}$ & 13.0 & 90.0 & 0.002 & 0.002 & 0.052 & 0.020 & 50.0 \\
\hline & & 1.45 & 1.45 & 2.2 & 2.45 & 2.2 & 3.75 & 0.95 & 14.6 & $5 . i$ & 0.68 & 0.9 & 17.0 & 15.3 & 17.7 & 0.7 & 10.9 & 4.3 & 1.45 & 1.45 & 0.6 \\
\hline \multirow[t]{2}{*}{20} & \multirow{2}{*}{$\begin{array}{l}\text { Penetration } \\
\text { Pressure } \\
\text { orop }\end{array}$} & 0.045 & 0.04 & 3.5 & 0.65 & 0.003 & 43.0 & 77.0 & 0.45 & 16.0 & 77.0 & 81.0 & 0.75 & 1.4 & 3.0 & 85.0 & 0.01 & 0.002 & 0.071 & 0.038 & 52.0 \\
\hline & & 2.9 & 2.9 & 4.6 & 4.9 & 4.4. & 7.7 & 1.95 & 27.3 & 10.7 & 1.35 & 1.9 & 33.0 & 28.6 & 35.2 & 1.45 & 21.6 & 8.5 & 3.0 & 3.05 & 1.05 \\
\hline \multirow[t]{2}{*}{28} & \multirow{2}{*}{$\begin{array}{l}\text { Penetration } \\
\text { Pressure } \\
\text { drop }\end{array}$} & 0.055 & 0.057 & 2.0 & 0.69 & 0.005 & 27.0 & 73.0 & 0.35 & 8.0 & 75.0 & 76.0 & 0.22 & 0.5 & 0.9 & 79.0 & 0.015 & 0.01 & 0.073 & 0.05 & 52.0 \\
\hline & & 4.2 & 4.05 & 6.3 & 6.9 & 6.1 & 10.6 & 2.8 & 38.0 & 15.0 & 2.0 & 2.7 & 45.5 & 40.0 & 48.5 & 2.1 & 31.0 & 11.8 & 4.25 & 4.25 & 1.6 \\
\hline \multirow[t]{2}{*}{50} & \multirow{2}{*}{$\begin{array}{l}\text { Penetration } \\
\text { Pressure } \\
\text { drop }\end{array}$} & 0.045 & 0.045 & 1.7 & 0.45 & 0.005 & 11.0 & $62.0^{\circ}$ & 0.3 & 2.8 & 67.0 & 65.0 & 0.02 & 0.2 & 0.15 & 67.0 & 0.015 & 0.015 & 0.08 & 0.051 & 51.0 \\
\hline & & 6.7 & 7.5 & 9.4 & 13.0 & $\cdot 10.8$ & 19.6 & 5.5 & 69.4 & 25.3 & $3.8^{\circ}$ & 5.5 & 81.0 & 71.0 & 86.0 & 3.9 & 59.6 & 24.5 & 7.8 & 7.7 & 3.0 \\
\hline \multirow[t]{2}{*}{100} & \multirow{2}{*}{$\begin{array}{l}\text { Penetration } \\
\text { Pressure } \\
\text { drop }\end{array}$} & 0.031 & 0.037 & 0.2 & 0.1 & 0.005 & 1.2 & 25.0 & - & 0.23 & 44.0 & 34.0 & - & - & - & 39.0 & - & 0.02 & 0.04 & 0.025 & 45.0 \\
\hline & & 13.3 & 17.0 & 21.8 & 27.0 & 19.8 & 40.5 & 11.5 & - & 54.0 & 8.1 & 11.5 & - & - & - & 8.5 & - & 39.0 & 16.0 & 15.2 & 6.5 \\
\hline \multirow[t]{2}{*}{150} & \multirow{2}{*}{$\begin{array}{l}\text { Penetration } \\
\text { Pressure } \\
\text { drop }\end{array}$} & 0.021 & 0.018 & 0.1 & 0.025 & 0.003 & 0.3 & 12.0 & - & - & 29.0 & 21.0 & - & - & - & 18.0 & - & - & 0.018 & 0.013 & 34.0 \\
\hline & & 22.5 & 25.5 & 34.5 & 38.2 & 32.5 & 60.0 & 18.1 & - & - & 12.5 & 17.0 & - & - & - & 15.0 & - & $\cdot$ & 26.7 & 25.0 & 10.8 \\
\hline \multirow[t]{2}{*}{200} & \multirow{2}{*}{$\begin{array}{l}\text { Penetratlun } \\
\text { Pressure } \\
\text { drop }\end{array}$} & 0.011 & 0.01 & $=$ & $=$ & $=$ & . & 2 & $=$ & a & 19.0 & 13.0 & - & - & - & 7.0 & - & - & - & - & 28.0 \\
\hline & & 29.5 & 35.0 & - & - & - & - & - & - & - & 17.8 & 24.0 & - & - & - & 22.7 & $\cdot$ & - & - & - & 16.3 \\
\hline
\end{tabular}

apressure drop in inches of water.

DDOP smoke penetration in percent (dloctylphthalate particles $0.3-\mu$ diam, $50 \mu \mathrm{g} / \mathrm{iter}$ of air).

CHollingsworth and Voss.

Ischleicher and Schuell co.

e Mine Safety Appliances co.

Both theory and experimental data reported in the literature indicate that the particulate penetration of high-efficiency filters will have a maximum value for particles between 0.01 - and 0.2 -micron diam. The maximum penetration size is not constant but increases with gas velocity. This maximum penetration size is attributed to the fact that diffusion becomes increasingly effective at very small particle size, while interception and impaction become increasingly effective at larger particle size.

A homogeneous fume, that is, a fume in which all particles are of the same size, will have the same fraction of particles removed on each pass through successive identical filters. A particle that penetrates a filter is not changed by that passage through the filter and therefore must have the same probability for penetrating the second filter. It is assumed that the filters are not being changed by nonlinear effects, such as loading or electrostatic charging, since these effects. would normally reduce the penetration factor of the first filter more than that of the following filters.

Generally, fumes are nonhomogeneous, and a lower fraction of the particles will penetrate the first filter than will penetrate the second. The fume that passes through the first filter will contain a larger fraction of particles of the maximum penetration size than the fume entering the filter. Thus in a practical situation the penetration of the first filter will be the lowest and will increase in each succeeding filter up to the maximum penetration value. If the value of the maximum penetration were known with confidence, it could be used to determine the number of filters necessary to achieve any desired degree of filtration. 
High-efficiency filters that have similar DOP penetrations at $100 \%$ of rated flow can have DOP penetrations at lower flow rates, which either. decrease or increase from those at the $100 \%$ rating. ${ }^{1}$. This is attributed to the presence of holes in the filter. The flow through a hole is limited by inertial effects, similar to orifice flow, even when the Reynolds number indicates that the flow is laminar. Thus, the velocity through a hole is proportional to the square root of the pressure drop across the filter. The flow through the filter media is proportional to the pressure drop. As the overall flow rate and pressure drop through a filter decrease, a larger fraction of the gas flows through the hole. A 1000-cfm filter with a DOP penetration of $0.05 \%$ can have a hole as large as $14 \mathrm{sq} \mathrm{mm} .^{1}$ The DOP penetration of this filter would increase rapidly with decreased flow rate. It is strongly recommended that any filter used below about $50 \%$ of rated flow also be tested for DOP penetration at a low flow rate (for example, $20 \%$ of rated flow) in addition to the $100 \%$ flow test. This would allow filters with high penetration at low flow rate to be eliminated from use at low flow rates.

\section{IV.. HUMIDITY MEASUREMENT AND CONTROL}

Moisture is of major importance in preventing $\mathrm{PuF}_{6}$ from passing through high-efficiency filters and being discharged to the atmosphere. Since the hydrolysis reaction followed by high-efficiency filtration is the only demonstrated technique for removing $\mathrm{PuF}_{6}$ from ventilation air, the methods of measurement of moisture and techniques of humidification used are important to the containment of $\mathrm{PuF}_{6}$.

\section{A. Measurement}

Moisture content of air (or nitrogen) was measured by the dew-point method. For dew points below the freezing temperature of water, two scales are in current practice. One is based on the vapor pressure of ice, and the other (used in the current work) is based on the vapor pressure of supercooled water. The concentration in the gas phase has been reported 9,42 to be more closely related to the vapor pressure of liquid than to that of frozen water, although the water that condensed on the surface where the dew point is: being measured is frozen.

An automatic dew-point recorder (General Electric Co., Model GEI$40444 \mathrm{~A}$ ) was used to determine the dew points of air (or nitrogen) that simulated the ambient air. The accuracy was $\pm 2^{\circ} \mathrm{F}$ at temperatures down to $-20^{\circ} \mathrm{F}$ and progressively decreased to $\pm 5^{\circ} \mathrm{F}$ at $-90^{\circ} \mathrm{F}$. The unit was operated in the automatic defrost cycle in which the mirror was heated once an hour to remove collected water or ice. When the mirror was clean, the indicated temperature, below $32^{\circ} \mathrm{F}$, was constant for the first 1 to $10 \mathrm{~min}$; then it would suddenly rise a few degrecs to a second constant value for the rest of the hour. During this rise, the freezing of water deposited at the previous 
temperature could be observed. The second temperature, with an ice deposit, was used to determine the partial pressure of water vapor from the data on the vapor pressure of supercooled water.

A manual dew-point recorder (General Electric Co., Model GEJ-2438) was used to measure dewpoints, from -90 to $-140^{\circ} \mathrm{F}$, of the air used as a carrier for $\mathrm{PuF}_{6}$ or $\mathrm{UF}_{6}$.

B. Supply-air Humidification

The frequency distribution of atmospheric moisture at ANL is given in Table IV. Standard air conditioning of the building supply air to a minimum relative humidity of $50 \%$ at $70 \%$ will increase the moisture content $n f$ the air by a factor of 37 times during the driest period. It will increase the moisture content of the air $98 \%$. of the time during: January and $65 \%$ of the time during the entire year.

TABLE IV. Frequency Distribution of Atmospheric Moisture at Argonne

\begin{tabular}{|c|c|c|c|c|c|c|}
\hline Dew point, ${ }^{\circ} \mathrm{F}$. & -30 & -10 & +10 & +30 & +50 & +70 \\
\hline $\mathrm{p}_{\mathrm{H}_{2}} \mathrm{O}, \mathrm{mm} \mathrm{Hg}$ & 0.25 & 0.71 & 1.8 & 4.2 & 9.2 & 18.8 \\
\hline $\begin{array}{l}\text { Relative humidity } \\
\text { at } 70^{\circ} \mathrm{F}, \%\end{array}$ & $\begin{array}{l}: i \\
1.3\end{array}$ & 3.8 & 9.6 & 22 & 49 & 100 \\
\hline $\begin{array}{l}\text { Probability of lower } \\
\text { value at Argonne, }{ }^{30} \%\end{array}$ & & $\therefore$ & & & & \\
\hline During Jälludry & 0.01 & $\cdot 1.5$ & $\angle U$ & 76 & 98.4 & 99.99 \\
\hline During year & 0.001 & $0.3 \ldots$ & 5 & 33 & 65 & 96 \\
\hline
\end{tabular}

C. Exhaust-air Humidification

The exhaust air is most effectively humidified with spray-type scrubbers. This type of scrubber can be used to process air at high flow rates when low pressure drops are desired. These scrubbers can be designed so that the quantity of water evaporated under conditions at which it reacts rapidly with $\mathrm{PuF}_{6}$ or $\mathrm{UF}_{6}$ far exceeds that evaporated under normal conditions. The following discussion will show that, in principle, these scrubbers can supply moisture at almost unlimited rates, when it is needed during a large release of $\mathrm{PuF}_{6}$ or $\mathrm{UF}_{6}$; and when $\mathrm{PuF}_{6}$ or $\mathrm{UF}_{6}$ is not present, these scrubbers will add moisture to air at a rate limited by the saturation limit of the air. 
Spray scrubbers usually consist of several units in series, each unit containing a spray nozzle. For the current analysis, the performance of these units is best determined in terms of the number of transfer units,

$$
N=\int_{y_{1}}^{y_{2}} \frac{d y}{y^{*}-y^{\prime}}
$$

where $y$ is the concentration of moisture in the air, including both reacted and unreacted water, which is increased from $y_{1}$ to $y_{2} ; y^{\prime}$ is the concentration of unreacted water in the air; and $\mathrm{y}^{*}$ is the equilibrium concentration of water vapor in the air at the temperature of the liquid water. Scrubbers are usually adiabatic in operation with the spray-water temperature constant at the wet-bulb temperature of the scrubbed air. The rise in temperature above the wet-bulb temperature due to pumping power and heat pickup by the water recycle system will be neglected in this treatment. Thus $\mathrm{y}^{*}$ is constant at a value corresponding to the vapor pressure of water at the wet-bulb temperature.

For humidification without chemical reaction, $\mathrm{y}^{\prime}=\mathrm{y}$, which gives

$$
y_{2}=y^{*}-\left(y^{*}-y_{1}\right) e^{-N}
$$

The largest value for the exit moisture content, $y_{2}$, is the equilibrium value,

For the hydrolysis of hexafluorides in these scrubbers, the chemical reaction of the gaseous reactants is more significant that those in the other phases. For a water drop moving through air containing unreacted $\mathrm{PuF}_{6}$ or $\mathrm{UF}_{6}$, the reaction rate will be controlled by diffusion of water vapor through the gas film at the drop surface. Because of its high molecular weight, $\mathrm{PuF}_{6}$ or $\mathrm{UF}_{6}$ diffuses much slower than water vapor. If the partial pressure of the hexafluoride in the gas is not much greater than the vapor pressure of water at the drop surface, water vapor will diffuse into the gas much faster than the hexafluoride can diffuse to the drop surface. The partial pressure of $\mathrm{PuF}_{6}$ would have to exceed $30 \mathrm{~mm} \mathrm{Hg}$ or $30 \%$ of its saturation vapor pressure at room temperature before the hexafluoride diffusion would exceed the water diffusion during average conditions (air temperature = $70^{\circ} \mathrm{F}$, dew point $\left.=50^{\circ} \mathrm{F}\right)$.

The maximum capacity of the scrubber, for a rapid hydrolysis reaction, is estimated by setting $\mathrm{y}^{\prime}=0$, which gives

$$
\mathrm{y}_{2}=\mathrm{Ny} *+\mathrm{y}_{1}
$$

Thus $\mathrm{y}_{2}$ with chemical reaction occurring can be increased without limit by increasing $\mathrm{N}$. 
Representative scrubbers in use at ANL that have been tested have two or three spray units in series with one-half to one transfer unit/spray unit. ${ }^{25,39}$ These scrubbers humidify dry air to between 75 and $90 \%$ relative humidity. Increasing the surface area of the water spray by increased pumping pressure and/or flow rate of water will increase the total transfer units of the scrubber, and thus the total transfer units could readily be increased to between 10 and 50 if needed. Also, more stages of spray units could be placed in series if needed. This would increase the capacities to react with hexafluorides of these systems without appreciably changing the amount of water evaporated under normal conditions.

The scrubbers are followed by a demister to remove any entrained water. The air is then heated 10 to $15^{\circ} \mathrm{F}$ to reduce the relative humidity below $75 \%$, which is the maximum relative humidity at which the AEC filters are rated. 


\section{THE BURST-TYPE RELEASE OF PURE HEXAFLUORIDES}

The initial experimental program was designed to simulate the sudden release of pure $\mathrm{PuF}_{6}$. This type of release has the potential for releasing more material in a shorter time than other types of releases. The majority of the $\mathrm{PuF}_{6}$ in any operating system is normally in a condensed state in a cold trap or storage vessel; further, the only diluting component in the major source of $\mathrm{PuF}_{6}$ in existing systems is $\mathrm{UF}_{6}$. Consequently, the current investigation centered on a study of the behavior of these hexafluorides in their releases, either individually or in mixtures.

A. Experimental Equipment and Procedure

The equipment used for the release of the hexafluorides (Fig. 5) consists of a glass mixing chamber attached to a heated enclosure. Within the heated enclosure is a valved, release vessel,* which contains the material, $\mathrm{UF}_{6}$ or $\mathrm{PuF}_{6}$, to be used for determining the filter efficiencies. The release vessel is so mounted that upon opening the valve the material contained in the vessel is discharged into the $385-\mathrm{ml}$, glass mixing chamber. Air enters the mixing chamber through the air prefilter containing AECtype filter medium, which prevents the back diffusion of released activity into the glovebox atmosphere. The moisture content of the air that enters the mixing chamber is controlled by mixing dry air with air that has been humidified. The humidity of the air entering the mixing chamber is measured with an automatic dew-point recorder as discussed in par. IV-A.

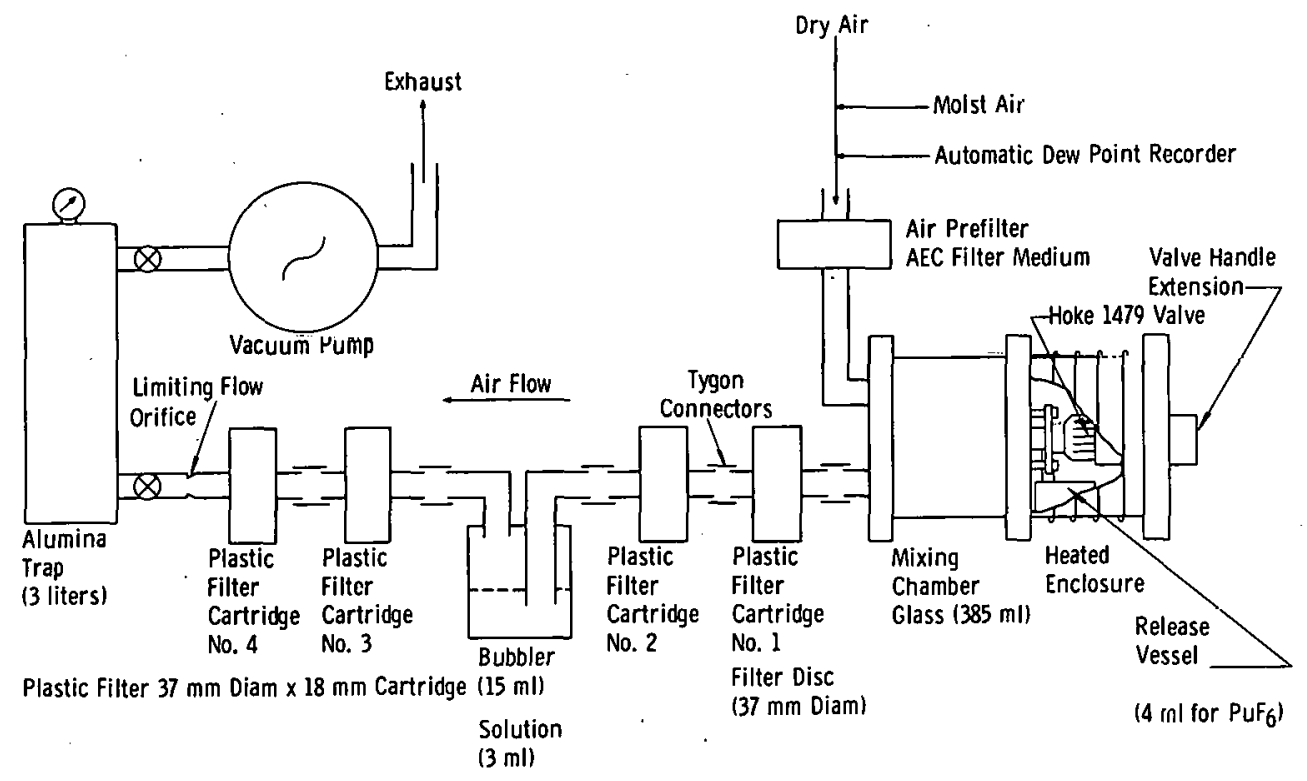

$108-4951$

Fig. 5. Equipment for Studying Plutonium Particulate Filtration of AEC Filter-media Discs

\footnotetext{
*A 20-ml vessel was used for $\mathrm{UF}_{6}$. A 4-ml vessel was used for PuF 6 .
} 
The filter series used for these experimental determinations consisted of two glass fiber filters (AEC type), mounted in positions liand 2, a water-filled bubbler, and two Millipore-type AA filters, mounted in positions 3 and 4 . Small circular discs ( $37-\mathrm{mm}$ diam) of the filter media, mounted in plastic aerosol sampler cartridges, were used for these tests. The bubbler was found to be effective in humidifying the air and completing the hydrolys is of the hexafluoride when the air input to the mixing chamber was dry and did not contain enough moisture to complete the hydrolysis before the material passed through the first two filters.

Alpha counting of the filter media and plates of the bubbler solution was done with an Eberline Instruments Corporation scintillation alpha counter, model SAC-1. This instrument has a combined geometry and counting efficiency of approximately $40 \%$ for the samples counted. The gamma counting of the samples was done with a single-channel pulse-height analyzer. The scintillation probe and sample are shielded with lead.

The release vessel charged with $\mathrm{UF}_{6}$ or $\mathrm{PuF}_{6}$ was heated to 65 to $70^{\circ} \mathrm{C}$, which is in excess of the normal boiling point of both substances. At this temperature, the pressure differential between the release vessel and the mixing chamber at atmospheric pressure resulted in a discharge of the material from the release vessel to the mixing chamber, when the valve was opened.

The uranium hexafluoride or plutonium hexafluoride was released into the glass mixing chamber through which air was flowing. The air flowed from the mixing chamber through the filter series being tested. The linear velocity of the air flowing through the series of filters was conlrulled by discharging the air through a small orifice into an evariua.ter, 3-liter, activated-alumina trap. The activated-alumina trap prevented the discharge of plutonium through the vacuum pump, which was vented to the enclosed facility.

When the liexalluoride was released, smoke from the hydrolys is reaction was immediately visible in the mixing chamber. An air flow of 0.54 liter $/ \mathrm{min}$ removed the smoke from the mixing chamber within $3 \mathrm{~min}$. A fraction of the smoke settled on the wall of the mixing chamber and was visible as a white deposit concentrated in the lower part of the mixing chamber. Very little deposit was observed in the lines or on the walls of the filter cartridges. The distribution of material deposited on the first filter appeared very uniform. The deposit from the UF 6 was yellow-green, and that from $\mathrm{PuF}_{6}$ was light brown. These colors were not evident in the mixing-chamber deposit, apparently because of its low density.

The quantity of the hexafluoride released was determined by weighing the release vessel on an analytical balance before and after each release experiment. The alpha counting was done directly on the entire filter paper. 
The solution in the bubbler was evaporated on a stainless-steel planchet, and the total residue was counted for alpha radiation. The gamma counting was done with the filter contained in a plastic filter cartridge, which was placed in a polyvinyl bag (thickness $18-19$ mils). To eliminate the count contribution of any material, the filter medium was transferred to a clean cartridge before gamma counting. The gamma counting was done in the energy span of 11 to $22 \mathrm{keV}$.

In the initial experimental work, $\mathrm{UF}_{6}$ was used for checking equipment and procedures. After the procedure for the experimental work was established, the equipment was enclosed in a glovebox, and studies were made using $\mathrm{PuF}_{6}$.

The size distribution of particles resulting from the vapor-phase hydrolys is of $\mathrm{PuF}_{6}$ was determined. The particulate matter was produced from the release of $6.0 \mathrm{mg}$ of $\mathrm{PuF}_{6}$ into a $385-\mathrm{ml}$ volume, containing air at $1 \mathrm{~atm}$ and water vapor at $7.66 \mathrm{~mm} \mathrm{Hg}$. An electrostatic precipitator, sketched in Fig. 6, collected particles formed by the vapor-phase hydrolysis of $\mathrm{PuF}_{6}$. The electrostatic precipitator was made from a piece of Lucite tubing $2 \frac{1}{4} \mathrm{in}$. in diam by $4 \frac{1}{2} \mathrm{in.}$ long. Two holes, located midway between the ends, were drilled through the tube wall directly opposite each other. A single-hole rubber stopper was placed in each end of the unit to provide an entrance and exit for the gas stream. Two rubber stoppers, one holding a brass rod that served as the collection electrode, the other holding a hypodermic needle that served as the discharge electrode, were located in the two holes drilled through the tube wall. A 12,500-V d.c.potential was applied across the electrodes, and the electrode spacing was adjusted to draw a 4- $\mu$ Amp current. Air containing the particulate material from the vaporphase hydrolysis of $\mathrm{PuF}_{6}$ was passed through the unit, and the sample was collected on an electron-microscope grid, which was covered by a thin carbon film. The grid was located at the end of the collection electrode.

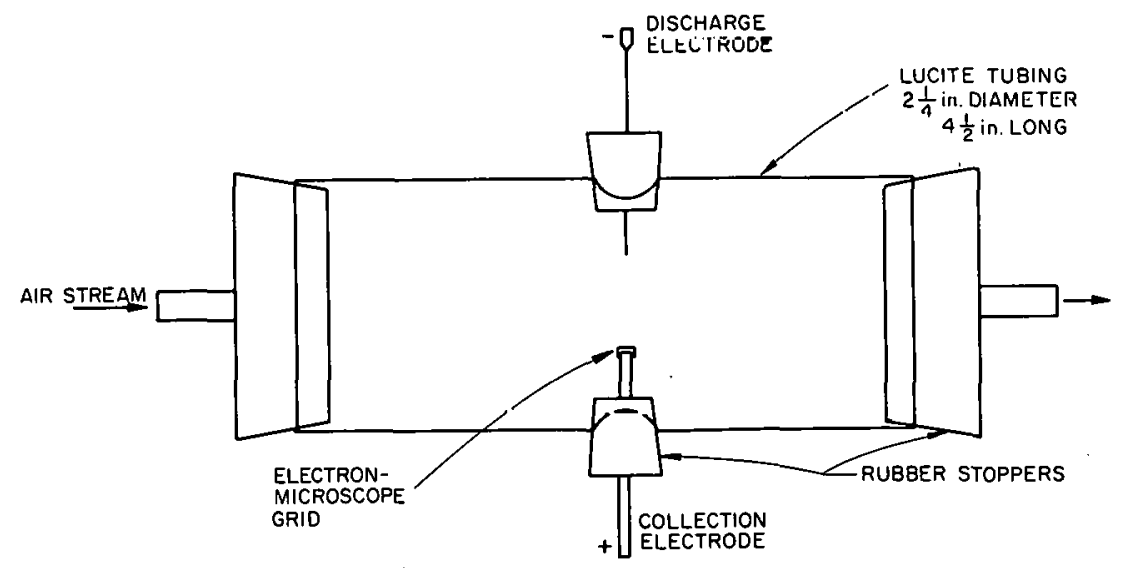

$108-9333$

Fig. 6. Filertrostatic Precipitator 
B. Results and Discussion

\section{Uranium Hexafluoride Releases}

The results obtained from the burst-type releases of $U_{F}$ are presented in Table $V$. An apparent initial mole ratio of $U^{F_{6}}$ to water can be calculated based on the volume of the mixing chamber into which the release takes place, the quantity of $\mathrm{UF}_{6}$ released, and the moisture content of the air. In reality a homogeneous mixture is not realized, and the mole ratio is an average initial value obtained in the dynamic system. This average value, besides being the only readily determined ratio, is the best single value that describes the ratio.

TABLE V. Filtration Results from Uranium Hexafluoride Release

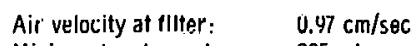

\begin{tabular}{|c|c|c|c|c|c|c|c|}
\hline \multirow[b]{2}{*}{$\begin{array}{c}\text { Wt } \mathrm{UF}_{6} \text {. } \\
\mathrm{mg}\end{array}$} & \multirow[b]{2}{*}{$\begin{array}{l}\text { Air Humidity, } \\
\mathrm{mg} \mathrm{H}_{2} \mathrm{O} / \text { liter }\end{array}$} & \multirow[b]{2}{*}{$\begin{array}{l}\text { Dew Point } \\
\text { of Air, of }\end{array}$} & \multirow{2}{*}{$\begin{array}{l}\text { Initial Moisture } \\
\text { Content in } \\
\text { Mixing Chamber, } \\
\text { mg }\end{array}$} & \multirow[b]{2}{*}{$\frac{\text { Moles } \mathrm{UF}_{6}{ }^{\mathrm{a}}}{\text { Mole } \mathrm{H}_{2} \mathrm{O}}$} & \multicolumn{2}{|c|}{ Uranium DIstrlbution b } & \multirow[b]{2}{*}{$\underset{\%}{\text { Penetration, }} d$} \\
\hline & & & & & $\begin{array}{l}\text { On First AEC Filter. } \\
\text { a counts } / \mathrm{min}\end{array}$ & $\begin{array}{l}\text { Through First } \\
\text { AEC Filter, } c \\
\text { a counts/min }\end{array}$ & \\
\hline 11.1 & 0.505 & -20 & 0.195 & 2.90 & $3.05 \times 10^{2}$ & $6.14 \times 10^{2}$ & 68 \\
\hline 210.9 & 0.555 & -18 & 0.212 & 50.2 & $1.39 \times 10^{3}$ & $4.45 \times 10^{3}$ & 76 \\
\hline 64.9 & 0.555 & -18 & 0.212 & 15.4 & $5.26 \times 10^{2}$ & $3.71 \times 10^{3}$ & 88 \\
\hline 7.6 & 8.20 & 46 & 3.15 & 0.122 & $1.20 \times 10^{3}$ & $<0.5$ & $<0.04$ \\
\hline 26.2 & 8.81 & 48 & 3.40 & 0.392 & $6.10 \times 10^{3}$ & $<1.1$ & $<0.02$ \\
\hline 42.9 & 11.8 & 51 & 4.54 & 0.480 & $5.76 \times 10^{3}$ & $<0.2$ & $<0.004$ \\
\hline 20.7 & 12 & 58 & 4.62 & 0.228 & $2.78 \times 10^{3}$ & $<0.3$ & $<0.01$ \\
\hline
\end{tabular}

${ }^{a}$ Calculated on the basis of initial moisture content of air in the mixing chamber and the quantity of uranium hexafluoride released.

bAlpha counting done with an Eberline Instruments Corporation scintillation alpha counter, Modẹl SAC-1 (combinen geametry and effiçiency of 40\%),

${ }^{C_{T}}$ Total a activity detected on all filters and bubbler solution residue beyond the initial AEC-type filter.

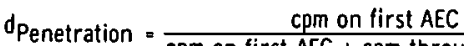

cpm on first AEC + cpm throuqh first AEC

A large change in the penetration of thc filter occuis belween a mole ratio $\left(\mathrm{UF}_{6} / \mathrm{H}_{2} \mathrm{O}\right.$ ) of 0.48 and 2.9. At high mole-ratio valuca (e.g., 15.4) the penetration of the first filter is $88 \%$, and at low values (e.g., 0.48 ) the penetration is less than $0.004 \%$.

\section{Hlutonium Hexafluoride Releases}

The results from $\mathrm{PuF}_{6}$ release experiments are given in Table VI and are plotted in Fig. 7. The data in Fig. 7 show considerable scatter. One source of this variation is the different amounts of $\Gamma_{u} \Gamma_{6}$ reledsed into the moisture-containing atmosphere. The resulting differences in the production of plutonyl fluoride may affect the filtration by two mechanisms:

a. The particles of the hydrolysis product may agglomcrate at different rates before reaching the filter.

b. Solid product may accumulate on the filter at different rates and may thereby affect the filter efficiency. 
TABLE VI. Filtration Results from Plutonium Hexafluoride Release

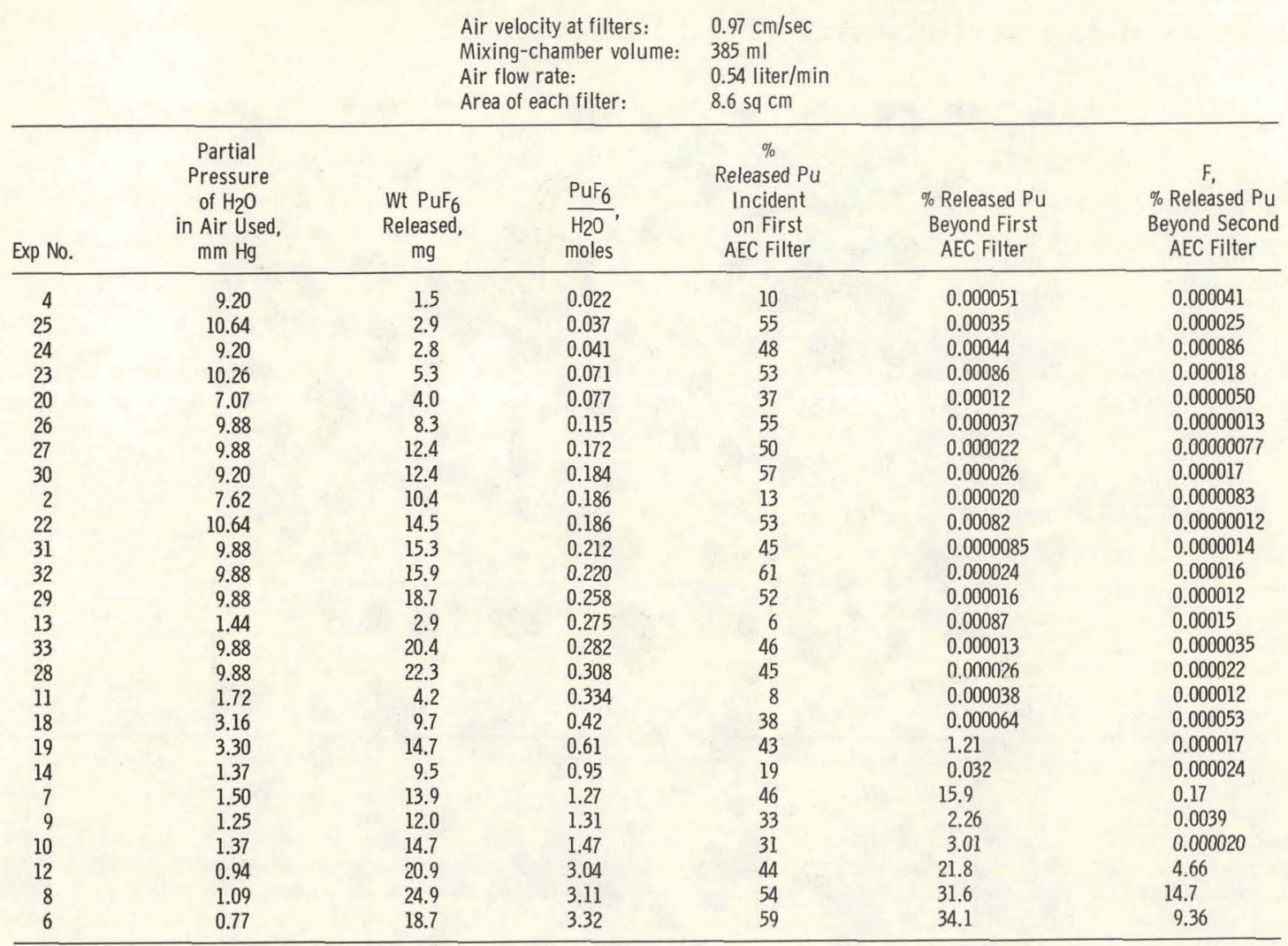

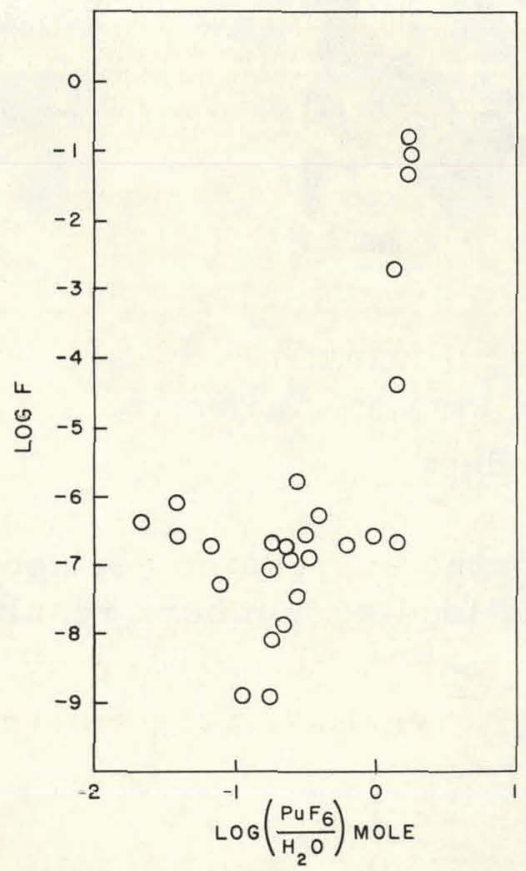

$108-6852$

Fig. 7. Fraction of Released Plutonium Hexafluoride (F) Passing through Two AEC Filter Discs
To obtain an improved correlation of filter efficiency by including the amount of $\mathrm{PuF}_{6}$ released, mathematical models were developed for the processes of agglomeration and of filtration under loading (see Appendixes B and C). These models may also indicate the range of operating conditions in which the effects of agglomeration and filter loading are appreciable. These models may be used as a basis for estimating the experimental conditions under which agglomeration and filter loading have important effects on filtration efficiency. For this application of the model, information is required about the surface area and size of the fume particles and the filter medium.

Figure 8 is an electron-microscope picture of the material collected by using the electrostatic precipitator. The measured particlesize distribution of the unagglomerated particles is given in Fig. 3. The particle-size distribution is accurately described by a logarithmic normalfrequency distribution with a geometric mean 
diameter of 0.0171 micron and a geometric standard deviation of 2.24.

The mass mean particle size is 0.12 micron.

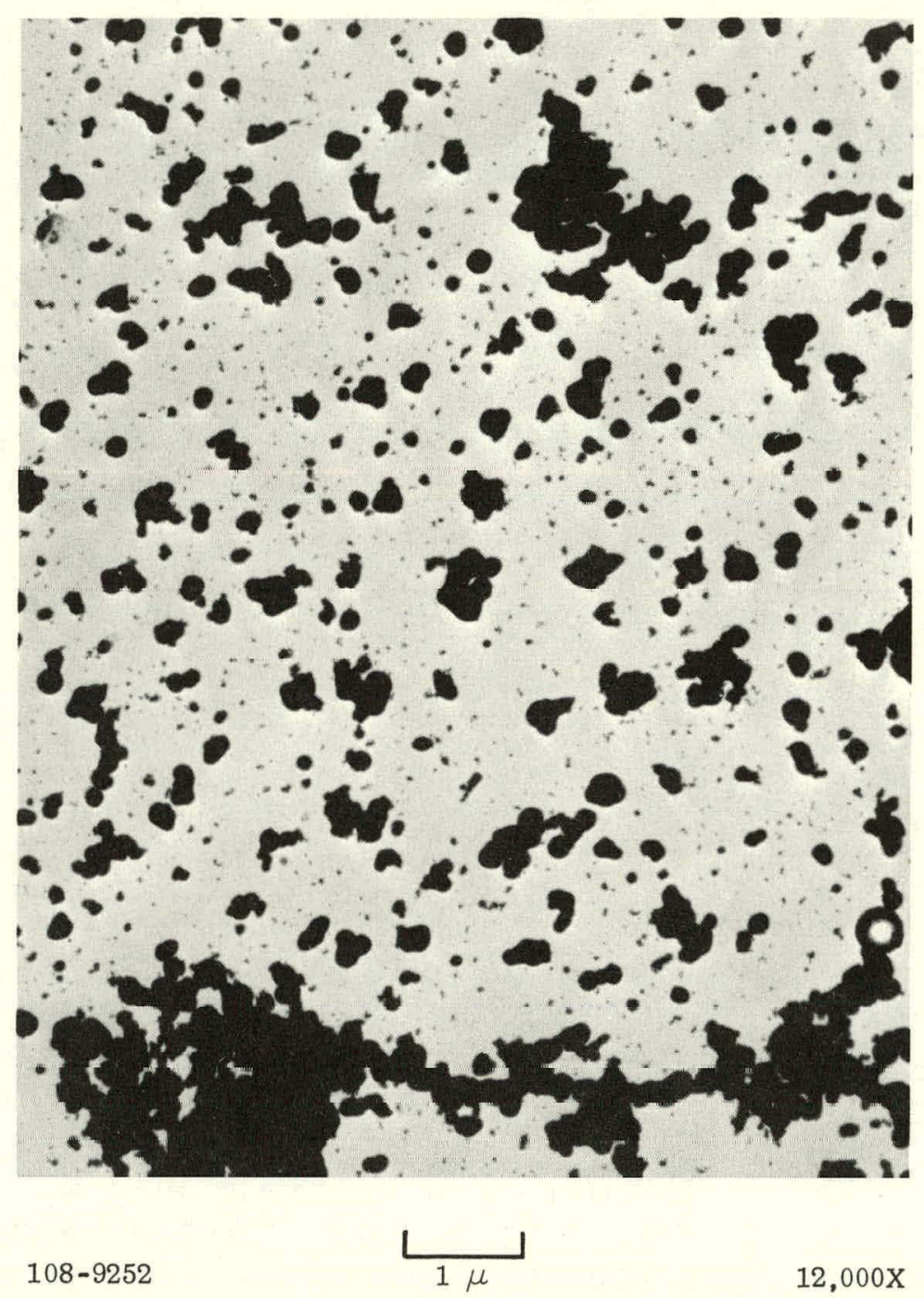

Fig. 8. Electron Micrograph of

$\mathrm{PuF}_{6}$ Hydrolysis Product

Substitutions of measured variables in the expression derived in Appendixes B and $\mathrm{C}$ for the agglomeration and loading numbers result in

$$
\begin{aligned}
& \mathrm{a}=0.50 \frac{\mathrm{w}_{0}}{\rho_{\mathrm{p}} \mathrm{Rd}_{\mathrm{p}}^{3}}\left(1+\frac{0.18}{\mathrm{~d}_{\mathrm{p}}}\right) \\
& \mathrm{L}=0.68 \frac{\mathrm{w}_{0}}{\rho_{\mathrm{p}} \mathrm{Ad}_{\mathrm{p}}} \ln \left(1 / \mathrm{P}_{0}\right)
\end{aligned}
$$

where $\mathrm{w}_{0}=$ mass of $\mathrm{PuF}_{6}, \mathrm{mg} ; \rho_{\mathrm{p}}=$ density of $\mathrm{PuO}_{2} \mathrm{~F}_{2}, \mathrm{~g} / \mathrm{cm}^{3} ; \mathrm{d}_{\mathrm{p}}=$ aiameter of particle, microns; $\mathrm{R}=$ gas flow rate, $\mathrm{cm}^{3} / \mathrm{sec}$; and $\mathrm{A}=$ superficial area of filter media, $\mathrm{cm}^{2}$. For $\rho_{p}=6.5 \mathrm{~g} / \mathrm{cm}^{3}, \mathrm{~d}_{\mathrm{p}}=0.1$ micron, and $P_{0}=10^{-4}$, 


$$
a=200 \frac{w_{0}}{R}
$$

and

$$
L=10 \frac{\mathrm{w}_{0}}{\mathrm{~A}} \text {. }
$$

For the $\mathrm{PuF}_{6}$ experiments, wo varies from 1.5 to $25, \mathrm{R}=9 \mathrm{~cm}^{3} / \mathrm{sec}$, and $A=8.6 \mathrm{sq} \mathrm{cm}$. Thus, $a$ is between 30 and 600 , and $L$ is between 2 and 30. Values greater than one indicate that agglomeration and loading are strongly affecting the penetration of the first filter. An important result here is that the values of $a$ and $L$ can be estimated for any operating system.

According to the above analysis, an effect of the quantity of $\mathrm{PuF}_{6}$ released would be expected to appear in the filter-penetration results

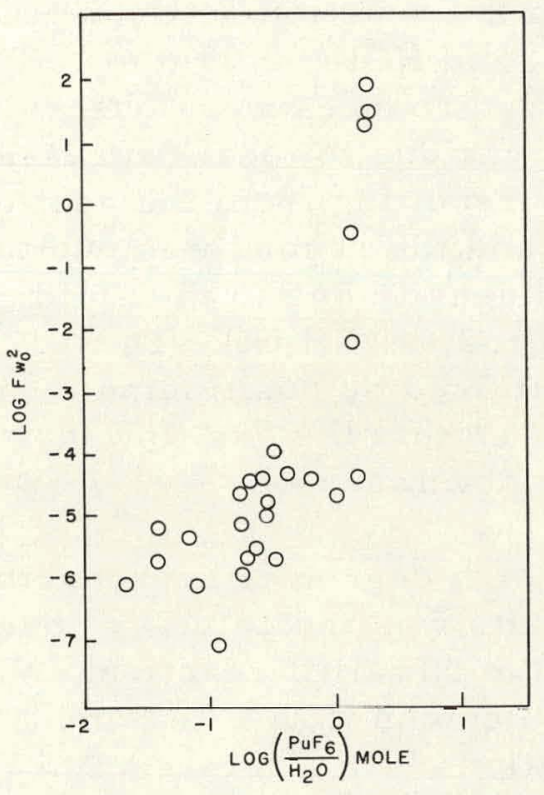

$108-6840$

Fig. 9. Correlation of Data of Filter Penetration in $\mathrm{PuF}_{6}$ Release Experiments shown in Fig. 7. Consequently, a function including both the overall penetration factor $F$ and the weight $\mathrm{w}_{0}$ of $\mathrm{PuF}_{6}$ released may give a better correlation (against the $\mathrm{PuF}_{6} / \mathrm{H}_{2} \mathrm{O}$ mole ratio) than does $F$ alone. Tests were made of $\mathrm{Fw}_{0}, \mathrm{Fw}_{0}^{2}$, and $\mathrm{Fw}_{0}^{3}$; the best correlation was obtained with $\mathrm{Fw}_{0}^{2}$, which is plotted in Fig. 9. Although considerable scatter remains in Fig. 9, a greater regularity of the data points is shown here than in Fig. 7, and this correlation is believed to be superior to the original one. The dependence of the penetration on the square of $\mathrm{w}_{0}$ is what would be expected when the effects of agglomeration and loading take place simultaneously, since each factor (a or L) is proportional to $\mathrm{w}_{0}$.

The value of $d_{p}$ used in the agglomeration and loading equations is also likely to be a function of the filter penetration characteristics under some conditions. The penetration of filters by particles with the size of interest is unknown. Also, the scatter of the existing data does not allow a good experimental verification of the agglomeration and loading models presented. These models should only be considered as a first approximation to these effects and as an indication of the conditions under which these effects would be expected to be observable. 


\section{SURFACE REACTION}

A. Laminar-flow Experiments with Uranium Hexafluoride

To increase the reproducibility of the experiments and to study the reaction when plutonium or uranium hexafluoride was diluted with a dry inert gas before contacting moist gas, a laminar-flow reaction device was designed and tested.

\section{Equipment Development}

Several equipment designs were tested with ammonia and $\mathrm{HCl}$, and the design shown in Fig. 10 was selected. This design would maintain

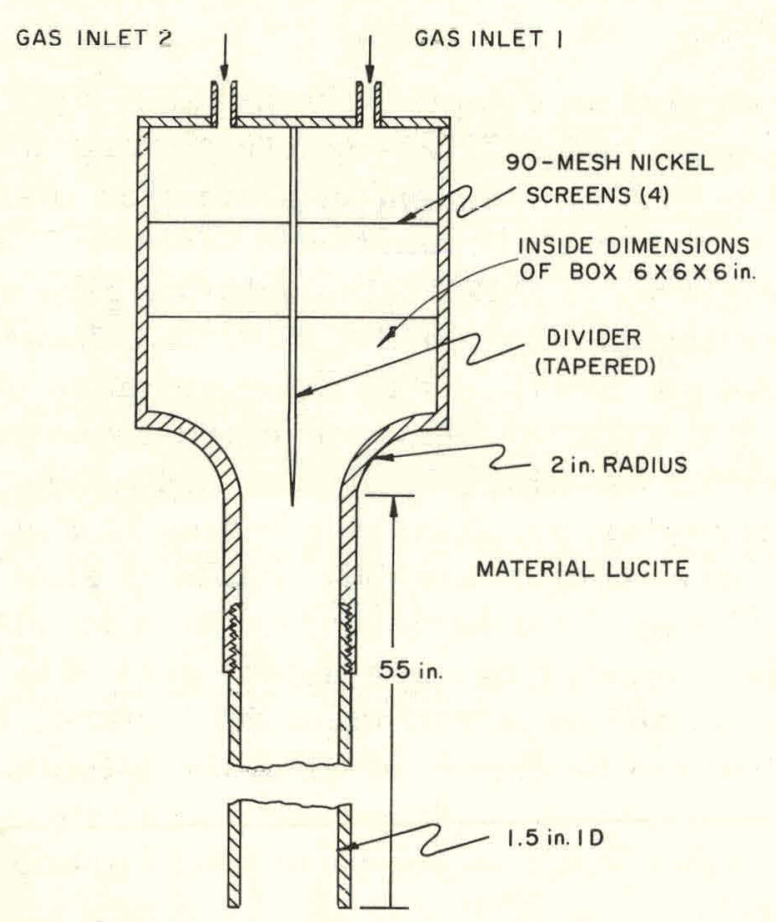

108-9336 Rev. 1

Fig. 10. Laminar-flow Apparatus for Hydrolysis of $\mathrm{UF}_{6}$ a smooth laminar flow over its entire length for velocities between 1 and $25 \mathrm{~cm} / \mathrm{sec}$. Flow disturbances at the lower velocity were generated by density differences in the flowing gas due to the reaction between dilute $\mathrm{NH}_{3}$ and $\mathrm{HCl}(\sim 0.05 \mathrm{~mm})$. Two types of disturbances were observed. The first was due to local decrease in density resulting from the heat of reaction, and the second was due to increased density due to the solid reaction product $\left(\mathrm{NH}_{4} \mathrm{Cl}\right)$. These were minimized by positioning the equipment so that the gas flowed vertically downward.

A high degree of reproducibility of results was indicated by observation of the $\mathrm{NH}_{3}-\mathrm{HCl}$ reaction. With properly matched flow rates and concentrations, all of the reaction occurred near the plane of the partition. The solid product would discharge from the end of the tube as a thin sheet of smoke, less than $1 / 16 \mathrm{in.} \mathrm{thick.} \mathrm{This} \mathrm{was} \mathrm{an} \mathrm{indicaliun}$ of the rapid reaction that prevented diffusion of the reactants into each other.

\section{Uranium Hexafluoride Experiments}

The initial experiments with $\mathrm{UF}_{6}$ indicated that the gas-phase hydrolysis reaction was much slower than had been expected. Even under conditions of high concentration, where the $\mathrm{UO}_{2} \mathrm{~F}_{2}$ product fume was visible in a strong beam of light, the fume was broadly distributed in the tube, indicating extensive diffusion of the reactants into each other. 
Several runs were made with filter-media discs sealed against the tube discharge. Sets of three or four filter-media discs, stacked on top of each other, were placed in the tube discharge position for times ranging from 5 to $3000 \mathrm{sec}$. The operating condition and results of these runs are given in Table VII. The filters were alpha-counted with a scintillation counter of $42 \%$ counting efficiency.

TABLE VII. Hydrolysis and Filtration of $\mathrm{UF}_{6}$ in Laminar-flow Equipment
Reaction time
Diluent gas:
Total superficial gas velocity in $1 \frac{1}{2}$-in. tube $\left(1 \mathrm{~atm}, 25^{\circ} \mathrm{C}\right)$ :
$14.5 \mathrm{sec}$
AEC type
Nitrogen
$9.7 \mathrm{~cm} / \mathrm{sec}$

\begin{tabular}{|c|c|c|c|c|c|c|}
\hline \multirow[b]{2}{*}{ Run } & \multicolumn{2}{|c|}{$\begin{array}{c}\text { Partial } \\
\text { Pressure, } \\
\text { mm Hg }\end{array}$} & \multicolumn{4}{|c|}{$\begin{array}{l}\text { Uranium Distribution, } \\
\text { alpha counts } / \text { min }^{a}\end{array}$} \\
\hline & $\mathrm{UF}_{6}$ & $\mathrm{H}_{2} \mathrm{O}$ & First Filter & Second Filter & Third Filter & Fourth Filter \\
\hline 1 & 0.0051 & 0.079 & 60 & 12 & 1.9 & \\
\hline 2 & 0.059 & 0.86 & 1982 & 723 & 476 & \\
\hline 3 & 0.0051 & 0.82 & 286 & 47 & 1.5 & 0.7 \\
\hline 4 & 0.0051 & 7.6 & 872 & 7.1 & 0.6 & 0.6 \\
\hline
\end{tabular}

aFilter collection time of 1000 sec.

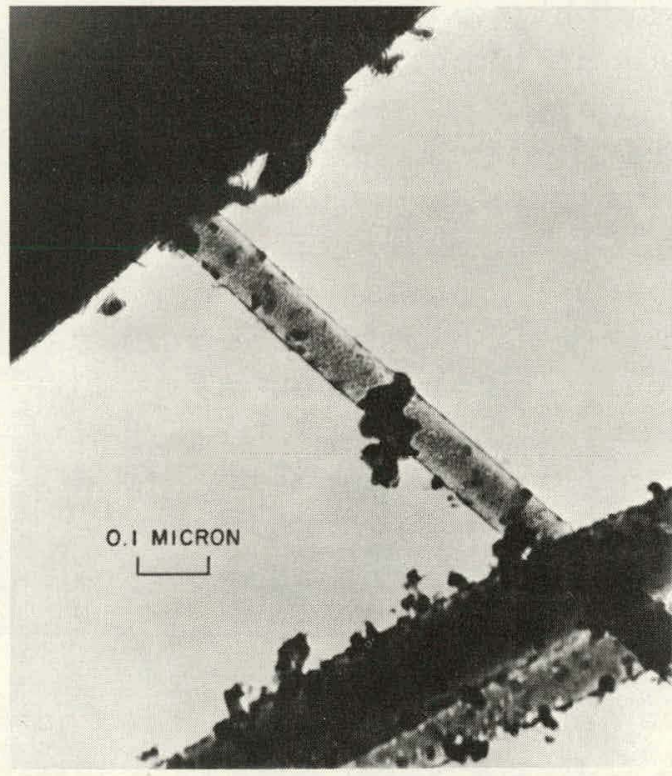

$108-6686$

Fig. 11. Uranium Hexafluoride Hydrolysis Product Deposited on Filter Fibers in Run 1. Collection time: $3000 \mathrm{sec}$.
Electron micrographs of fibers removed from the incident face of the filter used in each run are shown in Figs. 11 to 14. Figure 11 shows the initial surface reaction at active sites before the deposit has become continuous. Figures 12 and 13 show further deposition of a continuous layer. Sections of fibers exposed as a result of mechanical disruption of the deposit during fiber removal are evident. These disruptions of the deposit were not common and required long searches before they were located. This indicates that the deposit has nearly the strength of the glass fibers on which it is deposited. Figure 14 (Run 4) shows a particulate form of deposition as opposed to the continuouslayer form. The particulate solid is formed by reaction in the gas phase and is then collected by the filter. 


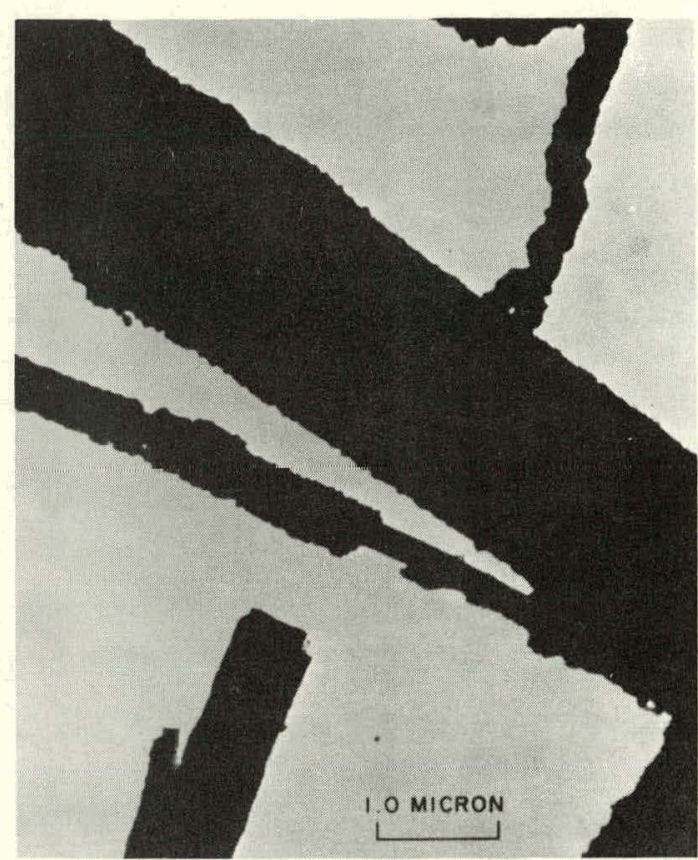

$108-6687$

Fig. 12. Uranium Hexafluoride Hydrolysis Product Deposited on Filter Fibers in Run 2. Collection time: $3000 \mathrm{sec}$.

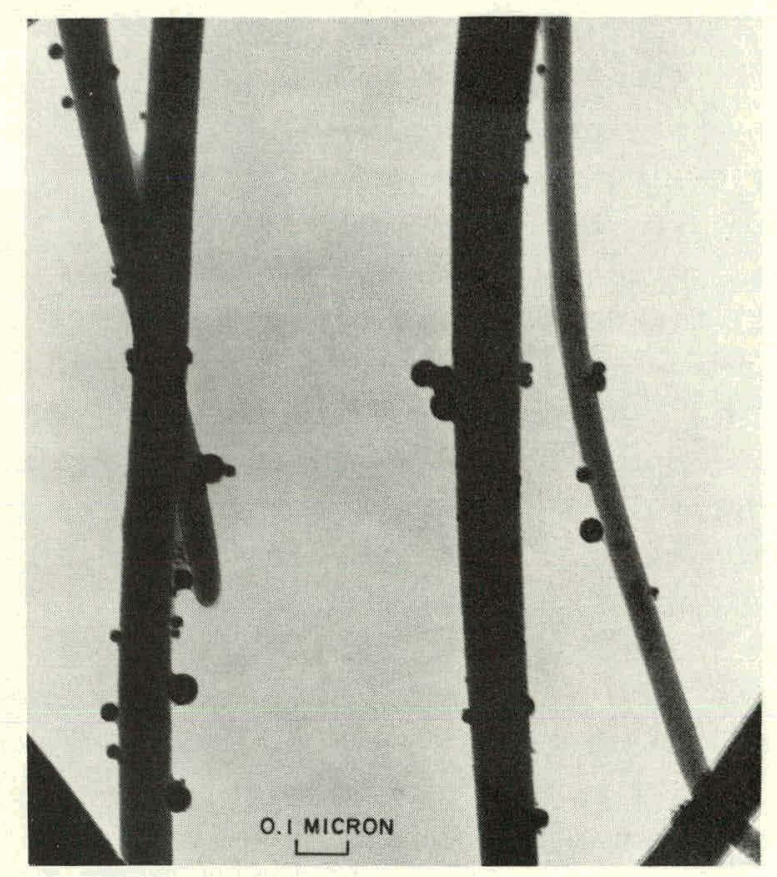

$108-6689$

Fig. 14. Uranium Hexafluoride Hydrolysis Product Deposited on Filter Fibers in Run 4. Collection timc: $30 \mathrm{sec}$.

in the plastic that contributed to the opaqueness. This deposit was accumulated during all runs for a total collection time of approximately $10 \mathrm{hr}$.

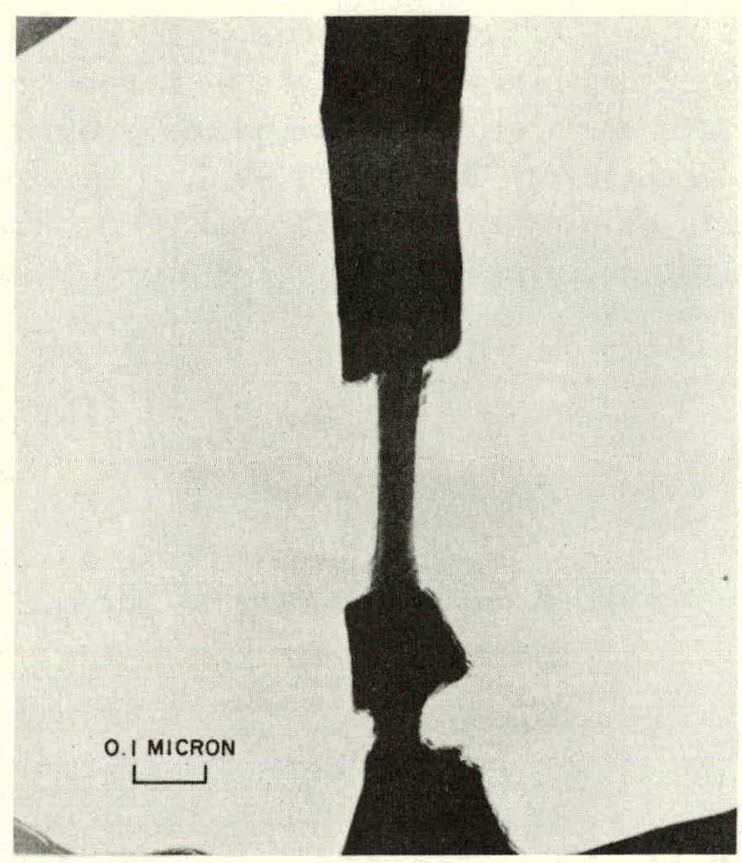

$108-6688$

Fig. 13. Uranium Hexafluoride Hydrolysis Product Deposited on Filter Fibers in Run 3. Collection time: 3000 sec.

An inspection, made after disassembly of the laminar-flow equipment, indicated the deposition product appeared as a smoothtextured material of high density. The thickness of the deposit greatly exceeded that observed by the electron microscope. During all these experiments the plastic tube remained as clear and transparent as at the start of the series with $\mathrm{UF}_{6}$. This indicates the smoothness of the deposit, since pores or surface irregularities larger than the wavelength of light would scatter light. Between experiments a small purge of dry air was maintained through the equipment. After several days exposure to room air, the deposit became completely opaque, like a ground-glass surface, indicating the thickness of the deposit. The opaque deposit was readily removed by wiping with a moist paper, thus indicating no change 
B. Hydrolysis of Uranium Hexafluoride in Packed Beds

A packed bed of glass spheres is better suited for measuring the surface reaction than are filters because (a) the surface area available for reaction can be accurately determined, (b) the packed bed can be removed and leached for the determination of deposited uranium and/or plutonium, and (c) a packed bed followed by filters will allow a separation of the effects of surface reaction and fume production. Since the diameter of the packedbed particles is larger than that of the filter fibers, the packed beds will have a low interception efficiency for particulate.

\section{Apparatus and Procedure}

Surface-reaction kinetics of the hydrolysis of dilute mixtures of $\mathrm{UF}_{6}$ were measured in a packed bed of $3.2-\mathrm{mm}$ glas spheres in the apparatus shown in Fig. 15. The bed was contained in a 1.5-in.-ID acrylic

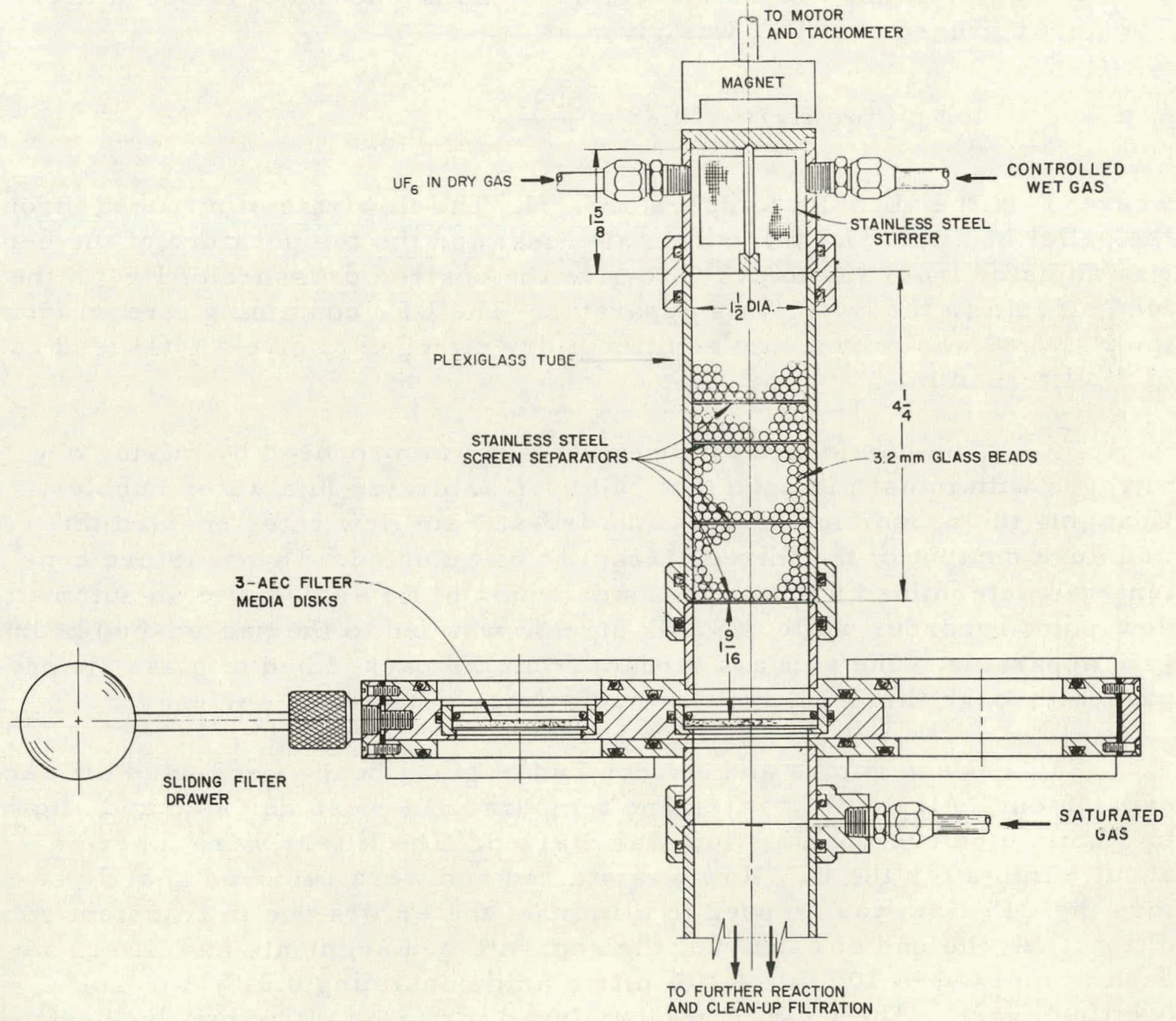

108-7978 Rev,

Fig. 15. Packed-bed Apparatus for Hydrolysis of $\mathrm{PuF}_{6}$ or $\mathrm{UF}_{6}$ 
(Plexiglas) tube and was supported on stainless-steel screen separators. The two entering nitrogen gas streams, one containing $\mathrm{UF}_{6}$ and the other containing moisture, were rapidly mixed by a stirrer rotating at $500 \mathrm{rpm}$. Results of scouting tests indicated that the reaction rates were independent of stirrer speeds between 500 and $1500 \mathrm{rpm}$.

An extremely dry source of gas was needed for this work, and nitrogen from a liquid-nitrogen supply was found satisfactory as the carrier gas since its dew point was very low $\left(-100^{\circ} \mathrm{F}\right.$ corresponding to $3 \mathrm{ppm}$ moisture). It was assumed that there would not be any difference in the experimental results if either nitrogen or air was used.

The $\mathrm{UF}_{6}$ stream was generated by passing a small flow of dry nitrogen over a bed of $1 / 8-i n$. NaF pellets that had been saturated with $\mathrm{UF}_{6}$. Equilibrium of the gas with the bed was attained since this system was very similar to that used in the original measurement of the equilibrium pressure of $\mathrm{UF}_{6}$ over the "UF $6-3 \mathrm{NaF}$ complex" as a function of temperature. ${ }^{5}$ The vapor pressure of $\mathrm{UF}_{6}$ was given as

$$
\log \mathrm{p}(\mathrm{mm} \mathrm{Hg})=10.88-\frac{5090}{\mathrm{~T}}
$$

where $\mathrm{T}$ is the absolute temperature, ${ }^{\circ} \mathrm{K}$. The flow rate of nitrogen through the pellet bed was $83.7 \mathrm{ml} / \mathrm{min}$ in all runs, and the temperature of the bed was adjusted from 134 to $212^{\circ} \mathrm{C}$ to give the desired pressure of $U F_{6}$ in the feed stream to the hydrolysis apparatus. The UF 6 -containing stream from the $\mathrm{NaF}$ bed was mixed with additional dry nitrogen to give a total feed rate of 3.3 liters/min.

The humidified nitrogen stream was produced by mixing dry nitrogen with moist nitrogen that had been saturated in a water bubbler. Changing the proportion of wet- and dry-stream flow rates enabled the moisture content of the mixed stream to be adjusted. The moisture content was determined by passing a small part of this stream to an automatic dew-point recorder while the bulk stream was fed to the packed-bed hydrolysis apparatus. The exit gas stream from the packed bed of glass spheres passed through three AEC filter media discs mounted in series.

Clean filters and a clean bed of glass beads were used for each experiment. All the flow rates and temperatures were adjusted and allowed to stabilize before the $\mathrm{UF}_{6}$ flow was started. The filters were inserted about 5 min after the $\mathrm{UF}_{6}$ flow was started and were removed shortly before the $\mathrm{UF}_{6}$ flow was stopped to eliminate the errors due to transient conditions. At the end of each run, the separate bed segments and filters were each immersed in $100 \mathrm{ml}$ of $10 \%$ nitric acid containing $0.01 \%$ Aerosol* (wetting agent). The solution was analyzed for uranium by the fluorophotometric method.

*Obtained from E. H. Sargent and Co. 


\section{Results and.Discussion}

Hydrolysis rates were calculated from the uranium deposited on the surfaces of glass spheres in each packed-bed segment. The quantities of uranium found in the various packed-bed segments and the quantity collected on each of the filter discs are reported in Table VIII. In all experiments, there was a large excess of water over that required for complete reaction.

TABLE VIII. Surface-reaction Data for Hydrolysis Kinetics of Uranium Hexafluoride

Column diameter: $1.5 \mathrm{in}$.

Linear velocity: $\quad 9.7 \mathrm{~cm} / \mathrm{sec}$

Room temperature: $23-25^{\circ} \mathrm{C}$

\begin{tabular}{|c|c|c|c|c|c|c|c|c|c|c|c|c|}
\hline \multirow[b]{2}{*}{ Run } & \multirow{2}{*}{$\begin{array}{l}\mathrm{P}_{\mathrm{UF}} \mathrm{6}^{\prime} \\
\mathrm{mm} \mathrm{Hg}\end{array}$} & \multirow{2}{*}{$\begin{array}{l}\mathrm{P}_{\mathrm{H}_{2}} \mathrm{O}^{\prime} \\
\mathrm{mm}^{\mathrm{Hg}}\end{array}$} & \multirow{2}{*}{$\begin{array}{c}\text { Feed Rate, } \\
\mathrm{mg} \mathrm{U} / \mathrm{hr}\end{array}$} & \multirow{2}{*}{$\begin{array}{c}\mathrm{t} \mathrm{Bed}_{,}^{\mathrm{a}} \\
\min \end{array}$} & \multicolumn{4}{|c|}{ mg $U$ per Bed Segment } & \multirow{2}{*}{$\begin{array}{c}\text { t Filter } \\
\text { min }\end{array}$} & \multicolumn{3}{|c|}{ mg U per Filter } \\
\hline & & & & & $0-\frac{1}{2}$ in. & $\frac{1}{2}-1$ in. & $1-2 \mathrm{in.}$ & $2-3 \mathrm{in}$. & & First & Second & Third \\
\hline UM-11 & 0.00310 & 0.050 & 15.9 & 55.2 & \multicolumn{2}{|c|}{$1.7^{c}$} & 1.0 & 0.9 & 50.0 & 0.48 & 0.40 & 0.38 \\
\hline UM-12 & 0.00310 & 0.15 & 15.9 & 56.0 & \multicolumn{2}{|c|}{$4.2^{c}$} & 1.6 & 0.9 & 50.0 & 0.35 & 0.099 & 0.035 \\
\hline$U M-13$ & 0.00310 & 0.27 & 15.9 & 55.0 & 3.2 & 1.6 & 1.3 & 0.20 & 50.0 & 0.063 & 0.0023 & 0.0017 \\
\hline UM-14 & 0.00310 & 0.42 & 15.9 & 58.4 & 4.3 & 1.3 & 0.7 & 0.07 & 50.0 & 0.040 & 0.005 & 0.0012 \\
\hline UM-15 & 0.00310 & 0.72 & 15.9 & 52.5 & 4.7 & 0.6 & 0.10 & $0.02^{\mathrm{e}}$ & 50.0 & 0.047 & 0.003 & 0.0011 \\
\hline UM-16 & 0.00310 & 1.3 & 15.9 & 56.8 & 5.2 & 0.3 & 0.04 & $0.03 \mathrm{e}$ & 50.0 & 0.070 & 0.006 & 0.0014 \\
\hline UM-18 & 0.00310 & 3.8 & 15.9 & 61.7 & 4.2 & 0.15 & $0.12^{\mathrm{e}}$ & $0.14^{\mathrm{e}}$ & 50.0 & 1.0 & 0.17 & 0.007 \\
\hline UM-19 & 0.00310 & 5.1 & 15.9 & 58.7 & 2.8 & 0.10 & $0.10^{\mathrm{e}}$ & $0.11^{\mathrm{e}}$ & 50.0 & 2.8 & 0.07 & 0.08 \\
\hline UM-20 & 0.000314 & 0.43 & 1.62 & 91.2 & 0.20 & 0.017 & $0.014^{e}$ & $0.015^{\mathrm{e}}$ & 50.0 & 0.002 & 0.002 & 0.002 \\
\hline UM-22 & 0.00155 & 0.43 & 7.96 & 90.0 & 4.2 & 1.0 & 0.26 & 0.025 & 70.0 & 0.004 & 0.0004 & 0.0008 \\
\hline$U M-14^{d}$ & 0.00310 & 0.42 & 15.9 & 58.4 & 4.3 & 1.3 & 0.7 & 0.07 & 50.0 & 0.040 & 0.005 & 0.0012 \\
\hline UM-23 & 0.0150 & 0.43 & 77.3 & 26.9 & 5.4 & 3.4 & 4.9 & 3.5 & 15.0 & 0.60 & 0.43 & 0.13 \\
\hline UM-21 & 0.0308 & 0.42 & 158.5 & 25.0 & 7.5 & 5.9 & 8.2 & - & 15.0 & 3.6 & 0.99 & 0.38 \\
\hline
\end{tabular}

$a_{t}$ Bed and $t$ Filter represent the time during which the reactant flow was maintained through the bed and the filter, respectively.

$b_{\text {Bed area }}=332 \mathrm{~cm}^{2} / \mathrm{in}$., wall area $=30.4 \mathrm{~cm}^{2} /$ in., area of screen between beds $=20.7 \mathrm{~cm}^{2}$.

$\mathrm{C}_{\text {Beds }}$ in UM-11 and -12 were divided into 1 -in. segments only.

Run UM-14 is tabulated twice to aid in comparison of data.

$\mathbf{e}_{\text {Not }}$ used in computation of rate equation constants since these values were affected by fume collection.

The hydrolysis rates increased with increase in the partial pressure of either water or $U_{6}$. The rates ranged from $0.3 \times 10^{-4}$ to $0.1 \mathrm{mg}$ of $\mathrm{U} /(\mathrm{hr})(\mathrm{sq} \mathrm{cm})$. The highest reaction rate was less than the mass transfer rate ${ }^{17}$ calculated from known physical properties, indicating that the reaction is not mass-transfer limited.

The ratios of the quantity of uranium collected on the first filter to that retained on the packed-bed segment immediately preceding the filter varied from about 0.1 to 25 , most being less than one. The higher ratios indicate the presence of gas-phase reaction (fume formation) and low filtration efficiency of the packed bed for such a reaction product.

Since the hydrolysis reaction produces a solid reaction product $\left(\mathrm{UO}_{2} \mathrm{~F}_{2}\right)$, any surface at which the reaction takes place will be covered with the reaction product. This is true for all solid surfaces, whether they be fixed solid parts of the equipment or particles being carried in the gas as fume. The reaction rate measured on the surface of packed beds may be expected to be the same as that at the surface of a particle suspended in the gas phase under the same conditions of gas composition and pressure 
at the reaction surfaces. Thus reaction rates measured in the packed beds may be used in predicting the particle growth rate and size distribution of the fume produced in the gas-phase part of the reaction.

To define the effects of partial pressures of $\mathrm{UF}_{6}$, water, and HF more clearly, the experimental data were correlated by using a semiempirical rate equation proposed by Hougen ${ }^{20}$ and $\mathrm{Walas}^{40}$ for reaction catalyzed by solid surfaces. The selected rate equation is

$$
r=\frac{k p_{U F_{6}} p_{H_{2}} \mathrm{O}}{1+\bar{K}_{1} \mathrm{p}_{U F_{6}}+\bar{K}_{2} \mathrm{p}_{\mathrm{HF}}}
$$

where

$$
\begin{aligned}
r= & \text { reaction rate, } \mathrm{mg} U /(\mathrm{hr})(\mathrm{sq} \mathrm{cm}) ; \\
\mathrm{k}= & \text { rate constant } \\
\mathrm{p}= & \text { partial pressure of subscripted component at the surface } \\
& \mathrm{mm} \mathrm{Hg} ;
\end{aligned}
$$

and

$$
K=\text { adsorption constants. }
$$

The rate equation and the following equations for describing mass transfer and material balance were programmed for a computer to estimate the constants in the rate equation by a least-squares method. For mass t.ransfer.

$$
r=k_{D}\left(\operatorname{PUF}_{6}(g)=P \cup F_{6}\right) \text {, }
$$

where

and

$$
\begin{aligned}
k_{D} & =\text { mass-transfer coefficient; } \\
\text { puF }_{6}(g) & =\text { partial pressure of } \mathrm{UF}_{6} \text { in the gas phase, } m m \mathrm{Hg} ;
\end{aligned}
$$

$$
\mathrm{p}_{\mathrm{UF}_{6}}=\text { pressure of } \mathrm{UF}_{6} \text { at the reacling surface, mm IIg. }
$$

Material balance was based on the reaction

$$
\mathrm{UF}_{6}(\mathrm{~g})+2 \mathrm{H}_{2} \mathrm{O}(\mathrm{g}) \rightarrow \mathrm{UO}_{2} \mathrm{~F}_{2}(\mathrm{~s})+4 \mathrm{HF}(\mathrm{g})
$$

When the fraction of $\mathrm{UF}_{6}$ unreacted, $\mathrm{x}$, is defined by the following equation

$$
\mathrm{P}_{U F_{6}}(\mathrm{~g})=\mathrm{xp}_{\mathrm{UF}} \mathrm{F}_{6}
$$


material balance on the other reactants gives

$$
\begin{aligned}
& \mathrm{p}_{\mathrm{H}_{2} \mathrm{O}}=\mathrm{p}_{\mathrm{H}_{2} \mathrm{O}}^{\circ}-2 \mathrm{p}_{\mathrm{U} F_{6}}^{\circ}(1-\mathrm{x}), \\
& \mathrm{p}_{\mathrm{HF}}=4 \mathrm{p}_{\mathrm{U} F_{6}}(1-\mathrm{x}),
\end{aligned}
$$

and

$$
\mathbf{r}_{\mathrm{ds}}=-\mathrm{Fdx}
$$

where

$$
\begin{aligned}
\mathrm{p}^{0}= & \text { partial pressure of subscripted component at the inlet, } \\
& \mathrm{mm} \mathrm{Hg} ; \\
\mathrm{S}= & \text { surface area of reaction bed; }
\end{aligned}
$$

and

$$
F=\text { input rate of } \mathrm{UF}_{6} \text {. }
$$

The result from the computer calculation is

$$
r=\frac{191.5 p_{U F_{6}} p_{H_{2} \mathrm{O}}}{1+597 p_{U F_{6}}+95.5 p_{H F}}
$$

The average error between the correlation and the measured rates was $\pm 26 \%$ (standard deviation) for individual bed segments. Data from eight bed segments were not used in the computation because of collection of gasphase reaction products (fume). This was apparent as a sudden large decrease in slope of a plot of $r$ vs $S$.

C. Hydrolysis of Plutonium Hexafluoride in Packed Beds

\section{Apparatus}

The hydrolysis rate for $\mathrm{PuF}_{6}$ was measured in an apparatus similar to that used for $\mathrm{UF}_{6}$ experiments. Air dried to about $0.1 \mathrm{ppm}$ of moisture was used as a carrier for $\mathrm{PuF}_{6}$. Air with a controlled moisture content between 0.1 and $10 \mathrm{~mm} \mathrm{Hg}$ was mixed with the $\mathrm{PuF}_{6}$ carrier stream for studying the hydrolysis reaction rates. Another air stream saturated with moisture was combined with the mixed stream after passage through the packed bed of glass spheres and AEC filter discs. This final addition of moisture insured the complete hydrolysis of unreacted hexafluoride and facilitated final cleanup of the gas before discharging to the glovebox atmosphere. The equipment for supplying these three streams is shown in the upper half of Fig. 16. 


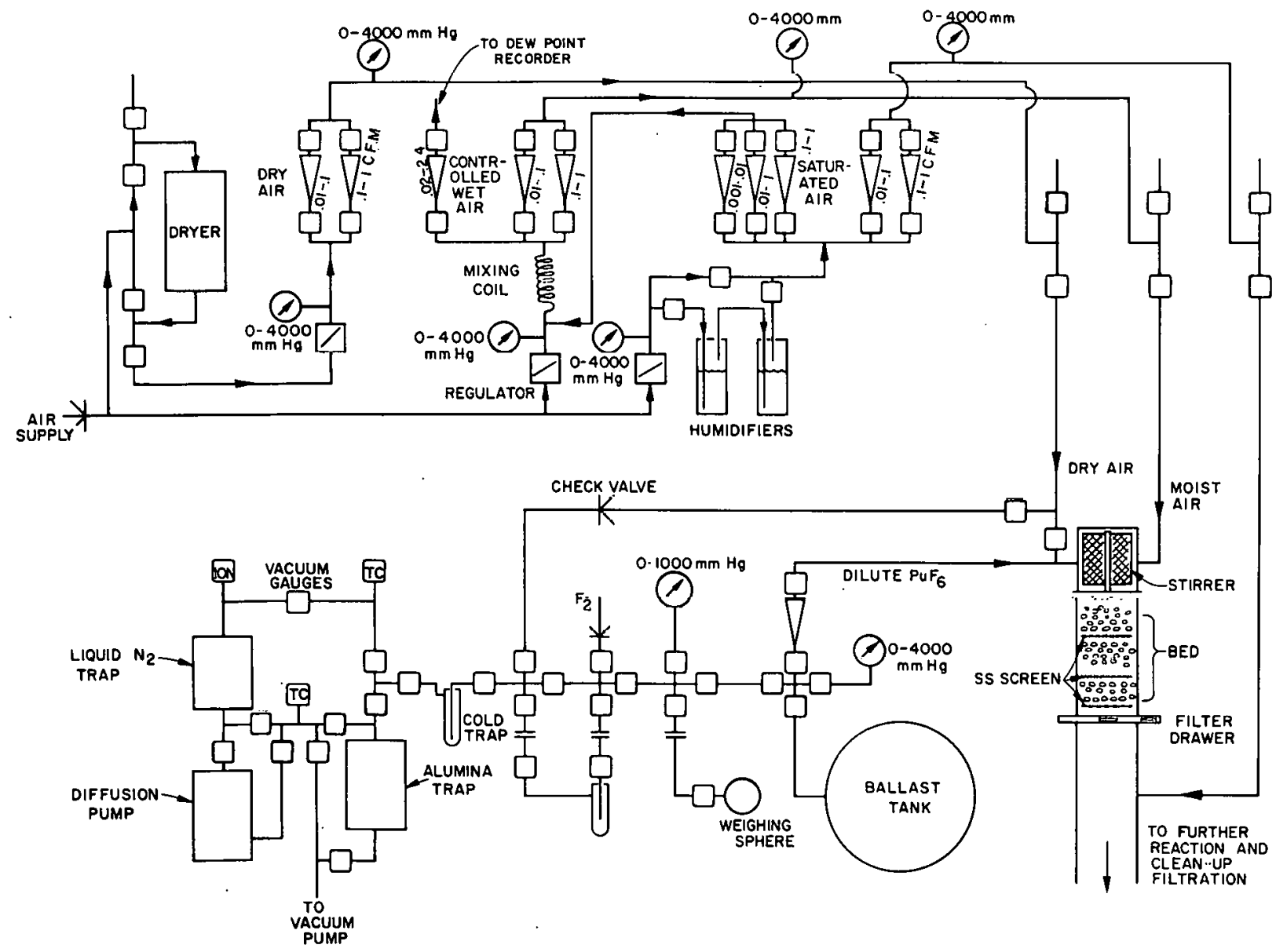

$108-8753$

Fig. 16. Schematic Diagram of Packed-bed Equipment for Hydrulysis of $\mathrm{PuF}_{6} \mathrm{Ul}_{1} \mathrm{UF}_{6}$

The remaining equipment, shown in the lower half of Fig. 16, includes hexafluoride purification and metering systems and the hydrolysis apparatus. This part of the equipment was constructed in duplicate: one set in the glovebox for $\mathrm{PuF}_{6}$ experiments, and the other set in the vacuum frame hood for $\mathrm{UF}_{6}$ experiments. Details of the hydrolysis apparatus were described earlier (see Fig. 15) in this report.

Plutonium hexafluoride, in solid form, was purified by vacuum pumping on the material at $-80^{\circ} \mathrm{C}$. The solid $\mu_{u} F_{6}$ was then sublimed and recondensed to release any impurities trapped within the solid. The vapor pressure was measured at temperatures slightly below room temperature and compared with reported values for pure $\mathrm{PuF}_{6}$, Ref. 36 , as a check of the purity of the hexafluoride. The purification process was repeated until the vapor pressure became constant at the value reported for the pure $\mathrm{PuF}_{6}$. A weighed quantity of $\mathrm{PuF}_{6}$ was then charged to the ballast tank, which was then pressurized to $1900 \mathrm{~mm} \mathrm{Hg}$ with dry air, and the contents were mixed. Mixing was accomplished by maintaining a temperature 
gradient across the ballast tank, the bottom of the tank being $5^{\circ} \mathrm{C}$ hotter than the top; this gradient was maintained for at least $16 \mathrm{hr}$. During a run, the $\mathrm{PuF}_{6}$-air mixture was metered with a rotameter at a constant rate between 50 and $100 \mathrm{ml} / \mathrm{min}$. This mixture was then further diluted with dry air to produce the feed to the hydrolysis equipment.

After each experimental run, the plutonium deposited on the bed segments, filters, mixer, etc. was dissolved by submerging the separated units in a measured volume of $10 \%$ nitric acid plus $0.01 \%$ wetting agent (Aerosol), for $24 \mathrm{hr}$. The solution was then mixed and sampled for analysis of plutonium and/or uranium. Complete dissolution of plutonium was verified in several instances by counting of dried media.

\section{Results and Discussion}

The $\mathrm{PuF}_{6}$ experimental results are reported in Table IX. The partial pressures in the initial mixed gas ranged from 0.06 to $5.6 \mathrm{~mm} \mathrm{Hg}$ of water vapor and 0.00001 to $0.02 \mathrm{~mm} \mathrm{Hg}$ of $\mathrm{PuF}_{6}$.

TABLE IX. Surface-reaction Data for Hydrolysis Kinetics of Plutonium-Uranium Hexafluorides

$\begin{array}{ll}\text { Column diameter: } & 1.5 \mathrm{in} . \\ \text { Linear velocity: } & 9.8 \mathrm{~cm} / \mathrm{sec} \\ \text { Temperature: } & 22-25^{\circ} \mathrm{C} \\ \text { Run time: } & 60.0 \mathrm{~min}\end{array}$

\begin{tabular}{|c|c|c|c|c|c|c|c|c|c|c|c|c|c|}
\hline \multirow[b]{2}{*}{ Run } & \multirow{2}{*}{$\begin{array}{l}\mathrm{P}_{2}^{\circ} \mathrm{O} \\
\mathrm{mm} \mathrm{Hg}\end{array}$} & \multirow[b]{2}{*}{$M$} & \multirow{2}{*}{$\begin{array}{l}\mathrm{P}_{M F_{6^{\prime}}} \\
\mathrm{mm} \mathrm{Hg}\end{array}$} & \multirow{2}{*}{$\begin{array}{l}\text { Feed, } \\
\mathrm{mg} \text { M/hr }\end{array}$} & \multicolumn{4}{|c|}{$\mathrm{mg}$ of $M$ per Bed Segment ${ }^{a}$} & \multicolumn{3}{|c|}{$\mathrm{mg}$ of $\mathrm{M}$ per Filter } & \multirow{2}{*}{$\begin{array}{l}\mathrm{mg} \text { of } M \text { in } \\
\text { Mixer }\end{array}$} & \multirow{2}{*}{$\begin{array}{l}\mathrm{mg} \text { of } \mathrm{M} \text { in } \\
\text { Cylinder } \\
\text { and } \\
\text { Screens }\end{array}$} \\
\hline & & & & & $0-\frac{1}{2}$ in. & $\frac{1}{2}-1$ in. & $1-2$ in. & $2-3$ in. & First & Second & Third & & \\
\hline \multicolumn{14}{|c|}{ Plutonium Hexafluoride Experiments } \\
\hline $\begin{array}{l}P M-4 \\
P M-1 \\
P M-6\end{array}$ & $\begin{array}{l}5.6 \\
0.54 \\
0.060\end{array}$ & $\begin{array}{l}\text { Pu } \\
\text { Pu } \\
\text { Pu }\end{array}$ & $\begin{array}{l}0.00098 \\
0.00150 \\
0.00217\end{array}$ & $\begin{array}{r}5.06 \\
7.84 \\
11.29\end{array}$ & $\begin{array}{l}1.067 \\
2.31 \\
1.98\end{array}$ & $\begin{array}{l}0.0619 \\
0.506 \\
1.30\end{array}$ & $\begin{array}{l}0.0863 \\
0.139 \\
1.49\end{array}$ & $\begin{array}{l}0.0604 \\
0.0438 \\
1.037\end{array}$ & $\begin{array}{l}0.231 \\
0.0515 \\
0.878\end{array}$ & $\begin{array}{l}0.00123 \\
0.00152 \\
0.00088\end{array}$ & $\begin{array}{l}0.00215 \\
0.00237 \\
0.00059\end{array}$ & $\begin{array}{l}3.07 \\
3.72 \\
3.23\end{array}$ & $\begin{array}{l}0.483 \\
1.068 \\
1.37\end{array}$ \\
\hline $\begin{array}{l}P M-5 \\
P M-8 \\
P M-9 \\
P M-7\end{array}$ & $\begin{array}{l}0.49 \\
0.45 \\
0.46 \\
0.45\end{array}$ & $\begin{array}{l}\mathrm{Pu} \\
\mathrm{Pu} \\
\mathrm{Pu} \\
\mathrm{Pu}\end{array}$ & $\begin{array}{l}0.0221 \\
0.000303 \\
0.000181 \\
0.0000115\end{array}$ & $\begin{array}{c}114.4 \\
1.56 \\
0.938 \\
0.059\end{array}$ & $\begin{array}{l}16.6 \\
0.316 \\
0.192 \\
0.00313\end{array}$ & $\begin{array}{l}12.2 \\
0.0301 \\
0.0209 \\
0.00102\end{array}$ & $\begin{array}{l}22.0 \\
0.0317 \\
0.0219 \\
0.0012\end{array}$ & $\begin{array}{l}14.9 \\
0.0198 \\
0.0133 \\
0.00212\end{array}$ & $\begin{array}{l}13.8 \\
0.0531 \\
0.0186 \\
0.00101\end{array}$ & $\begin{array}{c}0.394 \\
- \\
0.000135 \\
0.000073\end{array}$ & $\begin{array}{c}0.0364 \\
- \\
0.000246 \\
0.000073\end{array}$ & $\begin{array}{l}20.7 \\
0.963 \\
0.587 \\
0.0471\end{array}$ & $\begin{array}{l}13.8 \\
0.148 \\
0.0933 \\
0.00317\end{array}$ \\
\hline \multicolumn{14}{|c|}{ Mixed Hexafluoride Experiments } \\
\hline PM-11 & 5.3 & $\begin{array}{c}\mathrm{Pu} \\
\mathrm{U}\end{array}$ & $\begin{array}{l}0.00078 \\
0.00108\end{array}$ & $\begin{array}{l}3.97 \\
5.52\end{array}$ & $\begin{array}{l}0.875 \\
0.694\end{array}$ & $\begin{array}{l}0.0550 \\
0.086\end{array}$ & $\begin{array}{l}0.0406 \\
0.124\end{array}$ & $\begin{array}{l}0.0339 \\
0.114\end{array}$ & $\begin{array}{l}0.229 \\
0.945\end{array}$ & $\begin{array}{l}0.0001 \\
0.0001\end{array}$ & $\begin{array}{l}0.000098 \\
0.00022\end{array}$ & $\begin{array}{l}2.35 \\
3.14\end{array}$ & $\begin{array}{l}0.387 \\
0.412\end{array}$ \\
\hline PM-10 & 0.43 & $\begin{array}{l}\mathrm{Pu} \\
\mathrm{U}\end{array}$ & $\begin{array}{l}0.00090 \\
0.00113\end{array}$ & $\begin{array}{l}4.63 \\
5.80\end{array}$ & $\begin{array}{l}1.24 \\
0.94\end{array}$ & $\begin{array}{l}0.1215 \\
0.769\end{array}$ & $\begin{array}{l}0.184 \\
1.37\end{array}$ & $\begin{array}{l}0.0350 \\
0.512\end{array}$ & $\begin{array}{l}0.1004 \\
0.056\end{array}$ & $\begin{array}{l}0.00020 \\
0.00019\end{array}$ & $\begin{array}{l}0.00022 \\
0.00019\end{array}$ & $\begin{array}{l}2.42 \\
1.49\end{array}$ & $\begin{array}{l}0.529 \\
0.665\end{array}$ \\
\hline PM-12 & 0.052 & $\begin{array}{l}\mathrm{Pu} \\
\mathrm{U}\end{array}$ & $\begin{array}{l}0.00049 \\
0.00094\end{array}$ & $\begin{array}{l}2.51 \\
4.82\end{array}$ & $\begin{array}{l}0.699 \\
0.481\end{array}$ & $\begin{array}{l}0.1022 \\
0.358\end{array}$ & $\begin{array}{l}0.0368 \\
0.736\end{array}$ & $\begin{array}{l}0.0151 \\
0.748\end{array}$ & $\begin{array}{l}0.0362 \\
0.499\end{array}$ & $\begin{array}{l}0.000024 \\
0.355\end{array}$ & $\begin{array}{l}0.000110 \\
0.325\end{array}$ & $\begin{array}{l}1.32 \\
0.918\end{array}$ & $\begin{array}{l}0.300 \\
0.404\end{array}$ \\
\hline
\end{tabular}

${ }_{\text {Bed area }}=332 \mathrm{~cm}^{2} /$ in., wall area $=30.4 \mathrm{~cm}^{2} /$ in., area of screen between beds $=20.7 \mathrm{~cm}^{2}$.

The data for $\mathrm{PuF}_{6}$ were fitted by the rate equation used for the $\mathrm{UF}_{6}$ hydrolysis data. The result of the computer calculation is

$$
r=\frac{53.5 p_{\mathrm{PuF}_{6}} \mathrm{p}_{\mathrm{H}_{2} \mathrm{O}}}{1+142 \mathrm{pPuF}_{6}+1.9 \mathrm{p}_{\mathrm{HF}}}
$$


The average error between the rates from the correlation and the measured rates was $81 \%$ (standard deviation) for individual bed segments. This form of the rate equation does not correlate the $\mathrm{PuF}_{6}$ data as well as it did the $\mathrm{UF}_{6}$ data; but, considering the wide range of the partial pressures used in the experimental program, Equation (28) is regarded as a reasonable empirical correlation.

The ratio of $\mathrm{PuF}_{6}$ to $\mathrm{UF}_{6}$ reaction rates at similar concentrations of reactants, as indicated by the correlations, ranges from 0.28 to 2.4 . The extent of departure of this ratio from unity is not highly significant when compared with the average error of the $\mathrm{PuF}_{6}$ results from the correlation.

D. Hydrolysis of the Mixed Plutonium and Uranium Hexafluorides in Packed Beds

Three experiments were conducted with an appoximately equimolar mixture of $\mathrm{PuF}_{6}-\mathrm{UF}_{6}$ to determine more accurately the relative reaction rates of $\mathrm{PuF}_{6}$ and $\mathrm{UF}_{6}$ in the apparatus described in par. VI-B- 1 .

The hydrolysis rates of $\mathrm{PuF}_{6}$ were expected to be similar in mixed and unmixed experiments; a similar effect was also expected with $U_{6}$. Instead, an entirely new effect is indicated by the data in Table IX. The mixed $\mathrm{PuF}_{6}$ hydrolysis rates are higher than the rates obtained in experiments in which $\mathrm{PuF}_{6}$ alone was hydrolyzed in air with low moisture concentrations. The $\mathrm{UF}_{6}$ hydrolysis rates in the mixture are lower than the unmixed $\mathrm{UF}_{6}$ hydrolysis rates. Further, in the mixed experiments, $\mathrm{PuF}_{6}$ hydrolysis rates were uniformly higher than the $U F_{6}$ hydrolysis rates. These comparisons are substantiated by the approach presented in the following discussion.

The hydrolysis rate may be represented by the equation

$$
r=f p_{M_{6}}
$$

where $f$ is a function of the reactant and product partial pressures, and $\mathrm{PMF}_{6}$ is the partial pressure of the hexafluoride. For the data reported in Tables VIII and IX, in any single experimental run, $f$ changes more sluwly than $r$ or $\mathrm{P}_{M F_{6}}$. It it is assumed that $f$ is not widely variant, an average value of $f$ between any two sections of the packed bed can be computed by integrating the rate equation. The fraction of $\mathrm{PuF}_{6}$ or $\mathrm{UF}_{6}\left(\mathrm{MF}_{6}\right)$ unreacted, $x$, is defined by

$$
\mathrm{p}_{\mathrm{MF}_{6}}=\mathrm{xp}_{\mathrm{MF}} \text {, }
$$


where $\mathrm{PMF}_{6}$ is the initial value of $\mathrm{PMF}_{6}$ before any reaction occurs. Material balance gives

$$
\mathbf{r} \mathrm{d} S=-\mathrm{F} d \mathbf{x} \text {, }
$$

where $S$ is surface area in the packed bed, $s q \mathrm{~cm}$; and $F$ is feed rate of plutonium, $\mathrm{mg} \mathrm{Pu} / \mathrm{hr}$. Solving the above equations for $\mathrm{f}$ and integrating gives

$$
\bar{f}=\frac{F \ln \left(x_{1} / x_{2}\right)}{p_{M F_{6}}\left(S_{2}-S_{1}\right)} .
$$

Using (29) and (30) gives

$$
\frac{x_{1}}{x_{2}}=\frac{r_{1} f_{2}}{r_{2} f_{1}} \text { or } \bar{f}=\frac{F \ln \left(r_{1} f_{2} / r_{2} f_{1}\right)}{\operatorname{PMF}_{6}^{\circ}\left(S_{2}-S_{1}\right)} \text {. }
$$

The plutonium or uranium concentrations deposited on the packedbed surfaces give the average value of $r$ in each bed section. $S_{2}-S_{1}$ is the total surface area between the bed midpoints where $r_{1}$ and $r_{2}$ are determined. A first approximation $\left(\bar{f}^{\prime}\right)$ to $\bar{f}$ is obtained by setting $f_{1}=f_{2}$. It can be proved that

$$
f_{\text {minimum }} \leq \bar{f}^{\prime}\left[1-\frac{\ln \left(f_{2} / f_{1}\right)}{\ln \left(r_{2} / r_{1}\right)}\right] \leq f_{\text {maximum }} .
$$

As an example, if $f$ decreases by $10 \%$ and $r$ decreases by a factor of 100 ,

$$
1-\frac{\ln \left(f_{2} / f_{1}\right)}{\ln \left(r_{2} / r_{1}\right)}=0.98
$$

Thus the difference between $\bar{f}$ and $\bar{f}^{\prime}$ is only $2 \%$ in an interval where $f$ is decreasing by $10 \%$.

The first approximation to $\overline{\mathrm{f}}$ computed from the data of Tables VIII and IX is plotted as a function of $\mathrm{p}_{\mathrm{H}_{2} \mathrm{O}}^{\circ}$ in Fig. 17. For values of $\bar{f}$ less than 40 or $\mathrm{PH}_{2} \mathrm{O}$ less than $1.0 \mathrm{~mm} \mathrm{Hg}$, the first and last bed segments were used. For $\bar{f}$ greater than 40 or $\mathrm{P}_{\mathrm{H}_{2}} \mathrm{O}$ greater than $1.0 \mathrm{~mm} \mathrm{Hg}$, the first and second bed segments were used because the rapid decrease in concentration present in the first two beds was masked in the last bed by even a small collection of product from the gas-phase reaction. The curves in the figure illustrate the statements, made above, about the relative hydrolysis rates. 


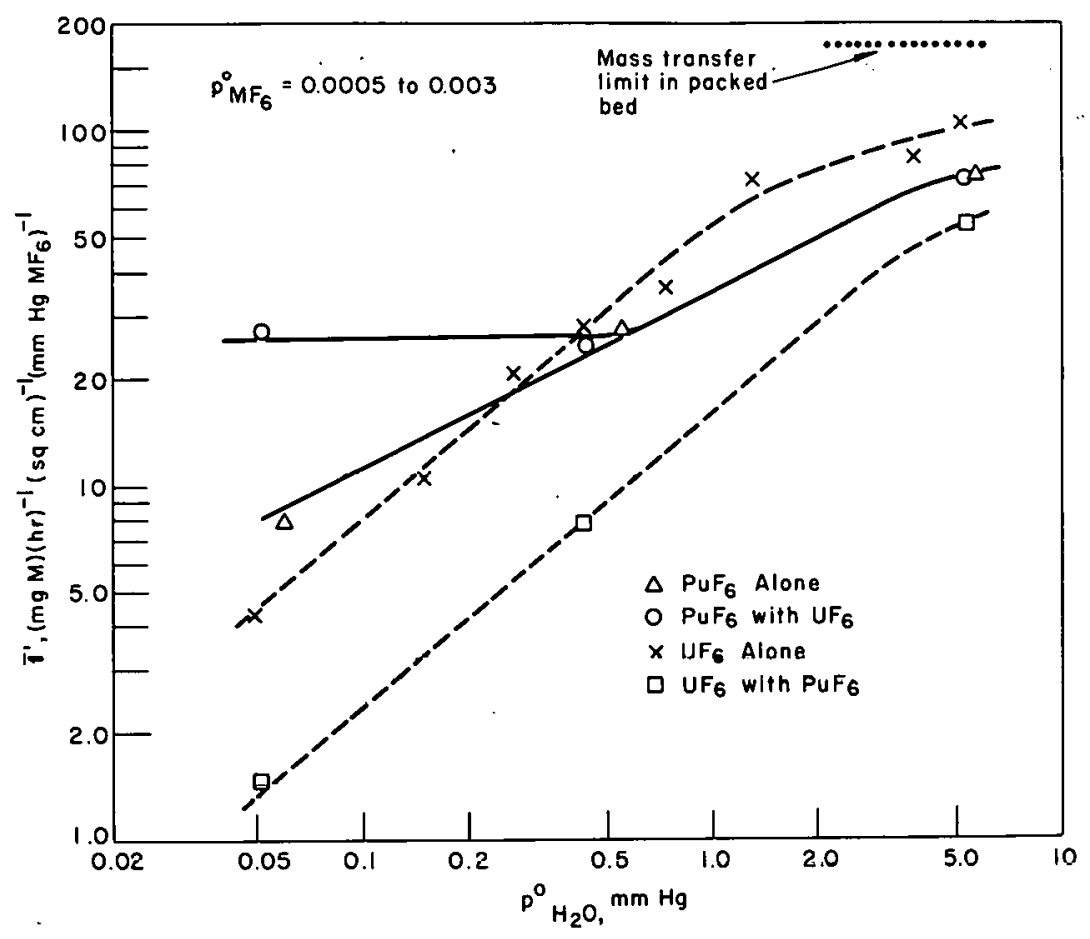

$108-9124$

Fig. 17. Pseudo-first-order Rate Constant for $\mathrm{PuF}_{6}$ or $\mathrm{UF}_{6}\left(\mathrm{MF}_{6}\right)$ Hydrolysis

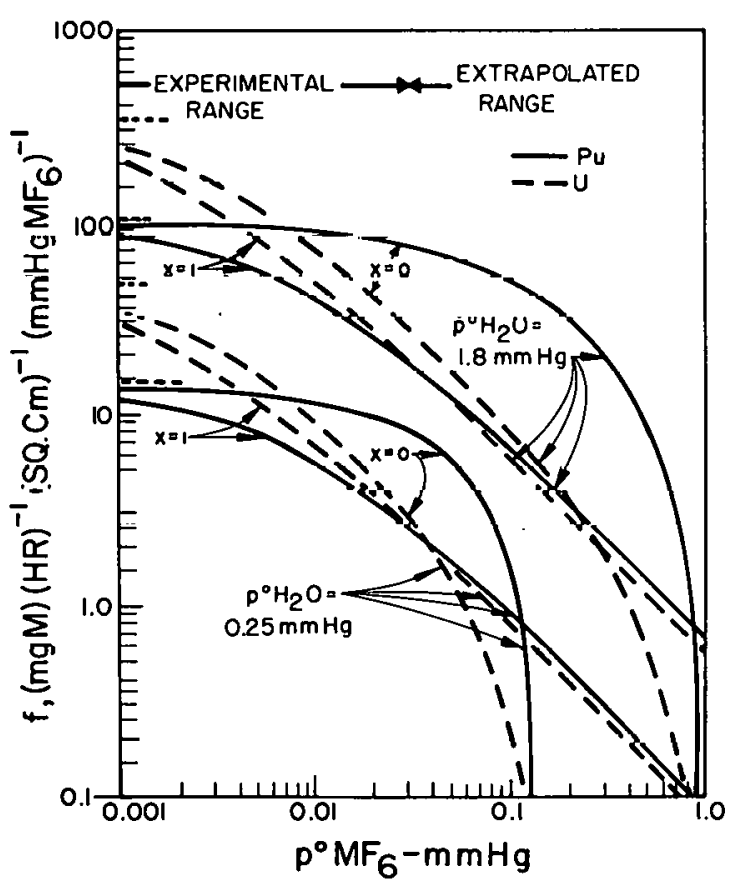

$108-9334$

Fig. 18. Pseudo-first-order Rate Constant from Rate Equations various types of reaction units. A value of 10 for $f$ at $\mathrm{p}_{\mathrm{MF}_{6}}^{\circ}<0.01$ and $\mathrm{p}_{\mathrm{H}_{2}} \mathrm{O}>0.25$ will be used.
The dependence of $f$ on the pressure of hexafluoride becomes small at pressures less than $0.001 \mathrm{~mm} \mathrm{Hg}$. The dependence at higher values is indicated in Fig. 18. The moisture values were selected from the frequency dictribution at ANI (Table IV) to have probabilities of $0.001 \%$ and $5 \%$ of having lower values than 0.25 and $1.8 \mathrm{~mm} \mathrm{Hg}$, respectively. 'l'he asymptotic values at low pressures are indicated as short dotted lines on the ordinate. Plutonium removal at high cfficiency by the surface reaction is approximatcd bcst by sclccting $f$ for $x=0$, since $x$ is very near zero over most of the reaction area; this approximation underestimates the final concentration.

A lower limit for $f$ will be useful for evaluating the design of 


\section{Evaluation of Packed Beds for Promoting the Surface Reaction}

Combining and integrating previous equations

$$
\begin{aligned}
r & =\mathrm{fp}_{\mathrm{MF}}, \\
\mathrm{PMF}_{6} & =\operatorname{xp}_{\mathrm{MF}}{ }_{6},
\end{aligned}
$$

and

$$
r d S=-F d x
$$

gives

$$
x=e^{-f p_{M F_{6}}^{\circ} / F}
$$

For a perfect gas,

$$
\frac{\mathrm{p}^{\circ}}{\mathrm{F}}=\frac{\mathrm{RT}}{\mathrm{qM}}
$$

where

$$
\begin{aligned}
& R=\text { gas constant } \\
& T=\text { absolute temperature, } \\
& q=\text { volume flow rate, }
\end{aligned}
$$

and

$$
M=\text { weight of } M \text { per mole of gas }(P u=239) \text {. }
$$

This gives

$$
x=e^{-(R T / M)(f S / q)}
$$

Thus at a given flow rate and temperature, the effectiveness of a packed bed is dependent only on the total internal surface area that is promoting the surface reaction. At $25^{\circ} \mathrm{C}$,

$$
x=e^{-0.0213 f s / q}
$$

where

$$
\begin{aligned}
& f=(\mathrm{mg} \mathrm{M})(\mathrm{hr})^{-1}(\mathrm{sq} \mathrm{cm})^{-1}(\mathrm{~mm} \mathrm{Hg} \mathrm{M})^{-1}, \\
& S=s q \mathrm{~cm},
\end{aligned}
$$

and

$$
\mathrm{q}=\mathrm{cm}^{3} / \mathrm{sec} \text {. }
$$


For an AEC filter that has an internal area that is 77 times the superficial area of the media,

$$
x=e^{-1.64 f / u_{0}}
$$

where $u_{0}$ is the superficial velocity in the media in $\mathrm{cm} / \mathrm{sec}$.

For a packed bed to operate in existing ventilation systems . without additional blowers, the pressure drop should be about 0.1 in. of water or less. For systems designed for additional pressure drop, packed-bed pressure drop of up to 10 in. $\mathrm{H}_{2} \mathrm{O}$ may be practical. Operation with blowers supplying a pressure drop of more than 10 in. $\mathrm{H}_{2} \mathrm{O}$ across an AEC filter may rupture the filters, since this is the maximum rated differential pressure for this type of filter. A pressure drop of 1 in. of water is a practical value which will be used in the following computation. Other values can be obtained by changing bed depth in proportion to the desired pressure drop.

A wide variety of materials could be selected for packing the bed. Large particles of porous material (charcoal, activated alumina, silica gel, NaF pellets, etc.) may provide internal area for reaction without increased pressure drop over that of a similar-sized packed bed of nonporous material. The availability of the internal surface area of a porous material will depend on the relative rates of mass transfer and surface-reaction kinetics, and in general only a small fraction of the internal area will be effective for this surface reaction. The internal porosity of the material will be neglected in this preliminary design optimization.

The capacity of the packed bed in terms of flow rate at the rated pressure drop will be proportional to the cross-sectional area. This factor is readily scaled when other factors are kept constant. A value of $1000 \mathrm{cfm}$ will be used since it corresponds to the most commonly used filter unit.

The surface structure of the packing material has wide variations possible, but effects due to changing the size of the structure will be similar for various structure types. Therefore, a simple, well-understood, practical structure, which will indicate these trends, is a packed bed of spherical particles of uniform size and random packing.

For packed beds to be practical, they should be more effective in promoting the surface reaction than an AEC filter at similar flow rates and pressure drops. A model 1000 filter $\left(1000 \mathrm{cfm},<1.0\right.$ in. $\left.\mathrm{H}_{2} \mathrm{O}\right)$ has approximately $17,000 \mathrm{sq}$ ft of internal area (217 sq ft superficial area $x 77$, p. 11).

The internal area per unit volume of packed bed of spheres in a cubic array is

$$
\frac{A_{i}}{V}=\frac{\pi D_{p}^{2}}{D_{p}^{3}}=\frac{\pi}{D_{p}} .
$$


A random packed bed of spheres has a slightly higher packing density ( $60 \%$ solid fraction) than a cubic array of spheres (52\%). Thus, for random packing,

$$
\frac{A_{i}}{V}=\frac{1.15 \pi}{D_{p}}
$$

The pressure drop for laminar flow through a packed bed of uniform granular solid particles is ${ }^{32}$

$$
\Delta \mathrm{p}=\frac{1700 \mu \mathrm{Lu}_{0}}{\mathrm{D}_{\mathrm{p}}^{2}}
$$

where $L$ is the packed-bed length in the flow direction. The total volume of the packed bed is

$$
V=A_{c} L
$$

where $A_{c}$ is the cross-section area of the bed normal to the flow direction. The volumetric flow rate is

$$
\mathrm{q}=\mathrm{u}_{0} \mathrm{~A}_{\mathrm{C}} \text {. }
$$

It can be shown that

$$
A_{C}-\left(\frac{1700 \mu q A_{i}}{\Delta p D_{p} 1.15 \pi}\right)^{1 / 2},
$$

and

$$
L=\left(\frac{\Delta p D_{p}^{3} A_{i}}{1700 \mu q l .15 \pi}\right)^{1 / 2}
$$

These parameters are tabulated in Table $X$ for the conditions given and compared with AEC filters.

It is concluded from Table $X$ that the packed bed must either be large and massive or have a complex structure such as the pleated structure used in the AEC filter. The filter appears to provide more area at low pressure drop than would normal-sized packed beds.

The mass-transfer coefficient between the gas and the packedbed particles varies approximately inversely with the bed-particle diameter. For the experimental packed bed, $D_{p}=3.2 \mathrm{~mm}$, the masstransfer coefficient that gave the best correlation of the results was 
$170 \mathrm{mg} \mathrm{U} /\left(\mathrm{hr} \mathrm{cm}^{2} \mathrm{~mm} \mathrm{Hg} \mathrm{UF} 6\right)$. Computation from the literature correlations, ${ }^{17}$ using a diffusivity of $\mathrm{UF}_{6}$ of $0.086 \mathrm{~cm}^{2}$ atm sec $\mathrm{st}^{-1}$ at $25^{\circ} \mathrm{C}$, gave a value of $\left.150 \mathrm{mg} \mathrm{U} /\left(\mathrm{hr} \mathrm{cm}^{2} \mathrm{~mm} \mathrm{Hg} \mathrm{UF}\right)_{6}\right)$. These values differ by less than the probable error in either value.

TABLE X. Comparison of Packed Beds and Filters

$$
\begin{array}{ll}
\text { Internal surface area }\left(A_{i}\right) & =17,000 \mathrm{sq} \mathrm{ft} \\
\text { Air flow rate }(q) & =1,000 \mathrm{cfm} ; \\
\text { Pressure drop }(\Delta p) & =1.0 \mathrm{in} . \mathrm{H}_{2} \mathrm{O} .
\end{array}
$$

\begin{tabular}{|c|c|c|c|c|c|c|}
\hline & & & & & \multicolumn{2}{|c|}{ AEC Filter } \\
\hline & \multicolumn{4}{|c|}{ Packed Bed } & Media & Total \\
\hline Packing diameter, $D_{p}(\mathrm{~cm})$ & 0.1 & 0.01 & 0.001 & 0.0001 & \multicolumn{2}{|c|}{$(0.00014)$} \\
\hline Volume, $V\left(\mathrm{~cm}^{3}\right)$ & 440,000 & 44.000 & 4,400 & 440 & 13,000 & 110,000 \\
\hline Bed depth, L $(\mathrm{cm})$ & 8.4 & 0.27 & 0.0084 & 0.00027 & 0.063 & 30.4 \\
\hline Bed area, $A_{c}\left(\mathrm{~cm}^{2}\right)$ & 51,000 & 160,000 & 510,000 & $1,600,000$ & 200,000 & 3,700 \\
\hline Bed weight, (Ib) & $1,200^{\mathrm{a}}$ & $120^{\circ}$ & $12^{\mathrm{a}}$ & $1.2^{\mathrm{a}}$ & 2.7 & 41 \\
\hline
\end{tabular}

${ }^{a}$ For packing density of $2 \mathrm{~g} / \mathrm{cc}$.

The mass-transfer coefficient was estimated to be greater than $\left.10^{5} \mathrm{mg} \mathrm{M} /\left(\mathrm{hr} \mathrm{cm}^{2} \mathrm{~mm} \mathrm{Hg} \mathrm{MF}\right)_{6}\right)$ for the average fiber size in AEC filters. This is so much larger than the surface kinetic rate that the mass-transfer resistance can be neglected. For packed beds of larger particles $(>1 \mathrm{~cm})$, the reaction rate tends to be more mass-transfer limited. The advantage in using a porous packing would be minimal in this case.

Computed values for the penetration of AEC filters due to the surface-reaction kinetics are listed in 'l'able XI. The values in the lower ranges are extrapolations, since a decrease in concentration by factors of $10^{-2}$ to $10^{-3}$ were measured in the packed-bed experiments. The values indicate the very strong dependence on velocity and allow consistency between the high-filter penetration in the surface-reaction experiments $(10 \mathrm{~cm} / \mathrm{sec})$ and the burst-release experiments $(1 \mathrm{~cm} / \mathrm{sec})$.

\begin{tabular}{|c|c|c|c|c|c|}
\hline $\mathrm{v}, \mathrm{cm} / \mathrm{sec}:$ & 0.2 & 0.5 & 1.0 & 2.5 & 10 \\
\hline $\begin{array}{l}\text { Rated Flow, } \% \text { : } \\
\bar{f}\end{array}$ & 8 & 25 & 40 & 100 & 400 \\
\hline 1 & $3 \times 10^{-4}$ & 0.04 & 0.19 & 0.52 & 0.85 \\
\hline 3 & $10^{-11}$ & $5 \times 10^{-5}$ & $7 \times 10^{-3}$ & 0.14 & 0.61 \\
\hline 10 & $10^{-36}$ & $10^{-14}$ & $8 \times 10^{-8}$ & $10^{-3}$ & 0.19 \\
\hline 30 & $10^{-107}$ & $10^{-43}$ & $10^{-21}$ & $10^{-9}$ & $7 \times 10^{-3}$ \\
\hline 100 & $10^{-356}$ & $10^{-142}$ & $10^{-71}$ & $10^{-28}$ & $8 \times 10^{-8}$ \\
\hline
\end{tabular}

TABLE XI. Penetration of AEC Filters from Surface Reaction Data

$$
\mathrm{p}=\mathrm{e}^{-1.64 \overline{\mathrm{f}} / \mathrm{v}}
$$


The performance of a filter. system can be increased by using a combined series-parallel array of filters. If the number in series is equal to the number in parallel, the flow resistance is the same as it is for a single filter. The internal area for reaction will increase in proportion to the number of filters. The initial cost of the array of filters will be higher, but the operating cost should not be higher unless filter aging due to effects other than dust loading is significant. 


\section{DESIGN CRITERIA}

The following design criteria are based to a large extent on idealized models of what is expected to occur in facilities of the type presently used for handling $\mathrm{PuF}_{6}$, since sufficient experimental data are not available to prescribe a model accurately. The wide variations in the size of enclosures and the type of operations indicate that the safety of any operation, in the final analysis, will depend on the experimenter or operator. For this reason, the following factors must be understood for safe operation of these facilities. The capacity of the enclosure to contain released plutonium is dependent on the contact between $\mathrm{PuF}_{6}$ (and $\mathrm{UF}_{6}$ ) vapor and water vapor within the enclosure. Since the distributions of the two reactants are initially different, the reaction will to a large extent be controlled by the mixing and flow patterns within the enclosure. In an enclosure, in which the supply air is distributed to the interior by many small openings, the hexafluorides will effectively mix with the contained air better than in the enclosure with a single, large, low-velocity inlet. Partitions and excessive equipment will reduce the volume in which mixing takes place. Exhaust systems, which remove gas from many distributed points within the enclosure, mix the gas from all the intakes in the discharge system. These factors are significant because the working enclosure usually has a much larger volume than the discharge system.

\section{A. Types of Accidental Releases}

Accidental releases of $\mathrm{PuF}_{6}$ and $\mathrm{UF}_{6}$ may be considered to be either a sudden type, in which most of the material is released to the enclosure in less than a minute, or a continuous type, in which the release once started continues at a relative constant rate for longer than 5 min. The time periods used to classify the types of releases are the minimum and maximum residence times for air in presently used enclosures. There may be intermediate cases, and cases which combine both types, but these cases will not generally be as significant as the two possible extremes. The first. case will be referred to henceforth as a burst release, and the second case. as a continuous release.

B. Effect of Mixing Patterns in the Enclosures on the Plutonium ConcenIration in the Exhaust Air

A burst release in the air-inlet region of an enclosure with good mixing will produce a maximum exit concentration of plutonium that is equal to the quantity of plutonium released ( $\mathrm{as} \cdot \mathrm{PuF}_{6}$ ) divided by the enclosure volume. The same release occurring near an air discharge for the enclosure will produce a plutonium concentration that can be several orders of magnitude higher than in the first case. 
Incomplete mixing within the enclosure can be accounted for by a mixing safety factor which is defined as the ratio of maximum discharge concentration at the first filter (or scrubber) and the concentration computed for perfect mixing within the enclosure volume. This mixing safety factor can be easily measured using innocuous gases, such as $\mathrm{CO}_{2}$, that can be easily monitored (by a thermal-conductivity cell).

The mixing safety factors will in general not be the same for a burst release and a continuous release. In a continuous release, the mixing safety factor is dependent only on mixing that is effective normal to the flow direction since the average concentration in the direction of flow is constant. In a burst release, the mixing safety factor is strongly dependent on mixing in the direction of flow.

Since these mixing safety factors can vary over a wide range, they will only be estimated here for rather limited cases. For the continuous release case, two parallel enclosure exhausts to two separate filters give a mixing factor of two. An exhaust plenum in turbulent flow $(2 \times 2 \times 18$ in. long, $\left.25 \mathrm{cfm}, \mathrm{N}_{\mathrm{Re}}=16,000\right)$ is estimated to give at least $50 \%$ mixed flow after nine diameters of length. This gives another factor of two and an overall mixing safety factor of four for continuous release.

The safety factor for a burst release is more difficult to estimate, since it involves mixing both normal and perpendicular to the flow direction and is more strongly dependent on the position within the enclosure where the release takes place. A burst-release mixing safety factor of 20 seems to be a reasonable guess for presently used enclosures.

The capacity of existing enclosures for $\mathrm{PuF}_{6}$ is given in Tables XII and XIII. These capacities are based on reaction of two moles of water

TABLE XII. Maximum Release Burst of $\mathrm{PuF}_{6}-\mathrm{UF}_{6}$ Mixtures

$$
\text { Quantity: } g\left(\Gamma u \Gamma_{6} \mid U \Gamma_{6}\right)
$$

Mixing safety factor $=20$

\begin{tabular}{ccccr}
\hline $\begin{array}{c}\text { Enclosure Volume, cu ft: } \\
\text { Moisture Source }\end{array}$ & 25 & 180 & 240 & 1600 \\
\hline $\begin{array}{c}\text { Air Dew Point, }{ }^{\circ} \mathrm{F} \\
-30\end{array}$ & 0.085 & 0.61 & 0.82 & 5.5 \\
+50 & 3.1 & 23 & 30 & 200 \\
$\frac{\text { Number of Scrubber }}{\text { Transfer Units (N) }}$ & & & & \\
\hline 3 & 7.0 & 50 & 67 & 450 \\
10 & 23 & 170 & 220 & 1500 \\
30 & 70 & 500 & 670 & 4500 \\
\hline
\end{tabular}


TABLE XIII. Maximum Release Rate of $\mathrm{PuF}_{6}-\mathrm{UF}_{6}$ Mixtures

Rate: $g\left(\mathrm{PuF}_{6}+\mathrm{UF}_{6}\right) / \mathrm{min}$

Mixing safety factor $=4$

\begin{tabular}{llllll}
\hline $\begin{array}{l}\text { Air Flow Rate, cfm: } \\
\text { Moisture Source }\end{array}$ & 10 & 50 & 100 & 500 & 1000 \\
\hline
\end{tabular}

Air Dew Point, ${ }^{\circ} \mathrm{F}$

$\begin{array}{rlcccr}-30 & 0.17 & 0.85 & 1.7 & 8.5 & 17 \\ +50 & 6.3 & 31 & 63 & 310 & 630\end{array}$

Number of Scrubber

Transfer Units (N)

\begin{tabular}{rrrrrr}
\hline 3 & 14 & 70 & 140 & 700 & 1400 \\
10 & 46 & 230 & 460 & 2300 & 4600 \\
30 & 140 & 700 & 1400 & 7000 & 14000 \\
\hline
\end{tabular}

per mole of hexafluoride and the previously given estimates of mixing safety factors and scrubber performance. The scrubber performance is based on a water temperature of $42^{\circ} \mathrm{F}$, which is the wet-bulb temperature of air at $68^{\circ} \mathrm{F}$ with a dew point of $-30^{\circ} \mathrm{F}$. These estimated capacities are only a first approximation and should not preclude the need for safety analysis of each individual facility or experiment.

C. Stack Monitors

Stack monitors used at. ANL on all facilities handling $\mathrm{PuF}_{6}$ sample the discharge air after the final AEC filter. The sample flow of $20 \mathrm{~m}^{3} / \mathrm{hr}$ is filtered through an MSA-1106-B filter. The stack-monitor filter is counted with an alpha scintillation probe having a counting efficiency of $20 \%$. 'l'he output of the count-rate meter is recorded on a strip-chart recorder that is usually set at five counts/sec at full-scale reading. The monitor is basically an integrating device that indicates the total quantity of plutonium collected since the collection filter was changed. One maximum permissible concentration (mpc) of $\mathrm{Pu}^{239}$ collected for 1 hr. will increase the count rate by 2.7 counts $/ \mathrm{sec}$.

The background level of the instrument is limited by the collection of the solid daughter products of the radioactive inert gases radon and thoron.3,10 This background is normally less than 0.5 count/sec, but can be greater than 10 counts/sec if unfiltered air is allowed to enter the sampler through leaks or by backflow through standby blowers. Also, the background is not constant but fluctuates with weather conditions. It rises 
during conditions of poor atmospheric mixing, such as inversions or during the night, and falls with condition of good atmospheric mixing, such as those normally occurring on a sunny day.

The sensitivity of the stack monitor to short-term releases is primarily limited by changes in background reading. These fluctuations in background become less significant in determination of long-term averages. The count-rate meter can count up to $10^{4}$ counts/sec by switching the range and thus give rapid indication of a release up to $3000 \mathrm{mpc}$ hours.

D. Discharge Air Dilution

Final AEC filter discharge air may be combined with that from other units to give additional dilution. Also, the air discharged from the stack will entrain outside air in being slowed down from its discharge velocity. This dilution from stack to ground level or building intakes is highly variable and dependent on wind and atmospheric stability. Under the worst conditions it probably would not give ground concentrations greater than $1 / 10$ of the stack concentration for short stacks with discharge velocities of $1000 \mathrm{ft} / \mathrm{min}$.

\section{FUTURE WORK}

Cleanup of cell exhaust air contaminated with $\mathrm{PuF}_{6}$ is highly complex and is actually unique among all the air-cleaning methods because of the extremely low permissible concentrations of plutonium and the gaseous and solid forms of airborne $\mathrm{PuF}_{6}$. A preliminary basis for the design of equipment for the removal of the hexafluoride from air is established in the work to date; however, more data than were presented in the current work are needed for safe, accurate, and optimum design of the air-cleanup methods. Eight problems that, in the view of these investigators, need further investigation are outlined below.

\section{A. Effect of Air Velocity on AEC Filter Penetration}

Reproducible, accurate data on filter penetration at typical media gas velocities of 0.2 to $2 \mathrm{~cm} / \mathrm{sec}$ are needed. Experiments are planned with filters, containing $\sim 100 \mathrm{sq} \mathrm{cm}$ of media, assembled into a series of units and substituted in place of the packed-bed section in the existing equipment. By assembling the series of units outside the plutonium box, and removing those units containing plutonium in concentrations sufficiently low for disassembly in open-faced hoods, one can measure penetration down to less than $10^{-9}$. 
Both penetration of particulate and unreacted $\mathrm{PuF}_{6}$ should be measured by employing a wide range of reactant concentrations. At high concentrations of the reactants, the majority of the plutonium is converted to particulate material in the gas phase as evident in the results with the highest concentration in the packed-bed experiments.

Penetration of the particulate material would be expected to have less dependence on velocity than the penetration of unreacted $\mathrm{PuF}_{6}$ because the interception mechanism has a small dependency on velocity and is expected to be of major importance for the larger particle sizes.

B. Effect of Nonuniformity of the Filter Media on the Penetration

There is some uncertainty about the uniformity of filter media which may affect the reproducibility of the experimental results. If normal AEC-type filter media contains local statistical variations in efficiency, then the variation of the average efficiency of a section of media will be inversely proportional to the area of the section tested. Small sections of the media may have much wider variations in efficiency than would exist in the large commericial units. This effect is reported in the literature, ${ }^{26}$ but no quantitative estimate is available for the effect. To answer this question, and also to compensate for the effect in small-scale tests, a DOP (dioctyl phthalate) test is needed on the individual filter units.

Work is in progress to fabricate simple, inexpensive, DOP test equipment for use in the current study. Data will be obtained on the effects of nonuniformity of the filter media on plutonium penetration.

C. Effects of Chemical Reaction, Impurities, and Nuclei on Generatedfume Particle Size

The penetration of the filters depends to a large extent on the particle-size distribution of fume generated upon hydrolysis. The particle size of the fume resulting from hydrolysis of $\mathrm{PuF}_{6}$ in the gas phase will vary with the conditions of generation and could depend on many variables.

The simplest possible process for fume generation will be described first. Elementary reactions which involve no more than two reactant or product molecules and without catalytic or activation effects are

$$
\begin{aligned}
& \mathrm{PuF}_{6}+\mathrm{H}_{2} \mathrm{O} \rightarrow \mathrm{PuF}_{5} \mathrm{OH}+\mathrm{HF} ; \\
& \mathrm{PuF}_{5} \mathrm{OH}=\mathrm{PuOF}_{4}+\mathrm{IHF} ; \\
& \mathrm{PuOF}_{4}+\mathrm{H}_{2} \mathrm{O} \rightarrow \mathrm{PuOF}_{3} \mathrm{OH}+\mathrm{HF} ; \\
& \mathrm{PuOF}_{3} \mathrm{OH} \rightarrow \mathrm{PuO}_{2} \mathrm{~F}_{2}+\mathrm{HF} .
\end{aligned}
$$


The volatility of the intermediate plutonium compounds probably decreases from $\mathrm{PuF}_{6}$ to $\mathrm{PuO}_{2} \mathrm{~F}_{2}$, and the vapor pressure of at least one of the plutonium compounds will exceed the condensation partial pressure.

In the absence of condensation nuclei, supersaturation would become large enough to produce spontaneous nucleation. The particle size and concentration resulting from spontaneous nucleation can be calculated by using agglomeration equations extended to molecular particles. ${ }^{33}$

Surface reaction will take place on the surface of the particles suspended in the gas and will probably exceed the rate of the homogeneous reaction before a large fraction of the reaction has occurred. The resulting particle size could be independent of the homogeneous reaction mechanisms and kinetic rates.

Possibly the fume formation is not initiated by a simple homogeneous reaction. but by such things as solid nuclei present as an impurity in the source gases, or by radiation decomposition products, or by catalytic impurities.

Some survey-type experiments are planned to determine the effect of impurities and nuclei concentration on particle-size distribution to see if particle size is a quantity that could be predicted in a practical releaseaccident situation.

D. Size Distribution of Particles Discharged from AEC Filters

The measurement of size distribution of particles discharged from an. AEC filter is required for a complete understanding of filtration efficiency. Data from previous measurements with $\mathrm{UF}_{6}$ releases were not reproducible. Initial studies will be made with $\mathrm{UF}_{6}$. A thermal precipitator will be used for collecting concentrated samples on electron-microscope grids. Increased reproducibility of particulate penetration results will be developed before size measurements are again attempted. For similar work with $\mathrm{PuF}_{6}$, a metal shadow technique may need to be developed so that the plutonium can be removed from the collection film before it is examined in the electron microscope. Previous experience indicated that the examination of plutonium product in the electron microscope was a time-consuming process.

E. Determination of Mixing Safety Factors

As discussed previously (see Section B above) there are no data on the mixing safety factors for the enclosures of $\mathrm{PuF}_{6}$ handling facilities. The estimated safety factors presented previously should be confirmed even though they may vary from facility to facility. 
F. Capacities of Air Scrubbers

It is planned to test the capacity of very-small-scale scrubbers with $U F_{6}$. The scale of experimentation is limited by the generation rates for $\mathrm{UF}_{6}$. The smallest scrubber currently used on $\mathrm{PuF}_{6}$ systems has an estimated capacity in excess of $1 \mathrm{~kg}$ of $\mathrm{UF}_{6}$ per minute.

\section{G. Computational Program}

Most of the individual filtration mechanisms for particulate material are well understood. Many have been experimentally verified in limited ranges of variables where the specific mechanism could be separated from all the other mechanisms. Using the information available on the individual mechanisms to estimate the penetration in real, practical cases is either very approximate or very tedious. This is due to the difficulty of combining stochastic information for diffusion, particle-size distribution, fiber-size distribution, and filter structure with nonstochastic information for flow patterns, interception, and impaction. The best approach for overcoming this type of difficulty appears to be a Monte Carlo type computation on a high-speed digital computer. That this approach has not been attempted before may be attributed to the poor reproducibility of experimental results of practical-type filtrations and the difficulty of measuring all the necessary input parameters. It is possible that the program for removal of $\mathrm{PuF}_{6}$ from air may be modified to accommodate this approach.

\section{H. Full-scale Controlled Releases of Plutonium Hexafluoride}

Finally, it is planned to perform full-scale experiments to confirm predictions of small-scale experiments. Small-scale experiments are compared with a full-scale accidental release in Appendix A.

\section{CONCLUSIONS}

Moisture concentration and availability are the principal variables preventing the passage of $\mathrm{PuF}_{6}$ through an air filter. The overall reaction is

$$
\mathrm{PuF}_{6}+2 \mathrm{H}_{2} \mathrm{O} \rightarrow \mathrm{PuO}_{2} \mathrm{~F}_{2}+4 \mathrm{HF}
$$

At low concentration of reactants, the reaction occurs at any available solid surface, and the reaction rate is proportional to the product of the two reactant concentrations. Adsorbed $\mathrm{PuF}_{6}$ and $\mathrm{HF}$ reduce the reaction rate at partial pressures greater than $0.001 \mathrm{~mm} \mathrm{Hg}$. 
At high reactant concentration, the reaction proceeds rapidly in the gas phase and is usually limited in rate only by mixing or other masstransfer processes. Most of the product $\mathrm{PuO}_{2} \mathrm{~F}_{2}$ from this type of reaction remains in the gas phase as particles less than 0.1 micron in diameter. The high particle concentration that results principally from the small particle size and also from high $\mathrm{PuF}_{6}$ concentration will lead to rapid and extensive agglomeration of the particles. Agglomeration is beneficial in that it reduces filter penetration, and since agglomeration increases with an increase in the rate of release of $\mathrm{PuF}_{6}$, it tends to limit the maximum discharge rate of the filter. By a similar mechanism, loading effects in the filter tend to limit the maximum quantity of plutonium that could pass through the filter.

Preliminary analysis of scrubbers for completing the hydrolysis reaction indicates that the only significant rate-limiting step is the evaporation of water from the spray droplets. The overall hydrolysis rate in a scrubber is thus limited only by the size of the scrubber and the spray power input.

The use of high-efficiency filters for collection of the fine particulate and for providing the large surface needed in the heterogeneous reaction appears to be the most practical technique. With an excess of moisture and normal filter velocities of $40 \%$ of rated flow, the fraction of released plutonium passing through two AEC filters in series ranged from $10^{-9}$ to $10^{-6}$. The penetration of the second filter had even more variation than the combined result and was between $10^{-4}$ and 0.8 . This high penetration and large variation cannot be explained at present but probably involves penetration of particulate in the size range of 0.01 to 0.1 micron diameter. More work is needed on this problem to evaluate more fully the use of multiple filters in series. 


\section{APPENDIX A}

\section{Accidental Release of Plutonium Hexafluoride}

On 12 March 1965 at 12:10 p.m., a 3/4-in. Fluorethene tube containing $5.7 \mathrm{~g}$ of $\mathrm{PuF}_{6}$ exploded in glovebox number 3 of room G-133, Building D-205. The bottom end of the tube was blown off, and spherical brown particles, about $1 / 2 \mathrm{~mm}$ in diam, were spread about $3 \mathrm{ft}$ horizontally from the tube. These particles still contained $\mathrm{PuF}_{6}$ when they landed, as indicated by a white circle, $\sim 1 / 2-i n$. in diam, on the surface around each of them. The apparent cause was condensation of moisture on the $\mathrm{PuF}_{6}$ at liquid-nitrogen temperature due to a fine crack in the tube. The reaction occurred during the warming of the tube to room temperature (see Ref. 38 for details).

The above facts indicate that the release from the tube was rapid and occurred in a time much less than the 5.8-min air-residence time in the box. Therefore, this can be considered as an instantaneous or bursttype release. Although the release was accidental, it provided an excellent opportunity to study the containment of $\mathrm{PuF}_{6}$ in an alpha enclosure, especially since the glovebox and the glovebox filters had not been previously exposed to plutonium.

\section{Stack Monitor Performance}

As a result of this release, the stack monitor (record shown in Fig. 19) indicated an increase in counting rate of 0.8 count/sec over a

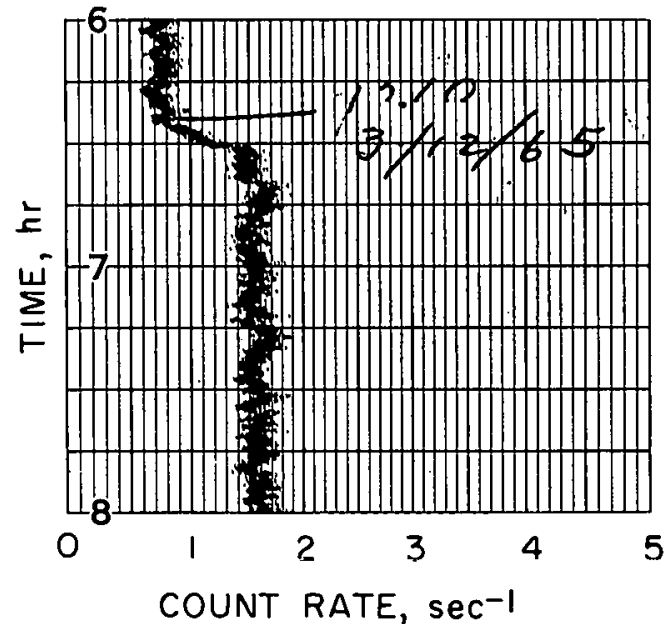

108-851.5 Rev. 1

Fig. 19. Graph Obtained from Stack Monitor
7 -min period that was preceded and followed by a constant counting rate. The counting efficiency was $20 \%$, and the sample flow rate was $21 \mathrm{~m}^{3} \mathrm{hr}^{-1}$. The computed stack discharge was 2 mpc (maximum permissible concentration). The mpc for these stacks is ten times room mpc for a $40-\mathrm{hr} /$ week exposure. This factor of ten is the estimated minimum dilution of the stack discharge at the ground. No increase in alpha activity was detected at any of the six air-monitoring stations on the site.

Three days after the release the stack-monitor filter was removed and its activity counted. The plutonium

content of the filter was considerably more than that indicated by the monitor. The best information indicates that stack concentration during the $7 \mathrm{~min}$ of discharge averaged $300 \mathrm{mpc}$. 
The total discharge from the stack was estimated to be $2.6 \mu \mathrm{g}$ of Pu. The most likely source of the discrepancy between the plutonium content indicated by the monitor and that estimated from the counting of the activity on the stack-monitor filter is a malfunction in the monitor electronics. The monitor was behaving exratically before and after the release even though the record at the time of the release was not erratic and had the normal noise level due to counting statistics.

\section{Plutonium Distribution}

The plutonium distribution following the accidental release was determined in order to evaluate the performance of a full-scale air-cleanup system and to compare the performance with the results of small-scale release experiments which had been designed to simulate larger releases of this type.

The filters were removed after the release and sampled by cutting cores with a thin-walled tube similar to a cork-boring tool. Four sample cores were taken from each filter by cutting cores from the center of each quadrant of the filter.

Each core was unfolded, and the filter media was freed from the separators. The distribution of plutonium between the media and the separators was determined by counting the $17-\mathrm{keV}$ gamma from plutonium. The results indicated that the separators contained $5 \%$ of the plutonium, and the media contained $95 \%$.

The filter media was then leached with 200 to $250 \mathrm{ml}$ of $10 \% \mathrm{HNO}_{3}$ containing $0.03 \%$ wetting agent (Aerosol). After complete wetting of the filter media by the solution, it was shaken to a pulp and left for at least $24 \mathrm{hr}$ before filtering off the solution. The analyzed concentration of plutonium in this solution times the original volume of leach solution used gave the plutonium values found in the cores (Table XIV). A schematic diagram of the system, showing the plutonium distribution after the release, appears in Fig. 20. The total plutonium content of the filter is based on the inside cross-sectional area of the coring tool and the adhesive-free area of the filter. An individual measurement of the height or width of this adhesivefree area can vary up to $1 / 2$ in., and the numbers reported are averages of six measurements, three each from the front and back faces of the filter.

\section{Filter Performance}

The airflow resistance and DOP penetration in Table XIV were the filter test specifications by the manufacturer (Flanders Filter Corp., Riverhead, New York) and the Oak Ridge Filter Testing Laboratory that were marked on the filter frame. Two numbers are reported when these test specifications do not agree. 
TABLE XIV. Plutonium Content and Test Results of Filters after $5.7-\mathrm{g} \mathrm{FuF}_{6}$ Release

\begin{tabular}{|c|c|c|c|c|c|c|}
\hline Filter & First East ${ }^{\mathrm{a}}$ & First West & Second East & Second West & Third East & Third West \\
\hline Rated Flow, cfm & 135 & 135 & 135 & 135 & 1000 & 1000 \\
\hline Resistance, in. $\mathrm{H}_{2} \mathrm{O}$ & 0.72 & 0.74 & $0.86-0.95$ & $0.86-0.96$ & $0.88-0.92$ & $0.86-0.92$ \\
\hline DOP penetration, $\%$ & 0.08 & $0.004-0.005$ & 0.008 & $0.004-0.008$ & 0.018 & 0.018 \\
\hline \multicolumn{7}{|l|}{$\begin{array}{l}\text { Adhesive-free } \\
\text { Dimensions }\end{array}$} \\
\hline Height, in. & 10.1 & 10.1 & 9.3 & 9.5 & 22.0 & 21.4 \\
\hline Width, in. & 9.4 & 9.3 & 10.1 & 10.0 & 21.4 & 21.8 \\
\hline Area, sq. in. & 94 & 94 & 94 & 95 & 472 & 468 \\
\hline \multicolumn{7}{|l|}{ Pu Found, mg } \\
\hline Core $\mathrm{Ib}^{\mathrm{b}}$ & 19.3 & 21.8 & 0.00155 & 0.000749 & 0.000346 & 0.000416 \\
\hline Core II & 23.4 & 19.4 & 0.00360 & 0.000568 & 0.000673 & 0.000294 \\
\hline Core ITT & 22,2 & 21.0 & $0.0597^{a}$ & 0.000793 & 0.000327 & 0.000352 \\
\hline Core IVb & 21.4 & 22.1 & 0.00137 & 0.000499 & 0.000309 & 0.000318 \\
\hline Average & 21.6 & 21.1 & 0.0166 & 0.000652 & 0.000413 & 0.000345 \\
\hline Total filter & 775 & 722 & 0.56 & 0.022 & 0.071 & 0.059 \\
\hline Pu Penetration, \% & $0.073^{a}$ & 0.0031 & \multicolumn{2}{|c|}{$(2 u)^{c}$} & \multicolumn{2}{|c|}{$2.0^{\mathrm{d}}$} \\
\hline Flow Ratc, cfm & 24 & 24 & 24 & 24 & 75 & 75 \\
\hline
\end{tabular}

aFirst East filter had torn media near center.

bSample core was $1.87 \mathrm{l}$ in. in diameter and was removed from center of quadrant.

c Could result entirely from a filter-gasket leak of $0.0003 \mathrm{sq}$ in. in the gasket perimeter of $92 \mathrm{in.}$

Includes $0.009 \mathrm{mg}$ of $\mathrm{Pu}$ (7\% collection) in scrubber between second and third filters.

dFilter discharge based on stack-monitor filter was $0.0026 \mathrm{mg} \mathrm{Pu}$.

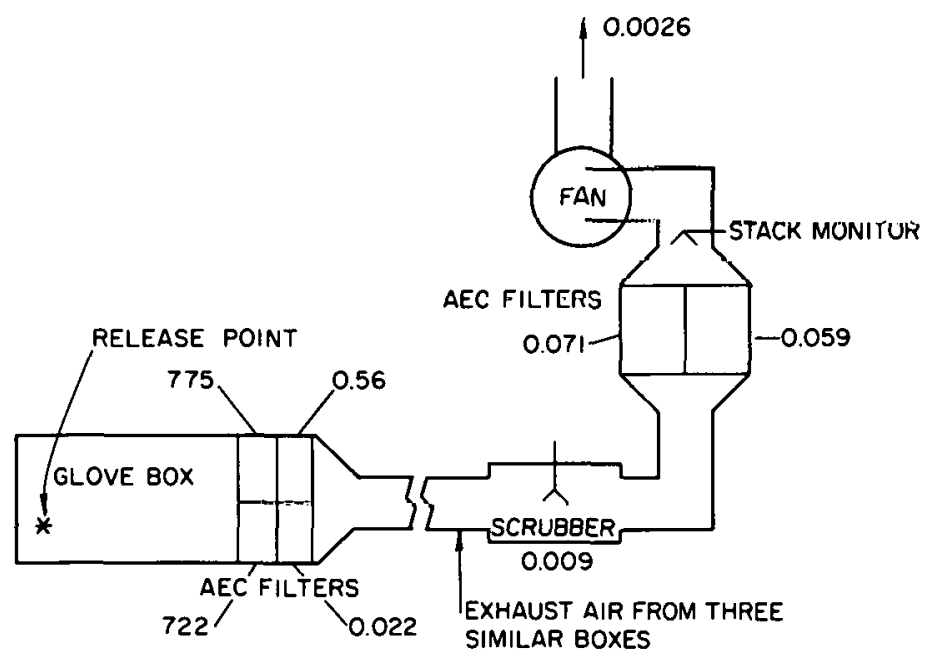

108-9331

Fig. 20. Schematic Diagram of Ventilation System of Glovebox
The plutonium penetrations are based on the plutonium found on the filter media and in the scrubber solution. Table XV compares these penetrations with the resilits from the small-scale release experiments.

The fraction of released plutonium passing through all filters is within the range expected from the small-scale experiments. Although high penetration of the second filter is within the range measured in the small-scale experiments, the high value could be

attributed to a small leak in the filter gasket. This would explain the lower penetration of the third filter. The first two filters are stacked in the same holder, with the result that a leak in the gasket of the second filter will bypass both filters. Thus, a small leak in this gasket will bypass significant quantities of plutonium. 
TABLE XV. Comparison of $\mathrm{PuF}_{6}$ Release Accident with Small-scale Experiments

\begin{tabular}{lcc}
\hline & $\begin{array}{c}\text { Full-scale } \\
\text { Accident }\end{array}$ & $\begin{array}{c}\text { Small-scale } \\
\text { Experiments }\end{array}$ \\
\hline $\mathrm{PuF}_{6}$ released, $\mathrm{mg}$ & 5700 & 1.5 to 25 \\
$\mathrm{PuF}_{6} / \mathrm{H}_{2} \mathrm{O}^{\mathrm{a}}$ & 0.006 & 0.022 to 3.32 \\
$\begin{array}{l}\text { Fraction of released Pu } \\
\text { discharged from last filter }\end{array}$ & $6.7 \times 10^{-7}$ & $10^{-6}$ to $10^{-9} \mathrm{~b}$ \\
Penetration of first filter, \% & $\begin{array}{c}0.0031 \\
(\text { west) }\end{array}$ & 0.0005 to $0.0016^{\mathrm{b}}$ \\
& 2 to 20 & 2 to $45^{\mathrm{b}}$ \\
\hline
\end{tabular}

a Average mole ratio in release enclosure volume due to moisture content of the contained air.

${ }^{b}$ Only for experiments where $\mathrm{PuF}_{6} / \mathrm{H}_{2} \mathrm{O}<0.1$.

4. Estimate of Possible Leak Size

The size of the leak that would account for the above results was estimated in the following way: The average penetration of both first and second filters was $0.0086 \%$. Multiplying this value by the gas flow rate $(48 \mathrm{cfm})$ gives a leak rate of $0.0041 \mathrm{cfm}$. The percent of rated flow $(17.8 \%)$ times the rated pressure drop $(0.73+0.91)$ gives the operating differential pressure of 0.29 in. $\mathrm{H}_{2} \mathrm{O}$ across the leak. Using Bernoulli's theorem, which relates pressure to kinetic energy in nonviscous flow $\left(2 \Delta \mathrm{P}=v^{2} \rho\right)$, and neglecting the coefficient of discharge gives a velocity of $36 \mathrm{ft} / \mathrm{sec}$ for the above pressure drop. The leak flow rate divided by the leak velocity gives a leak area of $0.0003 \mathrm{sq}$ in. A capillary leak 1/2 in. long (gasket width) will have a cross section of $0.003 \mathrm{sq}$ in. A leak of this size out of a total gasketed perimeter of 92 in. is not at all surprising and may in fact be a highly probable leak size.

The best solution to this type of problem appears to be separate installation of successive filters so that a leak can only bypass a single filter. In this case a leak of the computed size would not be significant since it is less than the required performance rating of the filters $(0.05 \%)$.

Two suggestions would improve the system performance in this type of accidental releases of $\mathrm{PuF}_{6}$ :

a. In-place testing of filters after each change of filters by a DOP-type test.

b. Separate installation of successive filters with more positive gasket-compression devices. 


\section{APPENDIX B}

Model of the Agglomeration Process Affecting Filtration

In the model developed in this appendix, the change with time in the number of particles in the mixing chamber (upstream of the filter) is expressed in terms of simple mathematical relations for the processes of agglomeration and gas purging of the mixing chamber. The following assumptions were used in deriving the mathematical expressions:

1. The plutonium hexafluoride and water vapor are combined in a reaction chamber, where they are instantly reacted and the solid product is perfectly mixed, i.e., evenly distributed in the chamber. Subsequently, the product particles are swept out by air passing through the chamber and to the filters. The gas purge sweeps out particles regardless of size.

2. The hydrolysis product particles are initially of the same size (unagglomerated), and the range of sizes of the agglomerated particles may be described by a Poisson distribution.

3. All the penetration of the filter is due to unagglomerated particles; that is, the agglomerated particles make a negligible contribution to the amount of material penetrating the filter. A penetration factor for unagglomerated particles is taken as a property of the filter.

Other workers have found that, when agglomeration alone is considered, the particle concentration varies with time as follows: ${ }^{18}$

$$
\frac{1}{\grave{n}}=\frac{1}{\ddot{n}_{0}}+K l \text {, }
$$

where $\mathrm{n}$ is the number of particles per unit volume at time $t, n=n_{0}$ at $\mathrm{t}=0$,

and

$$
\mathrm{K}=4 \mathrm{kTC} / 3 \mu \text {, }
$$

where $k$ is the Boltzmann constant, $T$ is the absolute temperature, $C$ is Cunningham's correction factor to Stokes' law, and $\mu$ is the gas viscosity.

Differentiation of Equation (52) gives

$$
-\frac{\mathrm{dn}}{\mathrm{dt}}=K \mathrm{n}^{2}
$$

This describes the change in particle concentration due to agglomeration alone. 
The removal of particles from the mixing chamber by the gas purge is treated as follows: Perfect mixing without agglomeration would give

$$
-\frac{\mathrm{dn}}{\mathrm{dt}}=\frac{\mathrm{Rn}}{\mathrm{V}}
$$

where $R$ is the gas flow rate, and $V$ is the volume of the mixing chamber. For both agglomeration and mixing, we have

$$
-\frac{\mathrm{dn}}{\mathrm{dt}}=\mathrm{Kn}^{2}+(\mathrm{R} / \mathrm{V}) \mathrm{n}
$$

Integration gives

$$
-\int_{n_{0}}^{n} \frac{d n}{K n^{2}+(R / V) n}=\int_{0}^{t} d t
$$

or

$$
n=\frac{n_{0} e^{-R t / V}}{1+\left(K V n_{0} / R\right)\left(1-e^{-R t / V}\right)}
$$

The effect of gas purge in Equation (54) may be expressed also in mass terms, in which form it is independent of agglomeration. The weight $\mathrm{w}$ of plutonium in the mixing chamber is independent of agglomeration, and the rate of decrease of $w$ is given by

$$
-\frac{d w}{d t}=\frac{R}{V} w
$$

or

$$
w=w_{0} e^{-R t / V} \text {, }
$$

where $w_{0}$ is the initial weight released at $t=0$.

For the whole collection of particles in the mixing chamber, the initial (unagglomerated) particle weight $m_{n}$ is given by

$$
\mathrm{m}_{0}=\mathrm{w}_{0} / \mathrm{n}_{0} \mathrm{v}
$$

Similarly, the average particle weight $m$ at any time is given by

$$
\mathrm{m}=\mathrm{w} / \mathrm{nV} \text {. }
$$


The average number of particles, $M$, per agglomerate is the ratio of the average particle weight to the weight of the initial particle, and is given by

$$
M=\frac{m}{m_{0}}=\frac{w n_{0}}{w_{0} n}
$$

Substitution of (57) and (59) in (62) gives

$$
M=1+\frac{K V n_{0}}{R}\left(1-e^{-R t / V}\right)
$$

The fraction $\mathrm{p}$ of unagglomerated particles is obtained by assuming that there is a Hoisson distribution of the number $x$ of (original) particles in an agglomerate. By the well-known statistical property of the mean, we may write this as

$$
p(x-1)=\frac{(M-1)^{x-1} e^{-(M-1)}}{(x-1) !}
$$

Substituting (63) in (64) and setting $\mathrm{x}=1$ for unagglomerated particles gives

$$
p=e^{-K V n_{0} / R}\left(1-e^{-R t / V}\right) \text {. }
$$

The total amount of plutonium passing through the filter is that fraction of unagglomerated material swept out of the mixing chamber that also is not trapped on the filter. Thus,

$$
w_{0} P=\int_{0}^{w} n p\left(w_{0} / n_{0} V\right) P_{0} R d t
$$

where $P$ is the average weight-fraction penetration measured, and $P_{0}$ is the weight fraction of unagglomerated material that passes through the filter. This $P_{0}$ is a standard property of the filter (for a particular particle size) and is not the empirical, overall penetration $P$ measured for agglomeration. The ratio $P / P_{0}$ is less than one in all actual cases in which some agglomeration occurs. Substituting Equations (57) and (65) in (66) and letting

$$
\mathrm{KVn} / \mathrm{R}=\mathrm{a}
$$

gives

$$
\frac{P}{P_{0}}=\int_{0}^{\infty} \frac{e^{-R t / V}+a\left(1-e^{-R t / V}\right) d t}{1+a\left(1-e^{-R t / V}\right)}
$$


The change of variables

$$
Z=1+a\left(1-e^{-R t / V}\right)
$$

gives

$$
\frac{P}{P_{0}}=\frac{e}{a} \int_{1}^{l+a} \frac{e^{-Z} d z}{Z}
$$

This integral is known as the exponential integral and has been tabulated. ${ }^{27}$ The function is plotted in Fig. 21 .

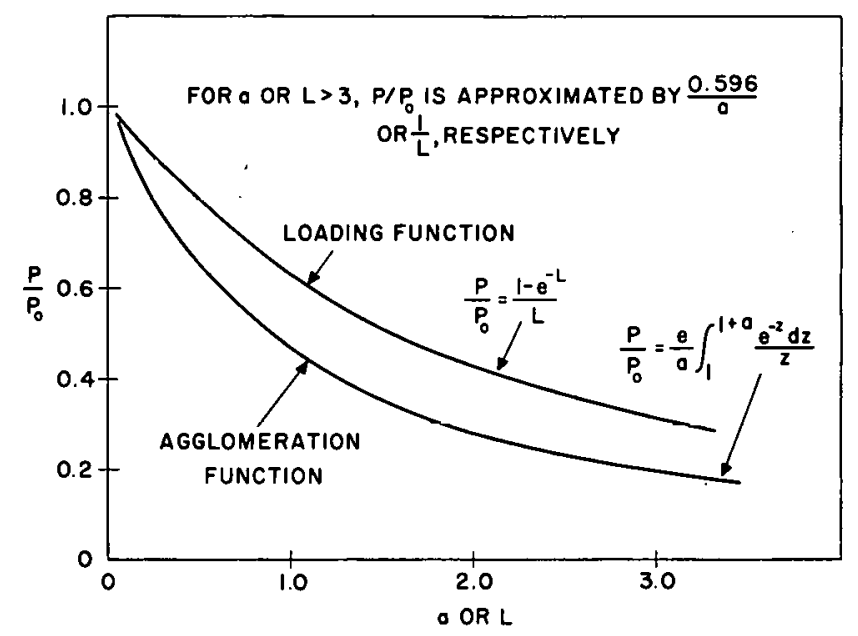

$108-6870-$ Rev. 1

Fig. 21. Agglomeration and Loading Functions

The function $P / P_{0}$ is the ratio of the following weight fraction:

Iredsured penetration

$\overline{\text { penetration by unagglomeratcd particles }}$.

The abscissa, a, in Fig. 21 is the dimensionless agglomeration number defined in Equations (67) and (52) in terms of physical constants, gas properties, flow rate, and the initial quantity of particles released. 


\section{APPENDIX C}

Model of the Effect of Filter Loading on Filtration Efficiency

A model for filter loading was developed along the same lines as those used for the agglomeration process. A mathematical relation was initially taken for the instantaneous penetration of the filter and the total surface of the filter (including the loading of trapped solids); subsequently an integrated relation including the weight fraction of filter penetration was developed.

The following assumptions were made for filter loading:

1. For the type of filter and fume particles of interest, the diffusion mechanism of filtration is controlling.

2. The filtration performance at any instant of time is a function of the total surface of the filter, which includes both the surface of the filter medium and of the collected fume particles.

The diffusion mechanism gives, for the instantaneous weight penetration,

$$
P_{i}=e^{-k A} t
$$

where $k$ is a diffusion constant for the process and

$$
A_{t}=A_{f}+A_{c} w
$$

where $A_{f}$ is the internal filter area and $A_{C}$ is the specific surface area per unit weight $w$ of the deposited fume particles.

The average penetration $P$ intcgrated over the total collection of d single release starting with a clean filter is

$\mathrm{P} \mathrm{w}_{0}=\int_{0}^{\mathrm{w}_{0}} \mathrm{P}_{\mathrm{i}} \mathrm{dw}$.

For a clean filter without loading,

$$
P_{0}=e^{-k A_{f}} ; \quad k=\frac{\ell n\left(1 / P_{.0}\right)}{A_{f}}
$$


Substitution in (71) gives

$$
\begin{aligned}
P_{i} & =e^{-\left[\ln \left(1 / P_{0}\right)\right]\left(A_{f}+A_{c} w\right) / A_{f}} \\
& =P_{0} e^{-A_{c}\left(w / A_{f}\right) \ell n:\left(1 / P_{0}\right)}
\end{aligned}
$$

Combination of (76) and (73) yields

$$
\begin{aligned}
\frac{P}{P_{0}} & =\frac{1}{w_{0}} \int_{0}^{w_{0}} e^{-A_{c}\left(w / A_{f}\right) \ln \left(1 / P_{0}\right)} d w \\
& =\frac{1-e^{-A_{c}\left(w_{0} / A_{f}\right) \ln \left(1 / P_{0}\right)}}{\left(\frac{A_{c} w_{0}}{A_{f}}\right) \ln \frac{1}{P_{0}}}
\end{aligned}
$$

This function is plotted in Fig. 21 as

$$
\frac{P}{P_{0}}=\frac{1-e^{-L}}{L}
$$

where $P / P_{0}$ is the ratio of the same quantities defined in Appendix B. However, the ratio here describes the decrease in the penetration of the filter due to loading. In Fig. 21 , the abscissa $L$ is the dimensionless loading number,

$$
L=\frac{A_{c} w_{0}}{A_{f}} \ln \frac{1}{P_{0}}
$$

Thus, $L$ relates $P / P_{0}$ to the specific area of the filter medium and of the fume, to the filtration efficiency of the unloaded filter, and to the weight of particles released. 


\section{APPENDIX D}

\section{Electron-microscope Techniques}

Filter examination in the electron microscope required a specially developed technique to work successfully. A full thickness of AEC filter

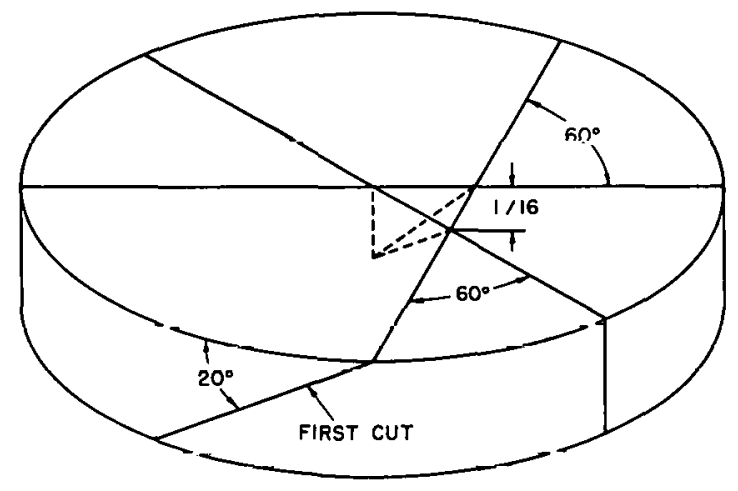

$1.08-9.3 .35$

Fig, 22. Tetrahedral Sectioning of AEC Filter Media media (0.025 in.) in the electron microscope is completely opaque to the electron beam. Small wads of fiber pulled from the surface were difficult to handle and did not give uniformly spaced fibers at low magnification. A thin tetrahedral section can be removed from the top surfare of the filter with three suts made with a single-edged razor blade as indicated in Fig. 22. The first cut is made with the blade al aboul a $20^{\circ}$ angle with the surface. The second and third cuts are made perpendicular to the surface and form an equilateral triangle approximately $1 / 16$ in. on edge with the first cut. The triangular filter section is then centrally placed on an electronmicroscope mounting grid in its holder, and a second grid is placed on top of the filter. The grid cap is put on the holder and compresses the filter section between the two grids. Motion of the fibers under the heating effect of the electron beam is a problem unless the fibers are clamped between two grids. The entire circumference of a properly mounted section can be observed in the electron microscope. Two of the observed edges are sharp; that is, most fibers end within the field of view at low magnification (1000 times).

The third edge is observed as a gradual change in fiber density with the density gradient barely observable in a single view. The fiber density can be adjusted to any value desired by moving perpendicular to the tapered edge. Also, the tapered edge is long enough so that one can take at least 20 pictures at a constant fiber density by moving along the tapered edge. This technique also gives assurance that the fibers observed were at the top surface of the sampled filter. This is important when particulate collected by the filter is being examined because the concentration and average size of collected particulate can change by orders of magnitude within a small fraction of the filter depth.

Examination of particulate $\mathrm{PuO}_{2} \mathrm{~F}_{2}$ or $\mathrm{UO}_{2} \mathrm{~F}_{2}$ on the glass fibers of an AEC filter in the electron microscope is a highly reproducible and stable observation. Even at the maximum electron-beam intensity, the only change observed with exposure time is an initial shift of some of the smaller fibers. 
Agglomerates of the finer particles occasionally become more compact but are still resolvable into particles. The $\mathrm{PuO}_{2} \mathrm{~F}_{2}$ or $\mathrm{UO}_{2} \mathrm{~F}_{2}$ is much more opaque to the electron beam than the glass fibers or other contaminants that are present on the fibers. The smaller glass fibers are partially transparent to the electron beam and reveal $\mathrm{PuO}_{2} \mathrm{~F}_{2}$ or $\mathrm{UO}_{2} \mathrm{~F}_{2}$ particles much smaller in diameter than the fibers on the front and back surfaces of the fibers. The average and large glass fibers are opaque to the electron beam and reveal only particles silhouetted on the sides of the fiber. 
The authors wish to acknowledge the efforts of M. J. Steindler and T. J. Gerding in the initial literature search, interest shown by W. J. Mecham, J.. Fischer, and A. A. Jonke, data collection by T. J. Gerding, L. J. Marek, and B. J. Misek, and computer programming by A. J. Strecok. 


\section{REFERENCES}

1. Adley, F. E., The Effect of Holes on the Performance Characteristics of High-Efficiency Filters, HW-77912 (Sept 1963).

2. Alenchikova, I. F., et al., Investigation of Physicochemical Properties of Plutonyl Fluoride, AEC-TR-3505 (Nov 1958).

3. Argonne National Laboratory, Environmental Radioactivity at Argonne National Laboratory, TID-21279(1964).

4. Bates, D. R., Atomic and Molecular Processes, Academic Press, New York, N. Y., p. 272(1962).

5. Cathers, G.I., Bennett, M.R., and Jolley, R. L., UF 6 -3NaF Complex Formation and Decomposition, Ind. Eng. Chem. 50, 1709 (1958).

6. Chen, C. Y., Filtration of Aerosols by Fibrous Media, Chem. Rev. 55, 595 (1955).

7. Davies, C. N., Viscous Flow Transverse to a Circular Cylinder, J. Phys. Soc. London 63, pp: 288-296 (1949).

8. Einstein, Albert, Investigation on the Theory of the Brownian Movement, Methuen and Co. London, (1926).

9. Ewell, A. W., Humidity Measurements in Freezer Rooms, Refrigerating Eng. 27, 131 (1934).

10. Feliers, P., Pomarola, J., and Risselin, A., Protection of Personnel Against Atmospheric Contamination by Plutonium in the Laboratories, French Report CEA-2311 (1963) (available in translation as ORNLTR-391).

11. Fischer, Jack, Trevorrow, L. E., Vogel, G. J., and Shinn, W. A., Plutonium Hexafluoride Thermal Decomposition Rates, Ind. Eng. Chem., Process Design Develop. 1, 47 (1962).

12. Fitzgerald, J. J., and Detwiler, C: G., Collection Efficiency of Air Cleaning and Air Sampling Filter Media in the Particle Size Range of 0.005 to 0.1 Micron, KAPL-1463 (Dec 1955).

13. Fitzgerald, J, J., and Detwiler, C. G., Optimum Particle Size for Penetration Through the Millipore Filter, KAPL-1592 (June 1956).

14. Florin, A. E., et al., J. Inorg. Nucl. Chem. 2, 379 (1956).

15. Fuchs, N. A., The Mechanics of Aerosols, Pergamon Press, New York, 1964.

16. Green, H. L., and Lang, W. R., Particulate Clouds: Dusts, Smokes and Mists, 2nd Ed., D. Van Nostrand Company, Inc., Princeton, New Jersey (1964). 
17. Gupta, A.S., and Thodos, G., Mass and Heat Transfer in the Flow of Fluids Through Fixed and Fluidized Beds of Spherical Particles, AIChE J. 8, 608 (1962).

18. Handbook on Aerosols, USAEC, Washington, D. C. (1950).

19. Hays, J. B., Performance of High Efficiency Particulate Filters Subjected to Steam-Air Mixtures, p. 549, TID-7627 (Oct 1961).

20. Hougen, O. A., and Watson, K. M., Chemical Process Principles, p. 922, John Wiley and Sons, Inc., London (1947).

21. Jonke, A. A., Reprocessing of Nuclear Reactor Fuels by Processes Based on Volatilization, Fractional Distillation, and Selective Adsorption, Atomic Energy Review 3, No. 1 (1965).

22. Katz, J. J., and Rabinowitch, E., The Chemistry of Uranium, lst Ed., McGraw-Hill Book Company, Inc., New York, N. Y. (1951).

23. LaMer, V. K., Studies on Filtration of Monodisperse Aerosols, USAEC Report NYO-512(Mar 1951).

24. Lamb, H., On the Uniform Motion of a Sphere Through a Viscous Fluid, Phil. Mag. 21, 112 (1911).

25. Liimatainen, R. C., and Mecham, W. J., Removal of Halogens, Carbon Dioxide, and Aerosols from Air in a Spray Tower, USAEC Report ANL-5429 (1955).

26. Lodge, J.P., Tentative Code for the Testing of Filters for the Collection of Suspended Particles from Air and Other Gases, J. Am. Assoc. Contamination Control, p. 15 (Feb 1965).

27. Lowan, A, N, (Dir.). Tables of Sine, Cosine and Exponential Integra.ls, Vol. 1, Federal Works Agency Work Projects Administration, New York (1940).

28. Mandleberg, C. J., et al., J. Inorg. Nucl. Chem. 2, 365 (1956).

29. Megaw, W. J., and Wiffen, R. D., The Efficiency of Membrane Filters, British Report, AERE-R-4211 (Jan 1963).

30. Moses, H., and Willett, J. H., Five Years Climatological Summary July 1949-June 1954, USAEC Report ANL-5592, p. 283.

31. National Bureau of Standards Handbook 69, Maximum Permissible Body Burdens and Maximum Permissible Concentrations of Radionuclides in Air and in Water for Occupational Exposure, p. 87, U. S. Government Printing Office, Washington, D, C. (June 5, 1959).

32. Perry, John H. (Ed.), Chemical Engineer's Handbook, McGraw-Hill, New York, N. Y., 3rd Ed., p. 393 (1950). 
33. Rosinski, J., and Snow, R. H., Secondary Particulate Matter from Meteor Vapors, J. Meteorol. 18, No. 6, pp. 736-745 (Dec 1961).

34. Smith, S. E., Filtration of Radioactive Particulates, Progress in Nuclear Energy, Series IV, Vol. 5, Pergamon Press, New York, p. 449-475 (1963).

35. Smith, W. J., and Surprenant, N. F., Properties of Various Filtering Media for Atmospheric Dust Sampling, ASTM Proceedings 53, 1122 (1953).

36. Steindler, Martin J., The Properties of Plutonium Hexafluoride, USAEC Report ANL-6753(1963).

37. Suits, C. G. (Ed.), The Collected Works of Irving Langmuir, Volume 10, Atmospheric Phenomena, Pergamon Press, New York, N. Y. (1961).

38. Trevorrow, L. E., Kessie, R. W., and Steindler, M. J., Analysis of an Accidental Multigram Release of Plutonium Hexafluoride in a Glovebox, USAEC Report ANL-7068 (1965).

39. Vogel, G. J., private communication.

40. Walas, S. M., Reaction Kinetics for Chemical Engineers, p. 160 , McGraw-Hill Book Co., Inc., New York (1959).

41. White, P. A. F., and Smith, S. E., High Efficiency Air Filtration, Butterworths, London (1964).

42. Zimmerman, O. T., and Lavine, I., Psychrometric Tables and Charts, Dover, N. H. (1945). 